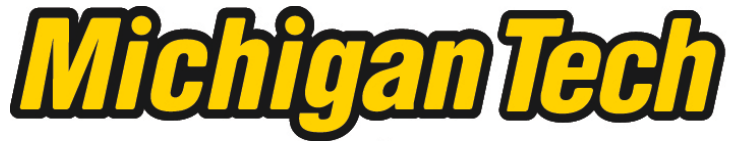 \\ Michigan Technological University Create the Future Digital Commons @ Michigan Tech
}

Dissertations, Master's Theses and Master's Reports - Open

Dissertations, Master's Theses and Master's

Reports

2014

\section{STABILITY ANALYSIS OF THE SLOPE ALONG US-2 BETWEEN EPOUFETTE BAY AND THE CUT RIVER BRIDGE}

Stephanie Watts-Garcia

Michigan Technological University

Follow this and additional works at: https://digitalcommons.mtu.edu/etds

Part of the Civil Engineering Commons

Copyright 2014 Stephanie Watts-Garcia

\section{Recommended Citation}

Watts-Garcia, Stephanie, "STABILITY ANALYSIS OF THE SLOPE ALONG US-2 BETWEEN EPOUFETTE BAY AND THE CUT RIVER BRIDGE", Master's report, Michigan Technological University, 2014.

https://doi.org/10.37099/mtu.dc.etds/768

Follow this and additional works at: https://digitalcommons.mtu.edu/etds

Part of the Civil Engineering Commons 


\title{
STABILITY ANALYSIS OF THE SLOPE ALONG US-2 BETWEEN EPOUFETTE BAY AND THE CUT RIVER BRIDGE
}

\author{
By \\ Stephanie Watts-Garcia
}

\begin{abstract}
A REPORT
Submitted in partial fulfillment of the requirements for the degree of MASTER OF SCIENCE

In Civil Engineering
\end{abstract}

MICHIGAN TECHNOLOGICAL UNIVERSITY

2014

(C)2014 Stephanie Watts-Garcia 
This report has been approved in partial fulfillment of the requirements for the Degree of MASTER OF SCIENCE in Civil Engineering.

Department of Civil and Environmental Engineering

Report Advisor: $\quad$ Stanley Vitton

Committee Member: Thomas Oommen

Committee Member: Evan Kane

Department Chair: $\quad$ David Hand 


\section{TABLE OF CONTENTS}

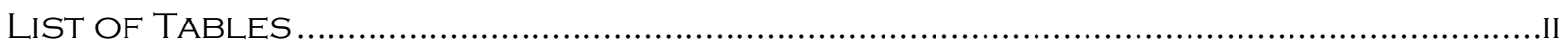

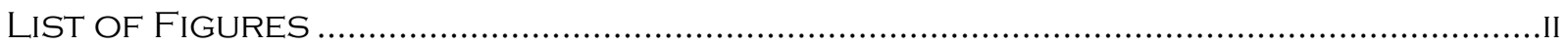

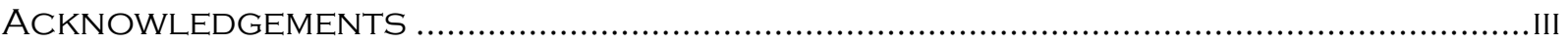

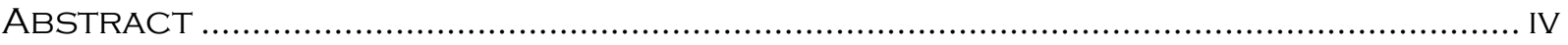

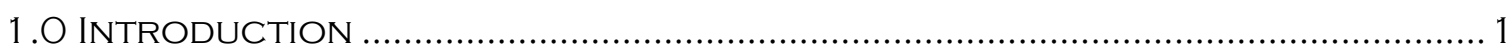

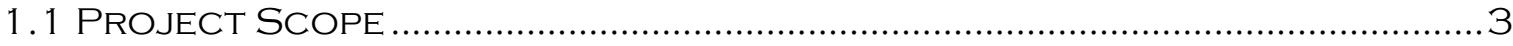

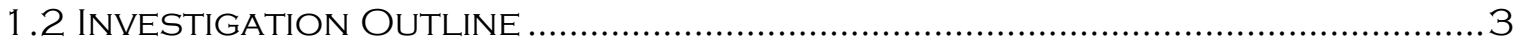

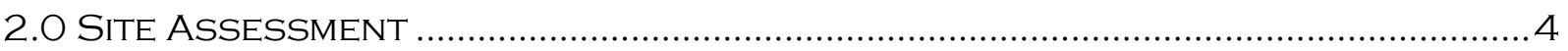

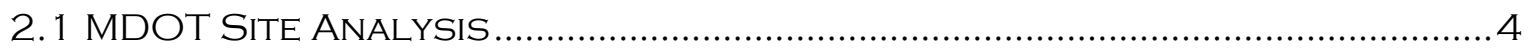

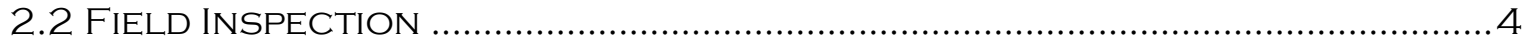

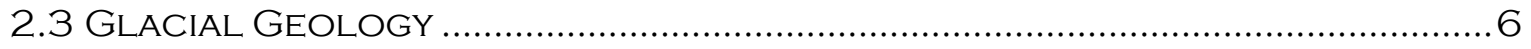

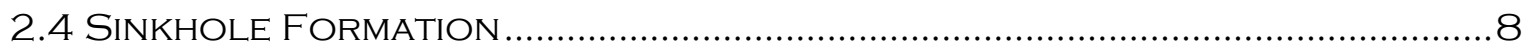

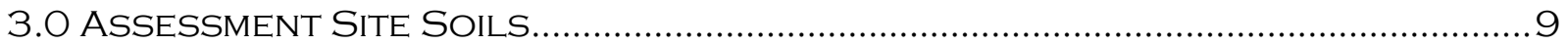

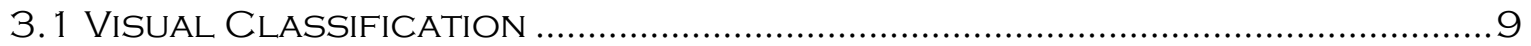

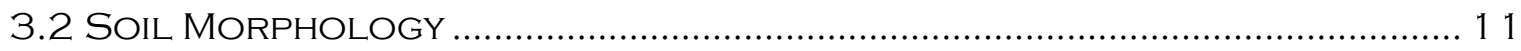

3.3 GRAin SizE ANALYSIS AND NATURAL MoISTURE CONTENT ........................... 13

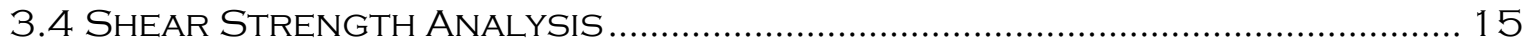

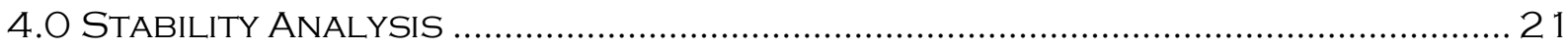

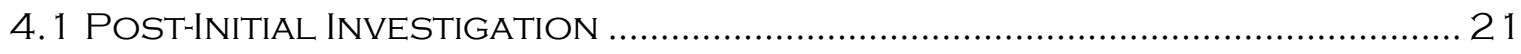

4.2 REASONING BEHIND MATERIAL ASSUMPTIONS ............................................... 23

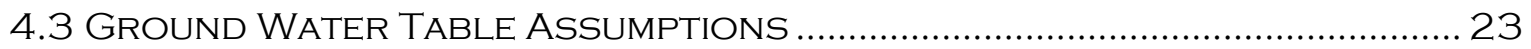

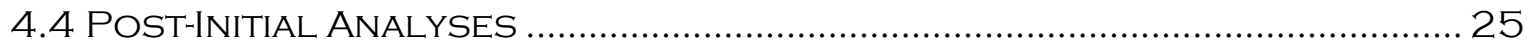

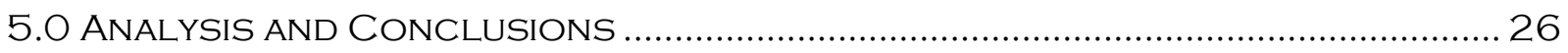

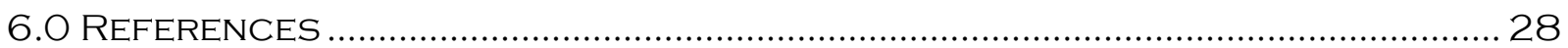

APPENDIX A: GRAIN SIZE DISTRIBUTION TABLES \& COMPARISON CHART ....................... I

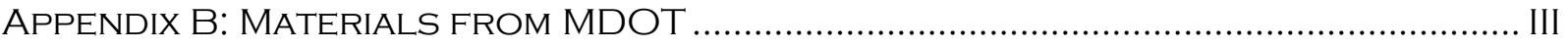

APPENDIX C: DEQ Well WATER LEVELS AND BEDROCK DEPTHS...................................IX

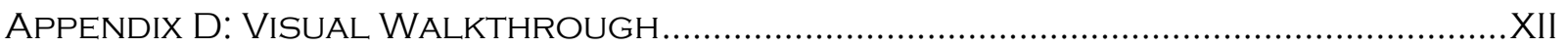

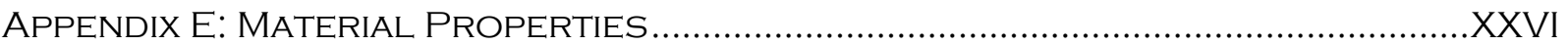

APPENDIX F: STABILITY ANALYSIS MODELS ............................................................XXI

APPENDIX G: ERM (ELECTRICAL RESISTIVITY METHOD) EXAMPLE ..........................XXXVII 


\section{LIST OF TABLES}

Table 1 : Natural Moisture Content .............................................................................. 13

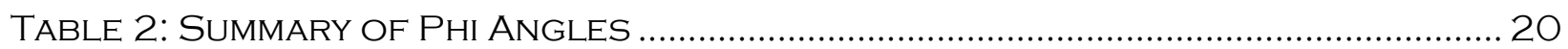

\section{LIST OF FIGURES}

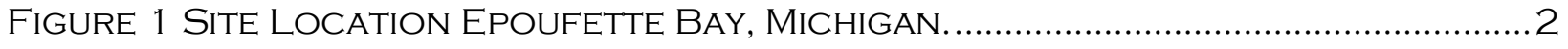

FIGURE 2 CONSTRUCTION DRAWING FOR THE SECTION OF US-2 ABOVE THE SLOUGH;

SINKHOLES ARE INDICATED IN RED. ..................................................................... 2

FIgURE 3: ARTESIAN WELL AT THE CUT RIVER BRIDGE .....................................................5

FIGURE 4: ARTESIAN WELL AND CREEK AT THE BASE OF THE AOI ....................................5

FIGURE 5: EXTENT OF LAKE ALGONQUIN.. .................................................................. 7

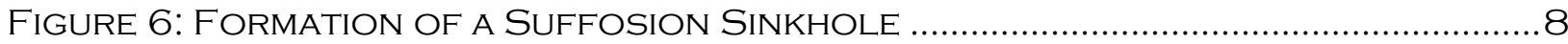

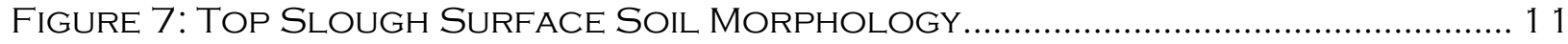

FIGURE 8: MidDLE OF SLOUGH SURFACE SOIL MORPHOLOGY ..................................... 12

Figure 9: 3' Below SuRface of Middle Slough SOIL MoRPhology ....................... 12

FIGURE 1O: TOP SLOUGH PARTICLE DISTRIBUTION .................................................. 14

Figure 1 1: 3' Below Surface of Mid Slough PARTICLE Distribution .................... 14

FIGURE 12: SURFACE OF MID SLOUGH PARTICLE DISTRIBUTION .................................. 15

FIGURE 13: SHEAR STRENGTH VS HORIZONTAL DisplaCEMENT FOR THE TOP SLOUgH 17

Figure 14: SHEAR StRENGTH VS. HORIZONTAL DisPlaCEMENT FOR 3' BELOW MiD

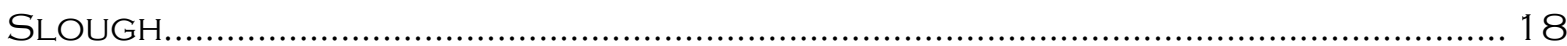

FIgURE 15: NORMAL VS. SHEAR STRESS FOR DENSE AND LOOSE SAMPLES OF BOTH TOP

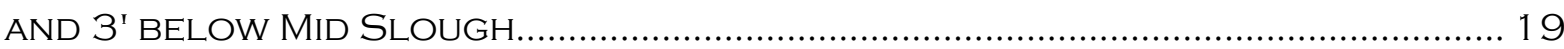

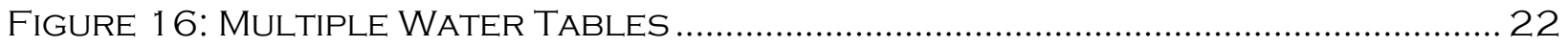

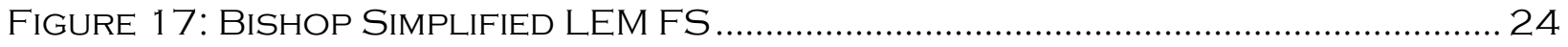




\section{Acknowledgements}

First, I would like to thank my advisor, Dr. Stan Vitton for the guidance and support throughout this research, this project would not be possible otherwise.

I am grateful for my committee, Dr. Evan Kane and Dr. Thomas Oommen for giving me helpful feedback and advice to make a more thorough analysis.

I give many thanks to many of my graduate colleagues especially, Christopher King and Bonnie Zwissler whom helped me collect samples, conduct testing as well as critiquing my work - this research would be at a dead end without all their help.

I also appreciate the previous testing and data collected through MDOT.

Lastly, I want to thank my friends and family for all the moral support throughout this graduate research.

Thank you all for your valued assistance, it is much appreciated and I could not have done this without your help. 


\begin{abstract}
Recently, water was observed flowing from a section of steep slope along US-2 near St. Ignace, Michigan in addition to soil sloughing in the area where the water is flowing from the slope. An inspection of the area also showed the presence of sinkholes. The original construction drawing for US-2 also indicated that sinkholes were present in this area prior to road construction in 1948. An investigation was conducted to determine the overall stability of the slope. The slope consists primarily of aeolian sand deposits. Laboratory testing determined the shear strength of the slope material to have a friction angle around $30^{\circ}$, which is also the slope angle. Thus, the slope is at its maximum angle for stability-however, the slope is also heavily wooded which provides additional support to the slope. Although the area surrounding the water flow has been sloughing, the remaining slope remains intact.
\end{abstract}




\subsection{Introduction}

In late March 2012 a routine traffic stop was made along US-2 near Epoufette Bay, Michigan about a mile west of the Cut River Bridge. This site is also located about thirty miles west of Saint Ignace, MI (see

Figure 1). At this location the highway is located on a steep bluff overlooking Lake Michigan, about 100 feet below the level of the highway. The police officer noticed a high rate of water shooting out of the slope about midway down and reported it to the regional Michigan Department of Transportation (MDOT) office shortly afterwards. MDOT officials examined the site but did not find the reported high flow water condition as noted by the police officer but did find a relatively large slough [Slough May 2012] about midway down where the water was coming out of the slope. MDOT personnel also noted the presence of sinkholes [Sinkhole] on top of the bluff along both sides of the highway in the vicinity of the slough. MDOT then contacted Michigan Tech and requested that a site visit be made to make an initial site investigation. This site investigation was made by Dr. Stan Vitton in May 2012 who also noted a large slough with water emanating from the slough as well as number of sinkholes in the immediate vicinity of the highway in the location of the slough.

The highway was constructed in 1948 and consists of a concrete pavement with asphalt overlays. A review of the construction drawing for this section of highway above the slough also indicated the presence of sinkholes. A section of the 1948 construction drawing is shown in Figure 2. A total of 13 sinkholes can be seen on this section of highway just about the area where the water was observed coming out of the slough area. During the summer of 2012 MDOT conducted field operations that included site drilling, falling weight deflectometer, ground penetrating radar and surveying to investigate the area.

While some of the sinkholes (noted in the 1948 drawings) along the sides of US-2 are still present, none of the drilling or GPR indicated the presence of sinkholes under the pavement. All of the data collected by MDOT at the site was sent to Michigan Tech for further analysis. 


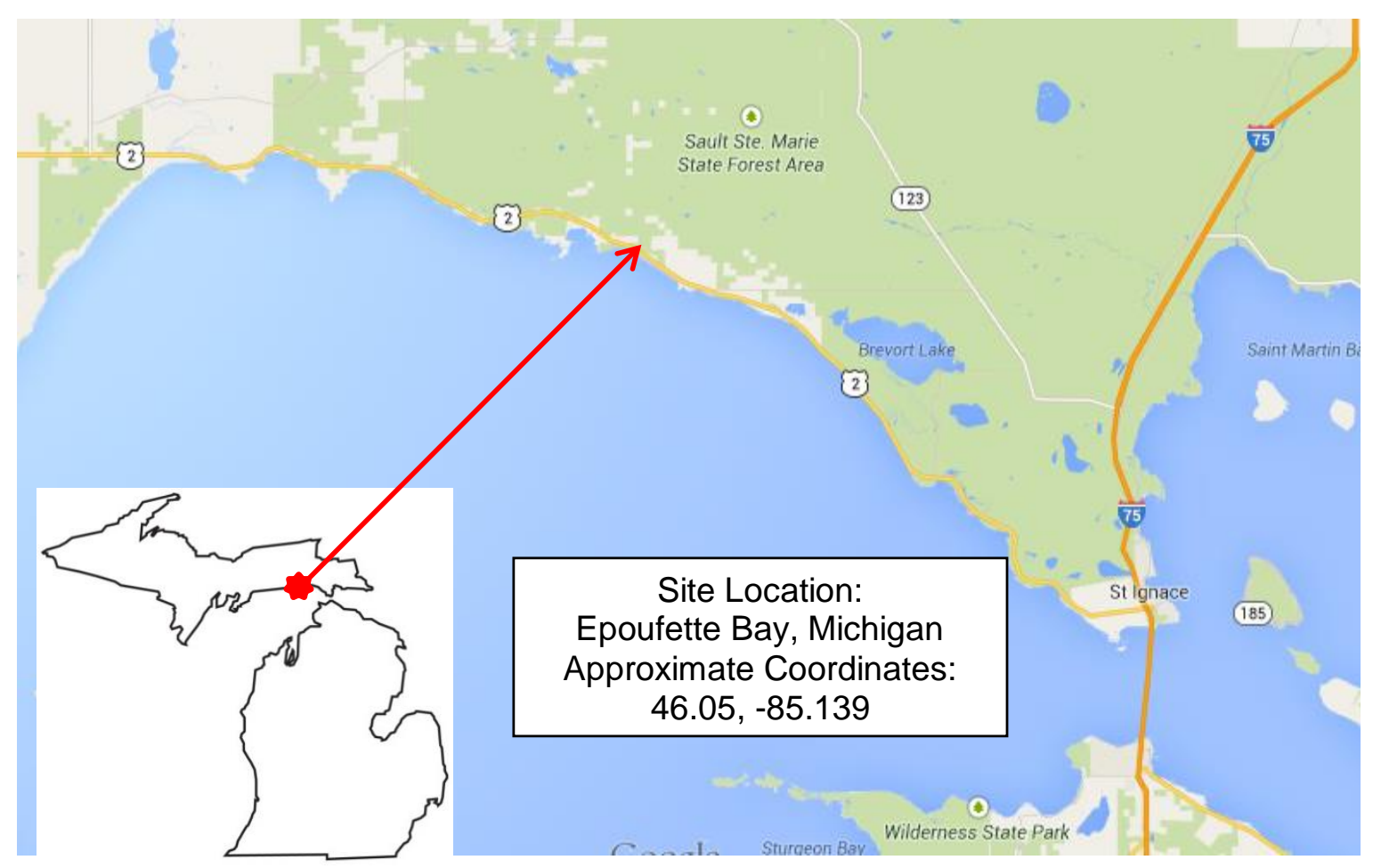

Figure 1 Site Location Epoufette Bay, Michigan.

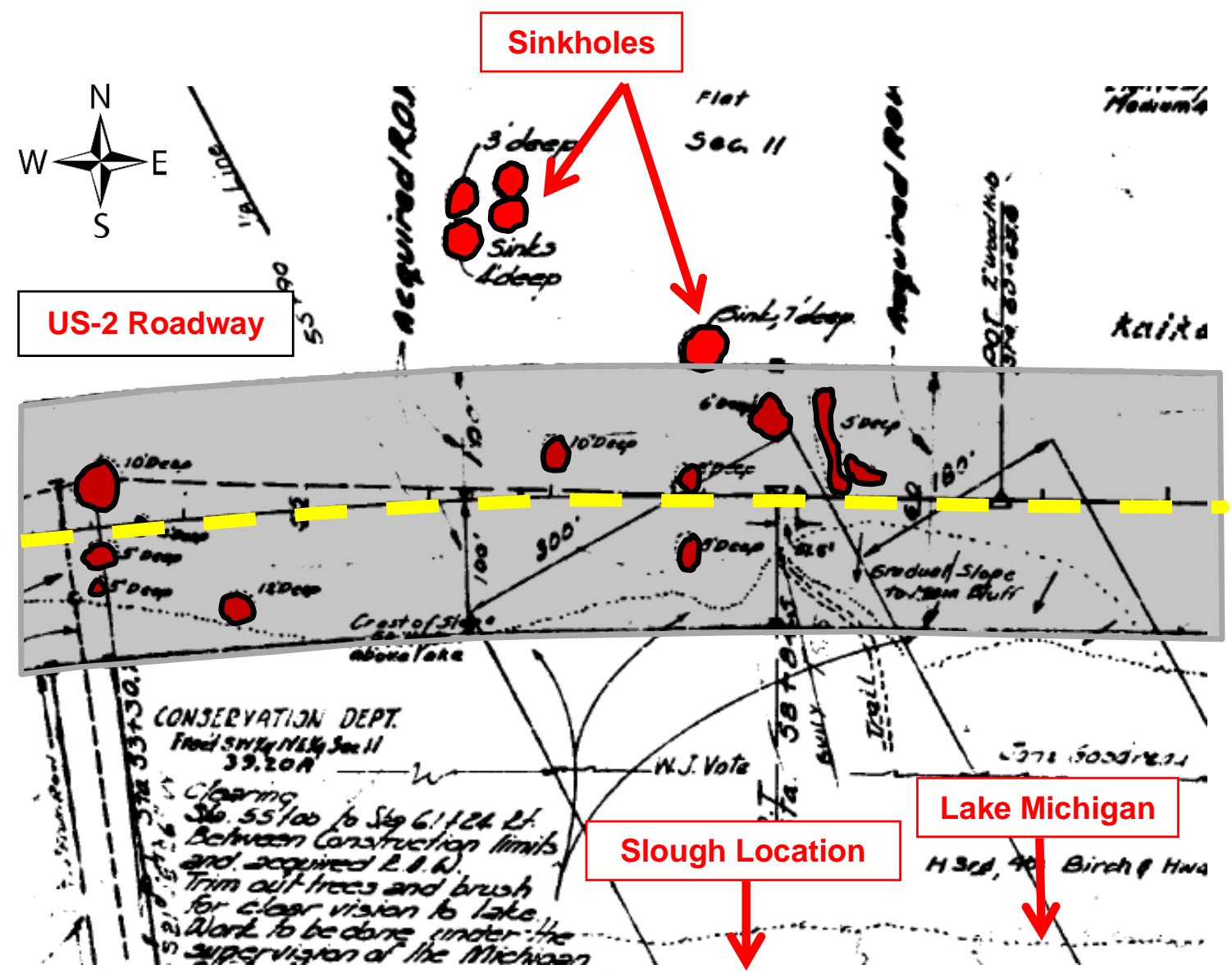

Figure 2 Construction drawing for the section of US-2 above the slough; sinkholes are indicated in red. 


\subsection{Project Scope}

The aim of this project was to provide a preliminary assessment of the overall stability of the slope. To accomplish this, a site visit was made in the summer of 2013. All of the data collected from the MDOT investigations was also obtained. This data includes nine drill holes, Ground Penetrating Radar (GPR), Falling Weight Deflectometer (FWD) and survey transections from the highway down to the base of the slope. Nine boreholes were drilled at the site to a depth of 21.5 feet. Since that lacks the depth to understand the natural soils, one drill hole was drilled to a depth of 96.5 feet [Truth Boring Data]. The main objective of the drilling operations was to assess if any sinkholes were present under the highway pavement structure.

\subsection{Investigation Outline}

The site assessment included an investigation of the site's geology, which included both the bedrock geology as well as the glacial history of the site. The primary intent of the geological investigation was to establish the crucial stratigraphy of the site. This way an analysis of the slope stability as well as an explanation for the formation of the sinkholes became possible. An additional component of the investigation was an analysis if adjacent areas with similar geology also might have had landslides and sinkhole development.

The main tools that were integrated into this analysis consisted of two Rocscience software programs. The initial model was created in Slide (version 6.0), a limitequilibrium slope stability analysis program which was then exported into Phase2 (version 8.0), a 2D elasto-plastic finite element stress program that can be used to assess slope stability. The primary emphasis of the Rocscience analytical study was concentrated on the stability of the slope.

The investigation of the sinkholes was limited to an assessment of the glacial and bedrock geology. While no analytical methods were used to assess the development of sinkholes, observations made concerning the geology of the site were proposed. 


\subsection{Site Assessment}

In order to assess the site, the area of interest (AOI) was investigated in the vicinity of the sinkholes and slough along US-2, east of Epoufette Bay. Since the site had already been documented as an area prone to sinkholes, further research was performed to help understand the issue that is occurring along the roadway. This section of the report will start with the field inspection followed by the glacial geology and will finish with the mechanics behind sinkhole formation.

\subsection{MDOT Site Analysis}

To investigate the possibility of unstable ground underneath this section of US-2, MDOT conducted GPR and FWD. Based on these tests, MDOT then conducted nine boreholes in areas that were suspect from the GPR and the FWD results and surveyed six cross-sections perpendicular to the highway and slope. The site consists mostly of fine sands, which vary from very loose to dense sands. Borehole \#2 had a depth of nearly 97 feet. None of the nine MDOT boreholes encountered bedrock nor groundwater. Based on water well data in the local area bedrock was estimated to be at approximately the elevation of Lake Michigan at an elevation of 577 feet above Mean Sea Level (MSL). The six cross-sections of the area were started at the center of the main depression (zero point), 75', 50' and 25' west of the zero point, 25' east of the zero point, as well as at the center of the artesian well. Truth boring data and ground surveyed cross-sections can be found in Appendix B: Materials from MDOT.

\subsection{Field Inspection}

As previously mentioned, over a year ago a concern (regarding roadway stability) occurred upon spotting water flowing out of the south slope along US-2. Later site inspections noticed water flowing from the slope. However, it is possible that artesian conditions could occur at this point in the slope, during the spring time. Artesian Conditions are common along the base of the slope between Epoufette Bay to the west and the Cut River Bridge one mile to the east of the AOI. Two examples were noted, on the following page. The first example occurs at the Cut River Bridge where an artesian well is located on the west side of the Cut River between the base of the slope and Lake Michigan. This artesian well is shown in 
Figure 3. A second example occur very near to the AOI and is shown in Figure 4.

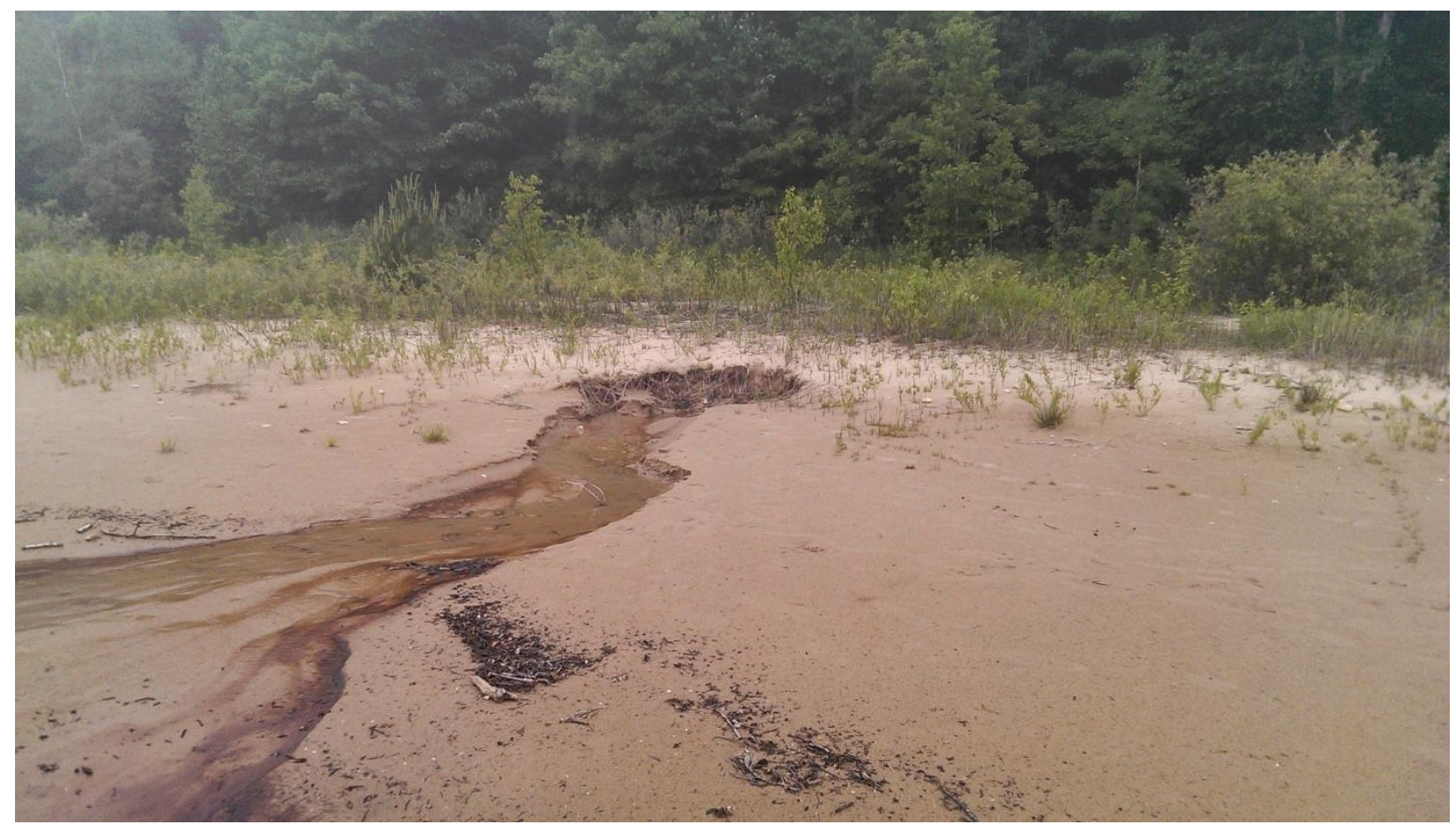

Figure 3: Artesian well at the Cut River Bridge

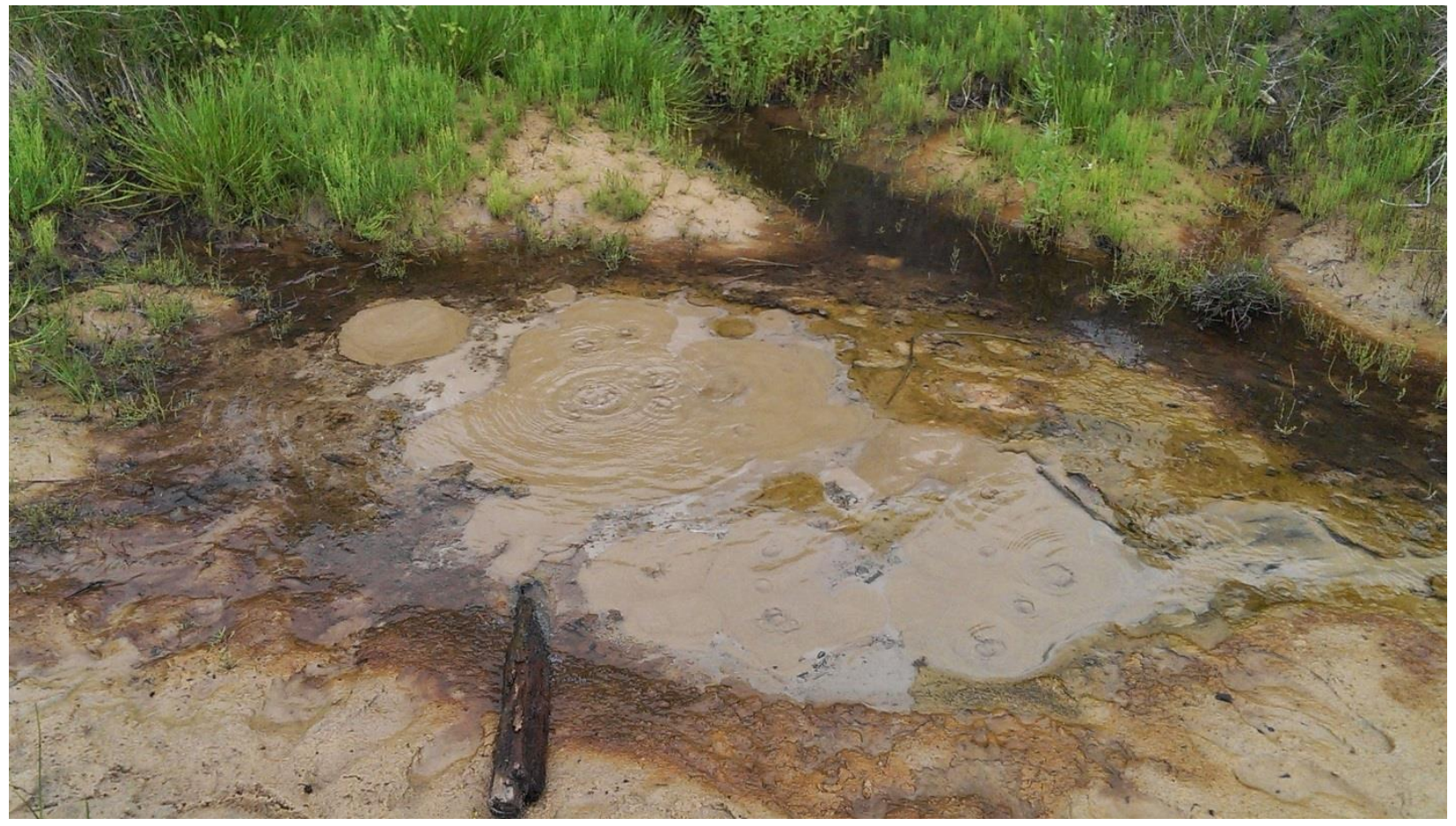

Figure 4: Artesian well and creek at the base of the AOI 
Upon the site to the AOI, more sinkholes were discovered. A sinkhole approximately 5' in diameter and 1.5'-2' deep has formed on both the North and South side of the roadway [Sinkhole]. Although sinkholes are much more numerous south of the road, it is possible that the sinkhole on the north side was initiated through similar means. As previously implied, the sinkholes off both sides of the roadway are relatively circular. This could mean one of two things: either it is a subsidence sinkhole or it is a sinkhole formed from the process called "rat-holing". Both of these types of sinkholes have somewhat similar mechanisms of development, which will be clarified in section 2.4 Sinkhole Formation.

Aside from the sinkhole concern another important issue is the development of the landslide potential. The slope between the highway and Lake Michigan has a very steep gradient, which was measured to be about $31^{\circ}$ [Ground Survey]. The slough area is about three-quarters of the way down the bluff, starting at an elevation of nearly 670 feet above MSL. After reaching the very top edge of the slough, the soil directly below the slough's escarpment had a slow settlement of sand particles falling from the weight of the observation group. More sand fell in greater amounts as the group moved around the top edge of the slough [Slough June 2013]. It was more than obvious that the land is experiencing some stabilization issues around this area; whether or not this slough is directly related to the sinkholes is unknown. Fortunately, while looking north (towards the road) from the Lake Michigan shoreline; there was no indication of any additional slough or sinkhole formation. The only suggestion of on-going weathering or potential stabilization issues was a small meandering stream that leads to Lake Michigan from the artesian well, located approximately at elevation 634 MSL.

A small water flow was observed coming out of the slough. The water flow was about 6 inches wide by about 3-4 inches deep and can be seen in Appendix D: Visual Walkthrough, [Small Stream 2012, 2013 respectively (Looking South), Stream April 2014].

\subsection{Glacial Geology}

Since the AOI was once covered by glaciers, it is important to understand the area's glacial geology. 
About 11,000 years ago, during a period of the glacial retreat, a proglacial lake formed, known as Lake Algonquin. Lake Algonquin was a large lake that encompassed current day Green Bay, Lake Michigan, Lake Huron, North Channel and the eastern half of Michigan's Upper Peninsula. Figure 5 is taken from Schaetzl el al. (2002) and is shown to illustrate the location of the ancient shoreline. Although this is only a hypothesized

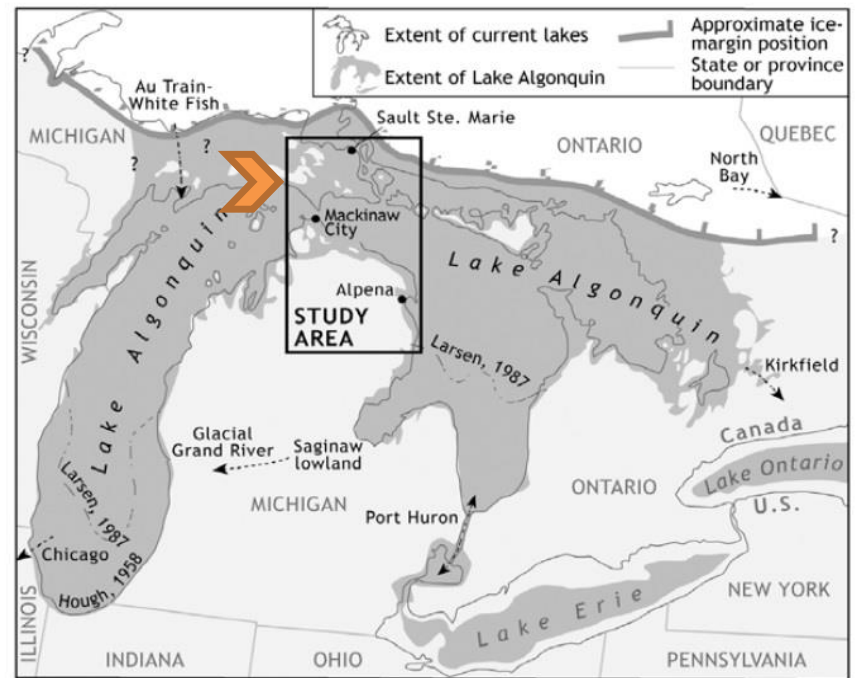

Figure 5: Extent of Lake Algonquin. The AOI is approximately where the orange arrow points (after Schaetzl et al. 2002).

coverage of the ancient lake, Larson et al. (2001), Drzyzga et al. (2002) and Sage (2006) all concluded that the latest proglacial lake was formed at a consistent elevation of roughly 630 feet above MSL. From observing the picture above, it is seen that parts of the U.P. were submerged, especially on the eastern end of the Upper Peninsula and only a small portion of the land was above Lake Algonquin, thus forming a number of ancient shorelines. The formation of these shorelines was a direct result of isostatic rebound of the land surface as the glaciers retreated and outlet control as the water either moved south through various rivers or east to the current St. Lawrence Seaway.

Schaetzl et al. (2002) confirms the existence of four definite Algonquin shorelines, as the lake phases changed over time. Schaetzl et al. recommended that the four shorelines be referred to as Main phase, Ardtrea phase, Wyebridge phase and Payette phase-from highest shoreline in elevation to the lowest. The research located a couple of data points near the Cut River Bridge, identifying the shoreline as being from the Payette phase at an elevation of approximately 630 feet above MSL.

Research conducted by Sterrett and Edil (1982) investigated artesian conditions in glacial slopes along Lake Michigan in Wisconsin and their stability. One of the first issues noted was the fact that a glacial sand unit was formed under artesian conditions about 15' from the base of the bluff. Sterett and Edil state that "wave action at the base 
of the bluff is the most important cause of bluff top retreat"-since the US-2 roadway AOI has decent bluff top erosion occurring, the base wave action should be considered. However, the article expands on this theory and concludes that the top of the bluff is not directly influenced by wave action but is related to the transmission of water through jointed till. This fact could explain a portion, if not all, of the mechanism behind the artesian well within AOI. Although their area of study is not near the US-2 roadway AOI, the area involves the same ancient shoreline of Lake Algonquin.

\subsection{Sinkhole Formation}

Sinkholes are generally associated with rocks that form as chemical precipitates. The more soluble the rock (e.g. rocksalt) the more the rock will likely dissolve. Unlike rocksalt, dolostone and limestone are less soluble and will tend to dissolve only through fissures and fractures, where water flows--slowly dissolving the rock from the discontinuity and eventually forming cavities in the rock. These rock types are referred to as karst.

There are two major classifications of sinkholes; one type is a subsidence sinkhole and the other is a dropout sinkhole. A subsidence sinkhole can be formed from any type of soil but are most commonly found in till, especially where Pleistocene glaciers coated sediment over a limestone surface. The key component of a subsidence sinkhole is suffosion-the transport or settlement of the top soil

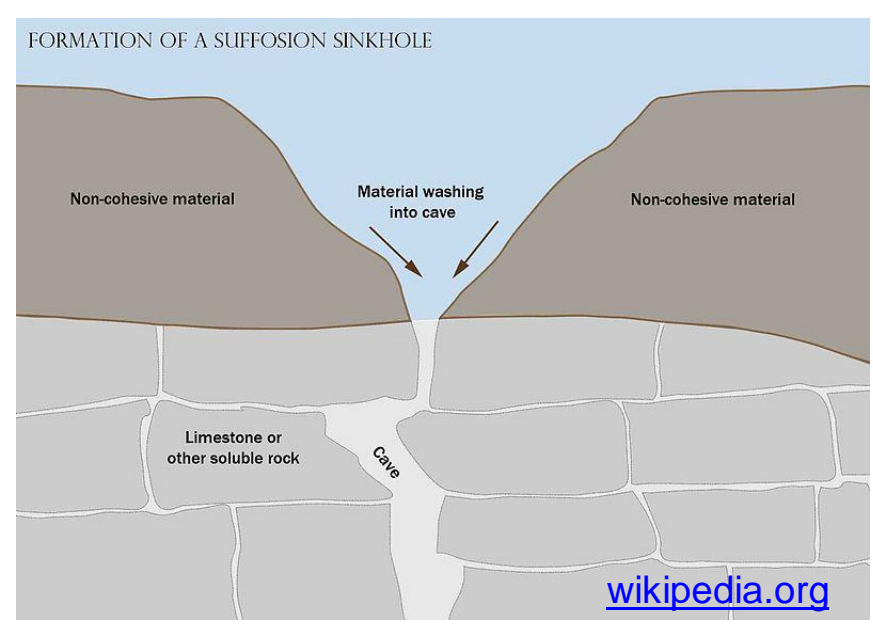

Figure 6: Formation of a Suffosion Sinkhole layer into a pre-existing fissure of the underlying bedrock. Figure 6 illustrates suffusion. Since both glacial till and sand are soils, a subsidence sinkhole is more common as they would have limited strength to hold the soil in place if a void were to form below, in the bedrock. Differing from a subsidence sinkhole is a dropout sinkhole, distinguished by their rather rapid (or seemingly instantaneous) development. A dropout sinkhole can easily be considered a dramatic failure since it deals with a 
sudden failure of soil over top a void in the bedrock. The reason it is such a sudden failure (many times without warning) is because a cohesive soil (e.g. clay) would be able to maintain the weight of the overlying soil until the void becomes too large for the cohesive soil to continue giving support. Unlike a subsidence sinkhole that is formed from sand slowly entering fissures in the bedrock, a clay layer would prevent any sort of suffosion of the topsoil but would continue to allow any possible water movement to dissolve the bedrock. A continuation of this process would ensure an increase in size of the fissures and ultimately increase the likelihood of a dropout sinkhole.

As previously mentioned, a dropout sinkhole can only be formed from a cohesive soil layer suddenly losing strength and a subsidence sinkhole is formed from suffosion of cohesionless soils. It should be understood that sinkhole formation mechanism may be different than expected. For example, if the soil from the area of interest consists of cohesionless soils it would seem that the sinkhole would form from suffosion and be considered a subsidence sinkhole. While this may be true, the possibility that an existing cohesive soil layer located beneath the cohesionless soil cannot be overlooked. If a cohesive soil layer exists, it is entirely possible that the sinkhole will start to form as a subsidence sinkhole, due to a crack in the cohesive soil layer, which eventually fails. Naturally, the cohesive layer will only fail after the strength of the cohesive soil is exceeded.

\subsection{Assessment Site Soils}

The samples obtained for this research were collected using a hand auger with a diameter size of 2". Because these were taken from a sloughing portion of a slope, stability for the one gathering the soil was rather difficult-meaning the soil was collected at a very shallow depth, 1-3' below the surface. Once the samples were collected they were taken back to the lab for testing. This section will cover all of the data gathered from testing.

\subsection{Visual Classification}

All of the soil samples obtained at the location of the slough consisted of sand, with the main difference being the sand's density and color. The sands varied between 
light, medium and dark brown sand, which seemed to be related to their depth below the roadway.

The roadway was at an elevation of about 742 feet above MSL. At an approximate elevation of about 690' the first soil sample was obtained at the very top of the slough. This sample indicated that the uppermost portion of this area consists of dark brown, medium grained sand that was in a relatively loose-compacted state. This sample was definitely the darkest sample out of the five but is just as uniform as the remaining samples.

Continuing down to the middle of the slough (elevation: 665'), another sample was taken at the surface. The middle of the slough consisted of a medium brown sand that was slightly more coarse-grained than the previously discussed sample. Another specimen taken using an extension to the auger was collected at 3' below the surface. Although these samples were taken at different depths, the visual classification of each of these two samples was identical.

Upon reaching where the water was flowing out of the slough at an elevation of nearly 635', a specimen was collected for testing. This sample was much lighter in color, a very light brown with a slight pink tint. The specimen is a medium-grain, light sand with distinctive traces of pink quartz.

The final specimen obtained was collected right from the very end of the creek, just before it runs into Lake Michigan (approximate elevation: 577'). The soil at the end of the creek consists of medium brown, fine-grained sand. This specimen seemed to be heavily composed of fine sand, much more so than any of the previous samples.

Although there was a total collection of five different soil samples, only the three that were taken directly from the slough will be discussed in detail throughout this report. The samples that will be discussed are the only ones that would have a direct effect on the stability of the slope. 


\subsection{Soil Morphology}

The three samples that were taken from the slough were viewed under a microscope to observe the morphology of the particles. This section will illustrate what was discovered though means of a microscope.

The first specimen was taken from the top of the slough and shown in Figure 7 (left picture), which is magnified to a setting of $1 \mathrm{X}$ with a field of view (FoV) equal to $1 \mathrm{~mm}$ across. On the right side is the same sample magnified to 2.7X and has a FoV of 0.4 $\mathrm{mm}$.
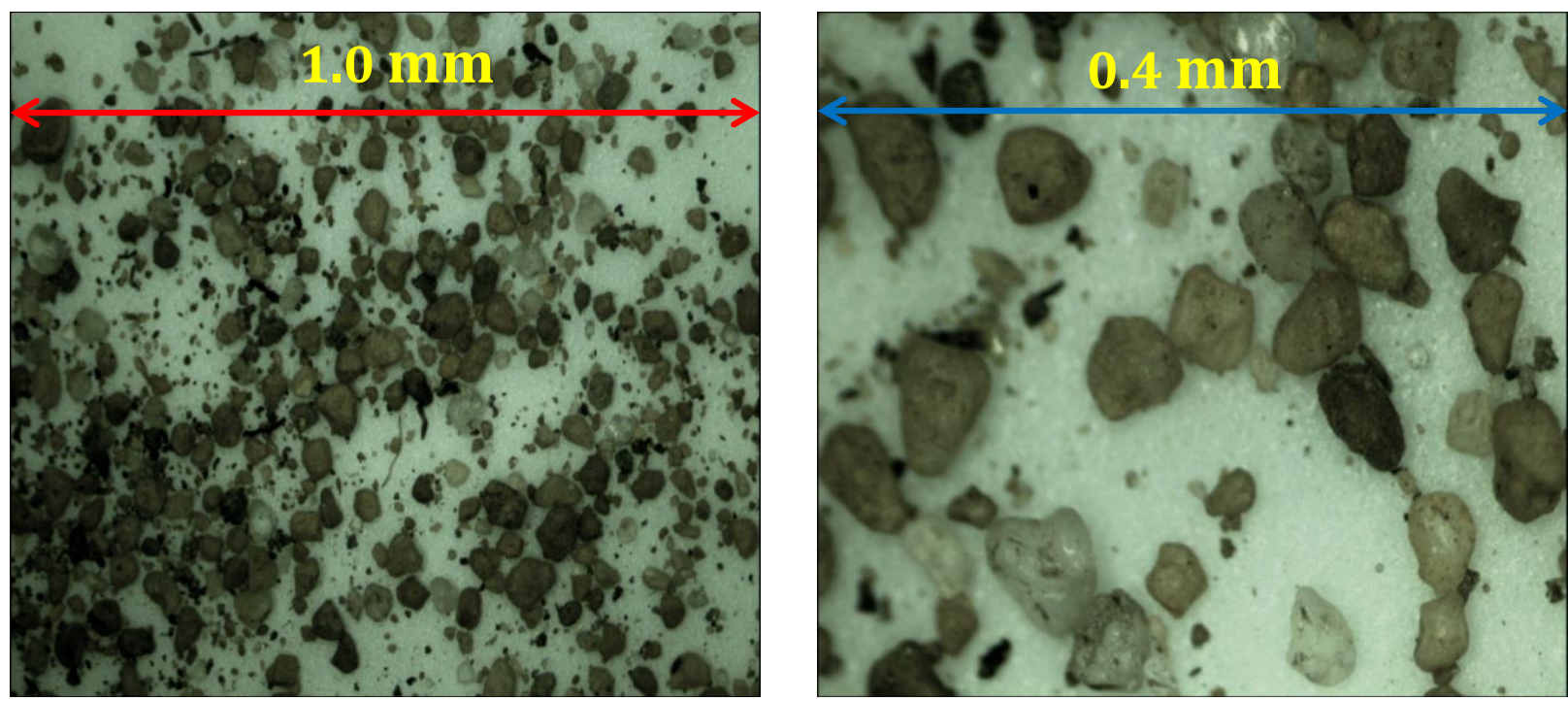

Figure 7: Top Slough Surface Soil Morphology

As mentioned in section 3.1, the sand from the top portion of the slough was considerably darker than the other samples taken at the site; the particles seem to have a consistent soil morphology that mostly resembles sub-rounded grains. From Figure 7, left, it is clear that the majority of the particles are composed of quartz (the grains near the bottom); it also seems to have traces of basalt (the very dark grains scattered about). 
Moving vertically down the slope, the next two pictures below are of the surface of the mid slough (Figure 8 and Figure 9). The illustrations below are of magnification $1 \mathrm{X}$ and $2.7 \mathrm{X}$, respectively.
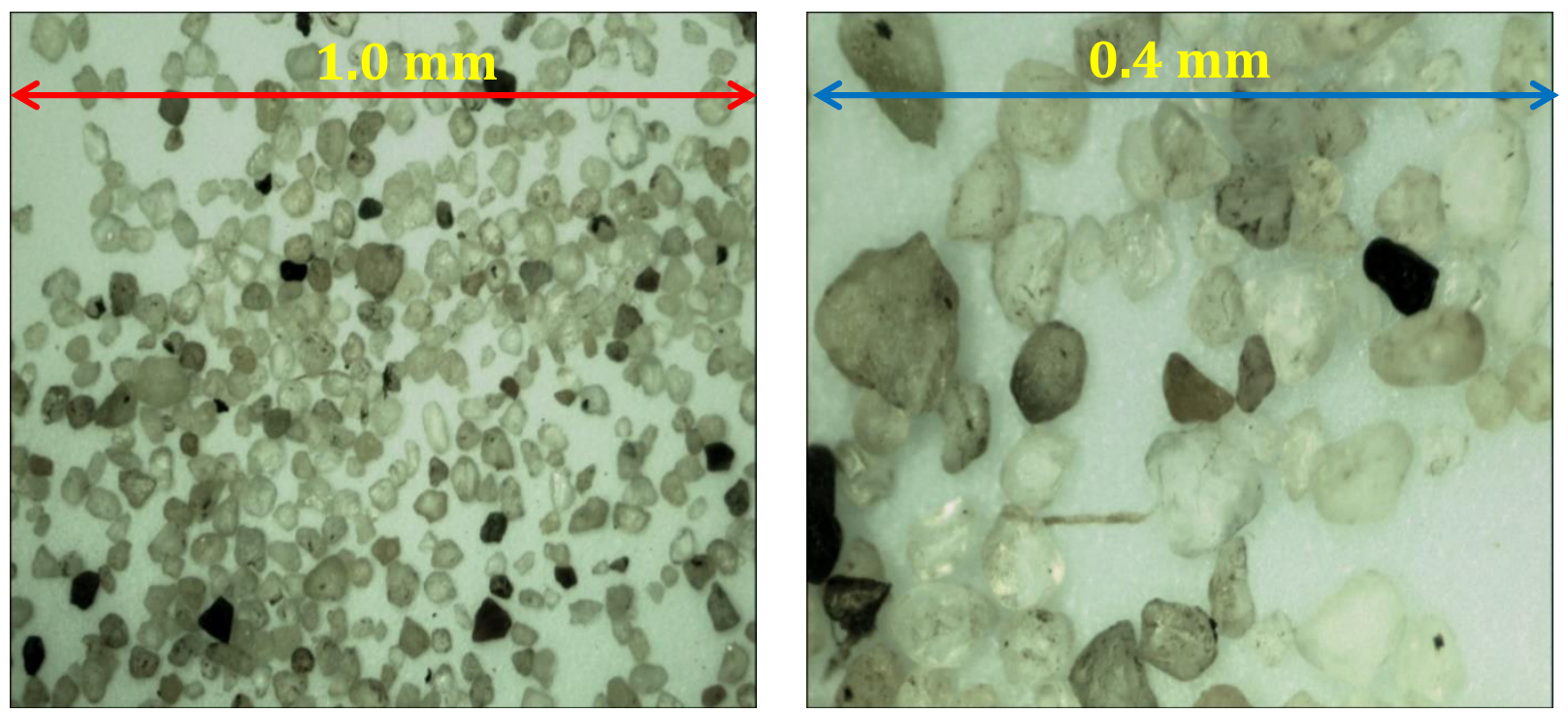

Figure 8: Middle of Slough Surface Soil Morphology

From Figure 8 it becomes very obvious that there is a heavy content of quartz in the make-up of this specimen.

Viewing Figure 9, it is seen that the soil particles look similar to the particles in Figure 8.
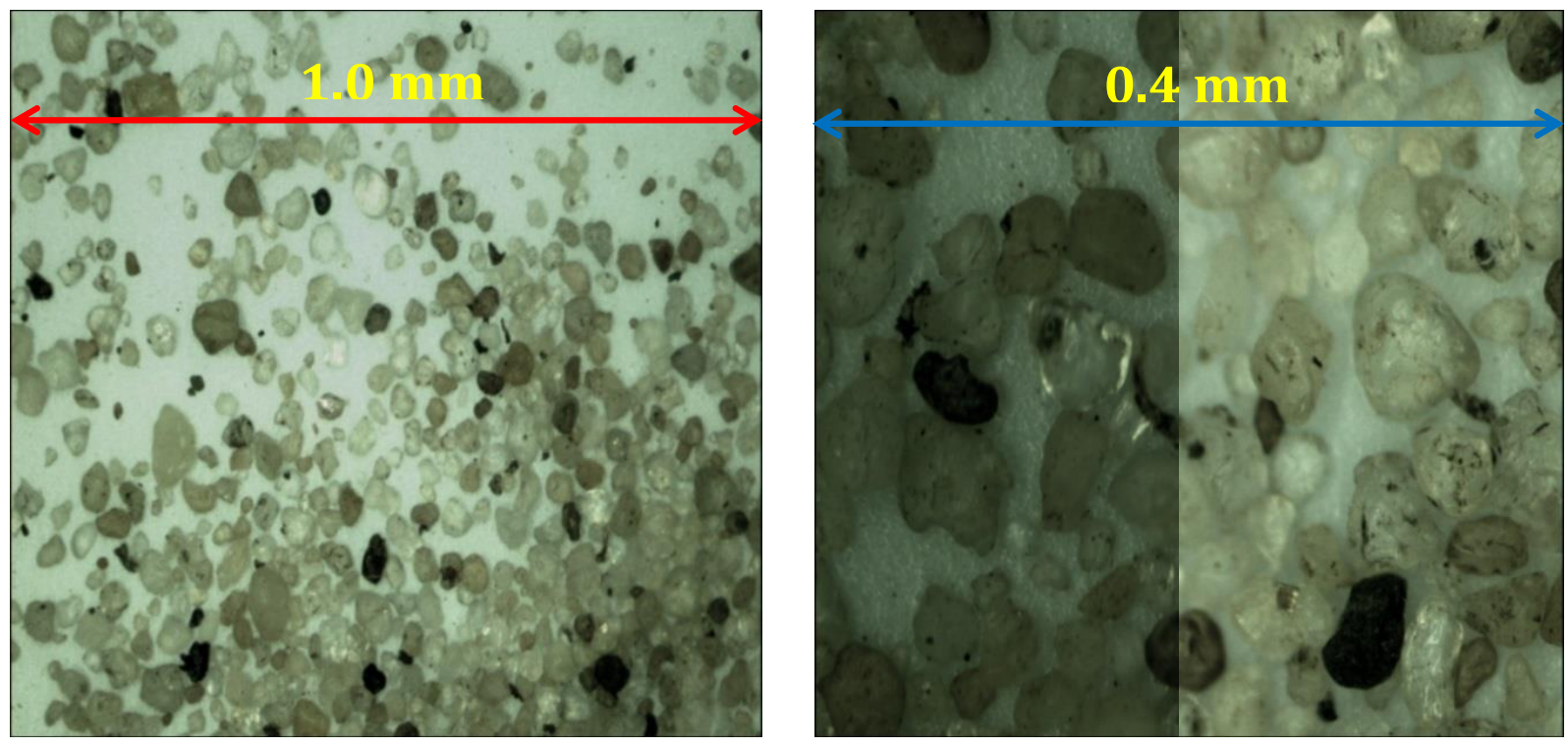

Figure 9: 3' Below Surface of Middle Slough Soil Morphology 


\subsection{Grain Size Analysis and Natural Moisture Content}

As previously discussed, the sands in this area are fairly similar in texture and color and this section will expand upon the results of the grain size analysis of these sands as well as the natural moisture content.

Samples were collected on Thursday, June $7^{\text {th }}$ 2013. The weather was dry with a temperature around $65^{\circ} \mathrm{F}$. The samples were collected and brought back to the labs but were not tested until Monday, June $10^{\text {th }}$ 2013. The soil samples were placed in an oven at $110 \mathrm{C}^{\circ}$ to dry for 24 hours prior to measuring their final dry weight. The moisture data is reported in Table 1.

Table 1: Natural Moisture Content

\begin{tabular}{|l|c|l|c|l|c|}
\hline \multicolumn{2}{|c|}{ Top Slough [g] } & \multicolumn{2}{c|}{ Surface of Mid Slough [g] } & \multicolumn{2}{c|}{ 3' Below Mid Slough [g] } \\
\hline Wet Soil Weight & 82.1 & Wet Soil Weight & 64.8 & Wet Soil Weight & 50.2 \\
\hline Dry Soil + Dish & 118.4 & Dry Soil + Dish & 87.3 & Dry Soil + Dish & 74 \\
\hline Dish & 38.2 & Dish & 24.7 & Dish & 25 \\
\hline Dry Soil & 80.2 & Dry Soil & 62.6 & Dry Soil & 49 \\
\hline Water & 1.9 & Water & 2.2 & Water & 1.2 \\
\hline \multicolumn{2}{|c|}{ Moisture Content [\%] } & \multicolumn{2}{c|}{ Moisture Content [\%] } & \multicolumn{2}{c|}{ Moisture Content [\%] } \\
\hline \multicolumn{2}{|c|}{3.51} & & \\
\hline
\end{tabular}

The grain size distributions for the three samples are shown in Figure 10 through Figure 11. All three grain-size curves show a very uniform sand. 


\section{Particle Distribution along the Top Slough}

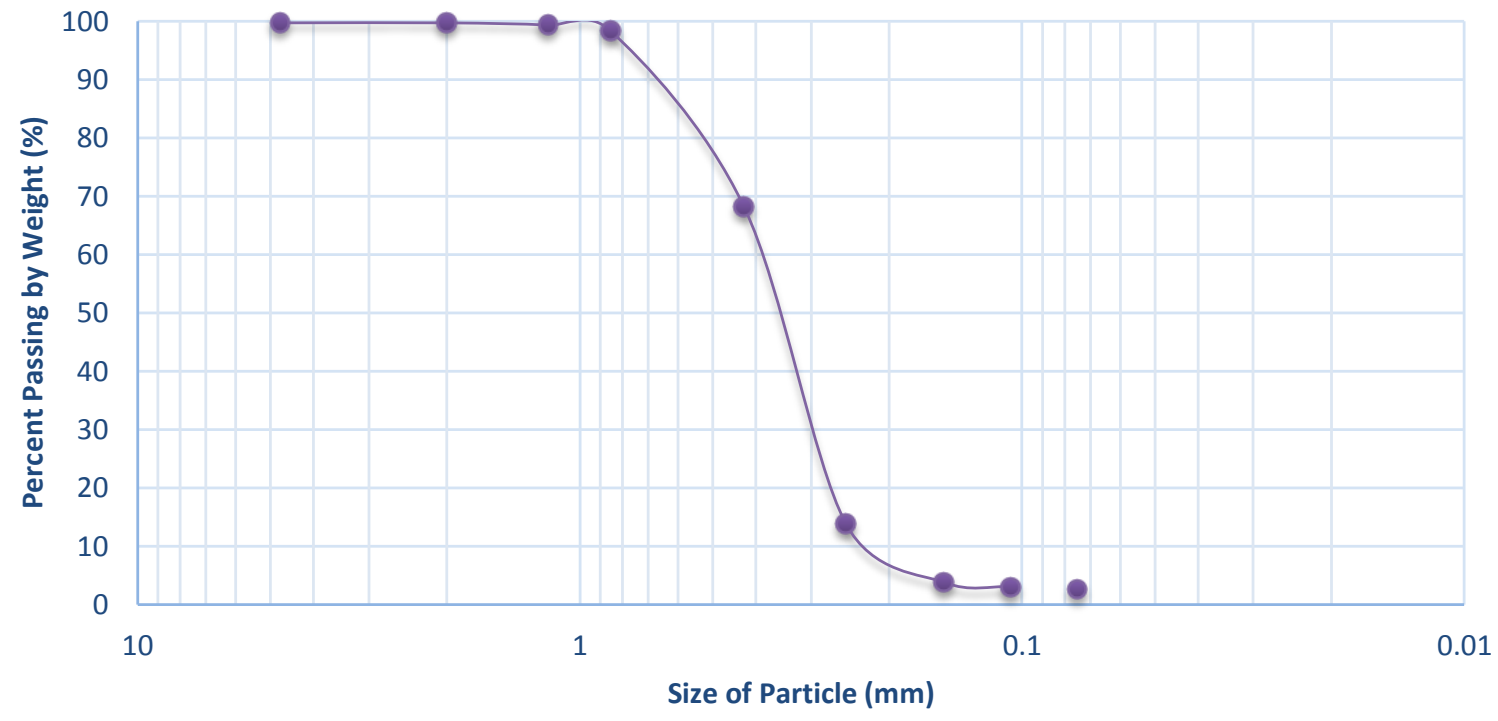

Figure 10: Top Slough Particle Distribution

\section{Particle Distribution 3' Below Surface of Mid Slough}

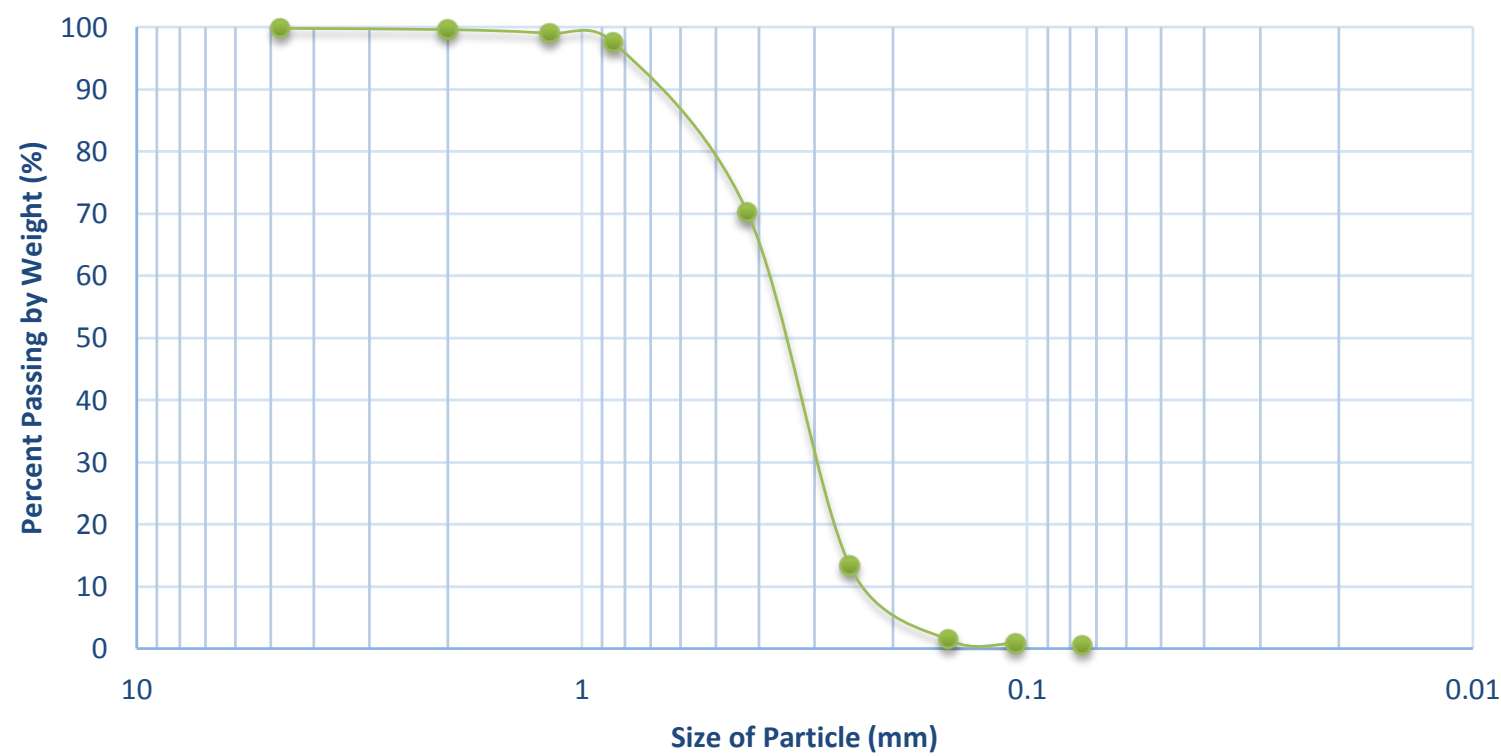

Figure 11: 3' below Surface of Mid Slough Particle Distribution 


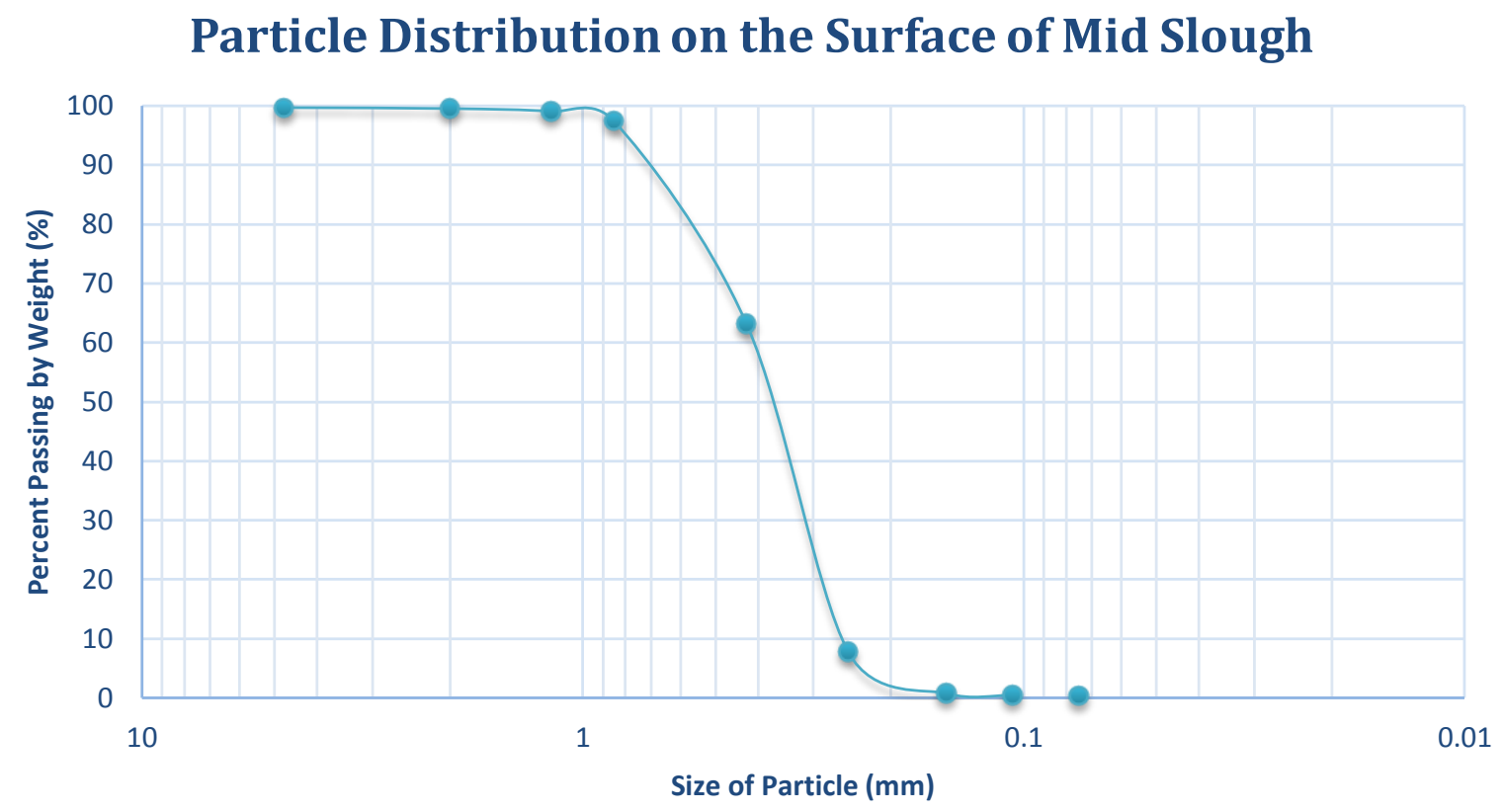

Figure 12: Surface of Mid Slough Particle Distribution

Please note-since the fines content in the samples were all less than $5 \%$ it was deemed unnecessary (by engineering standards) to perform a hydrometer analysis. Also, please reference Appendix A: Grain Size Distribution Tables \& Comparison Chart for the complete material from this section.

\subsection{Shear Strength Analysis}

Determining the sand's shear strength will be used to assess the slope stability of the slough area. A standard Direct Shear Test (DST) was used to assess the strength of the sands. The tests were run using an electrical direct shear test machine with proving ring 15209, which was connected to DasyLab - a program that records all data points into a file than can easily be transferred to Excel. One statement worth mentioning before continuing with this section, is that only the "Top Slough" and "3" Below Mid Slough Surface" will be reported. This was decided because of the similarity of the sands via visual classification, soil morphology and grain size analysis.

A number of DST tests were conducted. Since the DST were conducted with different compaction levels and various weights to get specific details regarding the soil's strength with respect to density. More specifically, both soil samples were tested a 
total of six times; three dense samples and three loose. For each set of three, the normal forces used were: $26.4 \mathrm{lbs}, 50.3 \mathrm{lbs}$ and $75.5 \mathrm{lbs}$.

For clarification, a 'densely' compacted specimen in this analysis implies that the soil sample consisted of three lifts and each lift was tamped 20 times versus a third of that compaction level (two lifts at 10 tamps each) for 'loosely' compacted samples..

On the following pages Figure 13 and Figure 14 display the shear strength vs horizontal displacement of the two samples. It was noticed that the loosely compacted and densely compacted samples gave very similar outcomes. Because the results show similarities between the dense and loose compaction stages, it confirms the grain-size analysis of uniform sand as well as the mostly rounded shape seen in the soil morphology - which is very similar to the results of Ottawa 20-30 sand-a sand that also has troubles being compacted. 

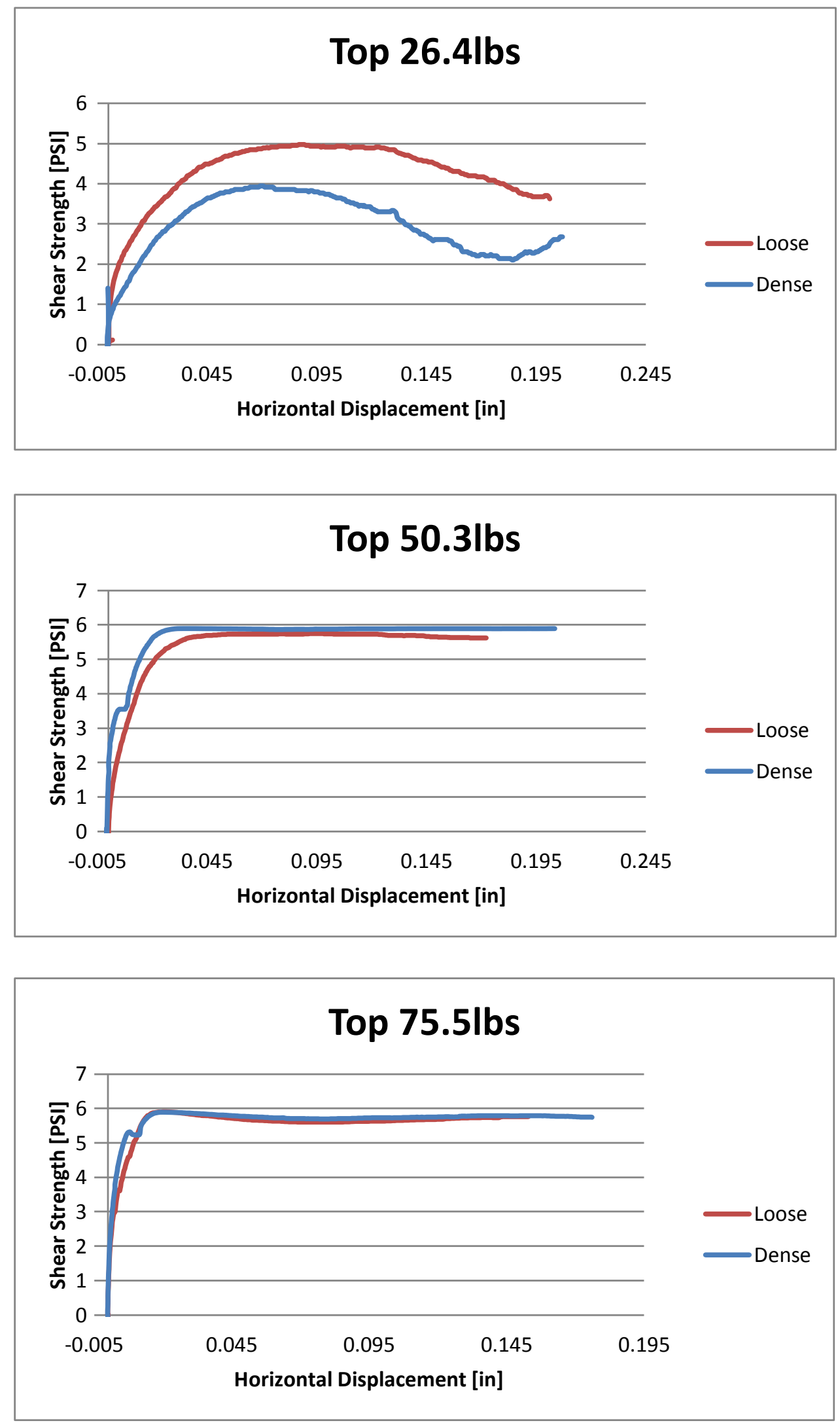

Figure 13: Shear Strength vs Horizontal Displacement for the Top Slough 

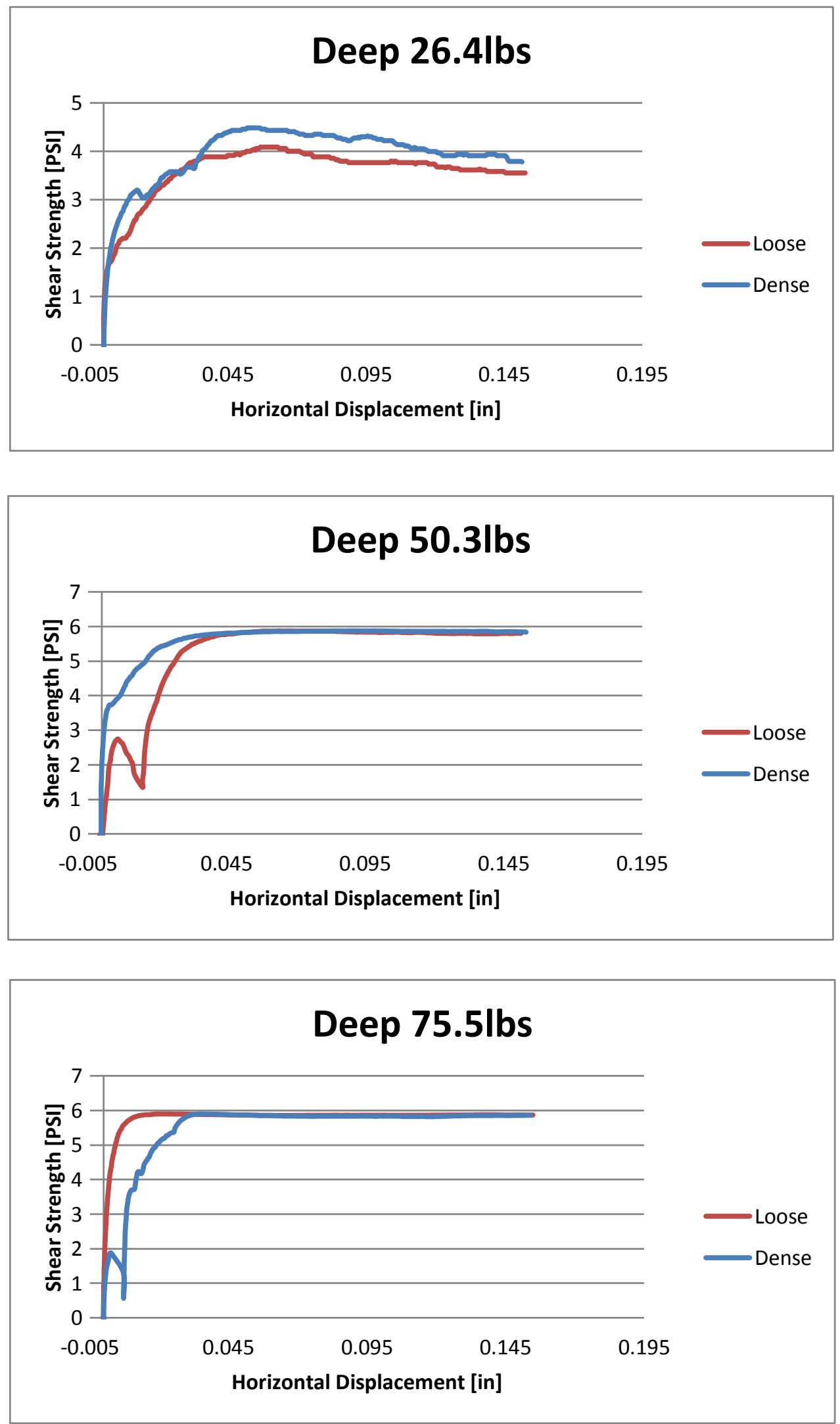

Figure 14: Shear Strength vs. Horizontal Displacement for 3' Below Mid Slough 
After completing these tests, the values from DasyLab were copied over to an Excel file to be analyzed. Below, Figure 15 shows the result of the shear strength analysis; shear strength of the soil to normal stress in pounds per square inch.
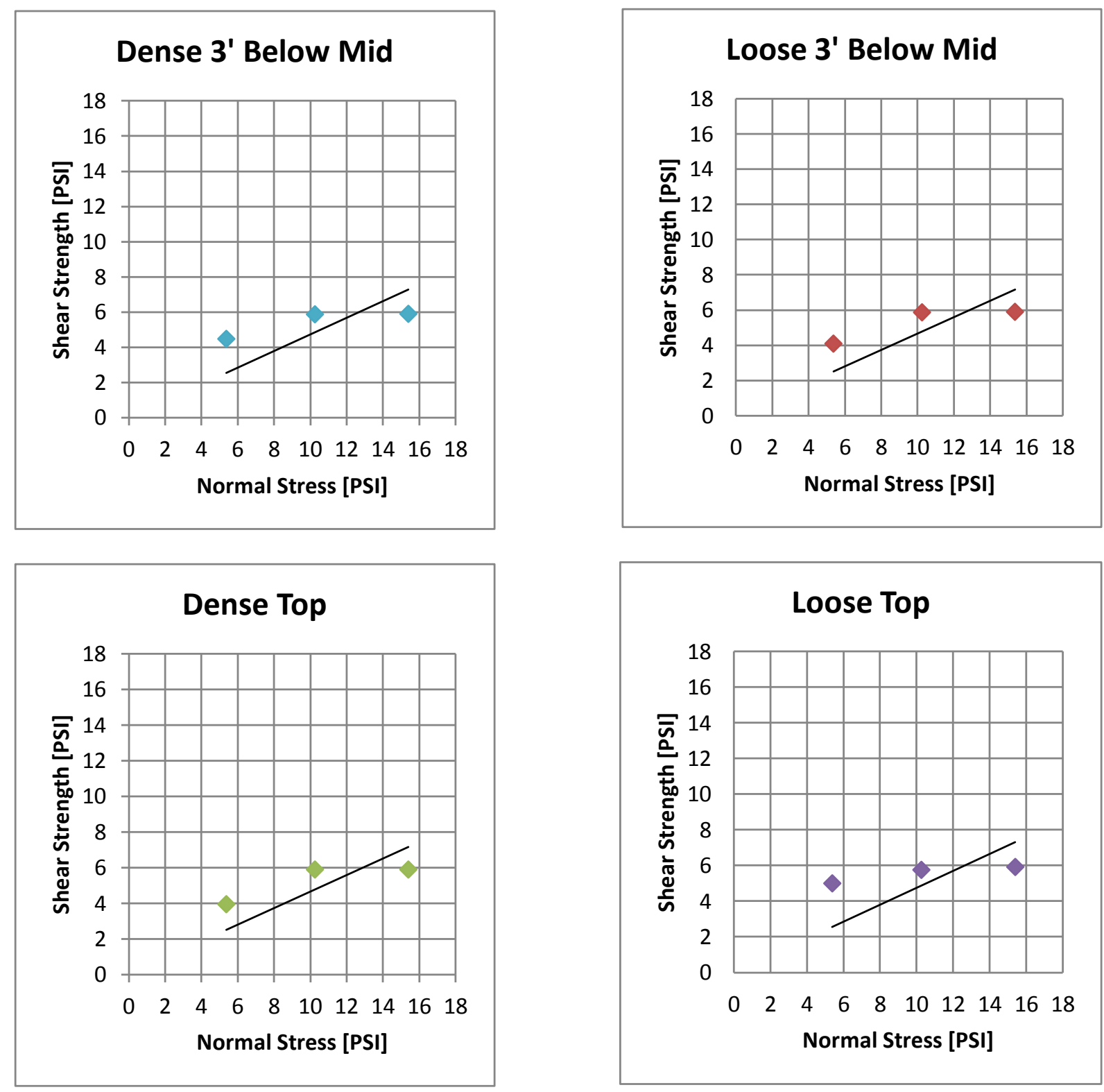

Figure 15: Normal vs. Shear Stress for Dense \& Loose Samples of both Top and 3' below Mid Slough

These angles were graphically measured to have an average phi of $24^{\circ}$. Considering a phi angle of $24^{\circ}$ is quite low, an average phi was calculated to be about $30^{\circ}$. Table 2 below, shows the graphically interpreted phi versus the calculated phi. 
Table 2: Summary of Phi Angles

\begin{tabular}{|c|c|c|c|c|c|c|c|}
\hline \multicolumn{4}{|c|}{ Dense 3' Below Surface of Mid Slough } & \multicolumn{4}{|c|}{ Loose 3' Below Surface of Mid Slough } \\
\hline TAU [PSI] & $\mathbf{N}[\mathbf{L B S}]$ & SIGMA [PSI] & $\begin{array}{c}\text { PHI } \\
\text { [DEG] }\end{array}$ & TAU [PSI] & $\mathbf{N}[\mathbf{L B S}]$ & $\begin{array}{c}\text { SIGMA } \\
\text { [PSI] }\end{array}$ & $\begin{array}{c}\text { PHI } \\
\text { [DEG] }\end{array}$ \\
\hline 4.48845053 & 26.4 & 5.378163837 & 39.85 & 4.0861435 & 26.4 & 5.378163837 & 37.23 \\
\hline 5.88067787 & 50.3 & 10.24703186 & 29.85 & 5.87500839 & 50.3 & 10.24703186 & 29.83 \\
\hline 5.89773521 & 75.5 & 15.3807337 & 20.98 & 5.89773317 & 75.5 & 15.3807337 & 20.98 \\
\hline \multicolumn{3}{|c|}{ Average Phi (calculated) } & 30.23 & \multicolumn{3}{|c|}{ Average Phi (calculated) } & 29.34 \\
\hline \multicolumn{3}{|c|}{ Average Phi (graphically interpreted) } & 24 & \multicolumn{3}{|c|}{ Average Phi (graphically interpreted) } & 24 \\
\hline
\end{tabular}

\begin{tabular}{|c|c|c|c|c|c|c|c|}
\hline \multicolumn{4}{|c|}{ Dense Top Slough } & \multicolumn{3}{c|}{ Loose Top Slough } \\
\hline \hline TAU [PSI] & N [LBS] & SIGMA [PSI] & $\begin{array}{c}\text { PHI } \\
\text { [DEG] }\end{array}$ & TAU [PSI] & N [LBS] & $\begin{array}{c}\text { SIGMA } \\
\text { [PSI] }\end{array}$ & $\begin{array}{c}\text { PHI } \\
\text { [DEG] }\end{array}$ \\
\hline 3.94303138 & 26.4 & 5.378163837 & 36.25 & 4.97481174 & 26.4 & 5.378163837 & 42.77 \\
\hline 5.89773521 & 50.3 & 10.24703186 & 29.92 & 5.74661695 & 50.3 & 10.24703186 & 29.28 \\
\hline 5.89773317 & 75.5 & 15.3807337 & 20.98 & 5.8976965 & 75.5 & 15.3807337 & 20.98 \\
\hline \multicolumn{3}{|c|}{ Average Phi (calculated) } & 29.05 & \multicolumn{3}{c|}{ Average Phi (calculated) } & 31.01 \\
\hline \multicolumn{3}{|c|}{ Average Phi (graphically interpreted) } & 23 & \multicolumn{3}{c|}{ Average Phi (graphically interpreted) } & 24 \\
\hline
\end{tabular}

When looking at Table 2 it becomes obvious that the calculated phi is much higher than the graphically interpreted phi. It is typical to gather useful phi angles from a graphical interpretation because the angle the trendline forms, relative to the horizontal, is the failure envelope. If you were to draw Mohr's circle on these graphs you would be able to tell where the strength of the soil will fail (in shear) with varying values of normal stress, as well as the angle of internal friction (phi)-assuming the grids are perfectly square. Also, since Figure 15 was adjusted manually and is not likely a perfect square; hence the fact that the graphically interpreted method (in this case) is probably not the most accurate. 


\subsection{Stability Analysis}

This section discusses the stability of the slope with regarding the slough. Please note, as the model is rather complex most figures for this section can be found (linked) throughout this section to .

\subsection{Post-Initial Investigation}

After the initial investigation from MDOT was completed, the MDOT officials contacted Dr. Stan Vitton to determine if there were any pending stability problems. Meanwhile, a conventional survey was performed to gather the topography of the six specified cross sections. Using the topographical cross section titled "25FT WEST" (found in the Appendix B: Materials from MDOT, Ground Survey), the slope coordinates were put into Rocscience: Slide, forming an external boundary.

Shown below, Figure 16 is a cross-sectional view of the land slope. The y-axis is set to feet above sea level and the x-axis zero-point is the center line of the roadway. In this model there are about 16 different programmed materials, most of which are slight variations of sand: loose (coarse) at the top and medium dense to dense (medium coarse to some fine) further below the surface. Finally, the bottom (not solid) shaded areas represent bedrock: limestone, dolostone, sandstone and shale (most to least). A complete list of materials are provided in Appendix E: Material Properties. The Original LEM Modeler and Original FEA Modeler can also be found in Appendix F: Stability Analysis Models. 


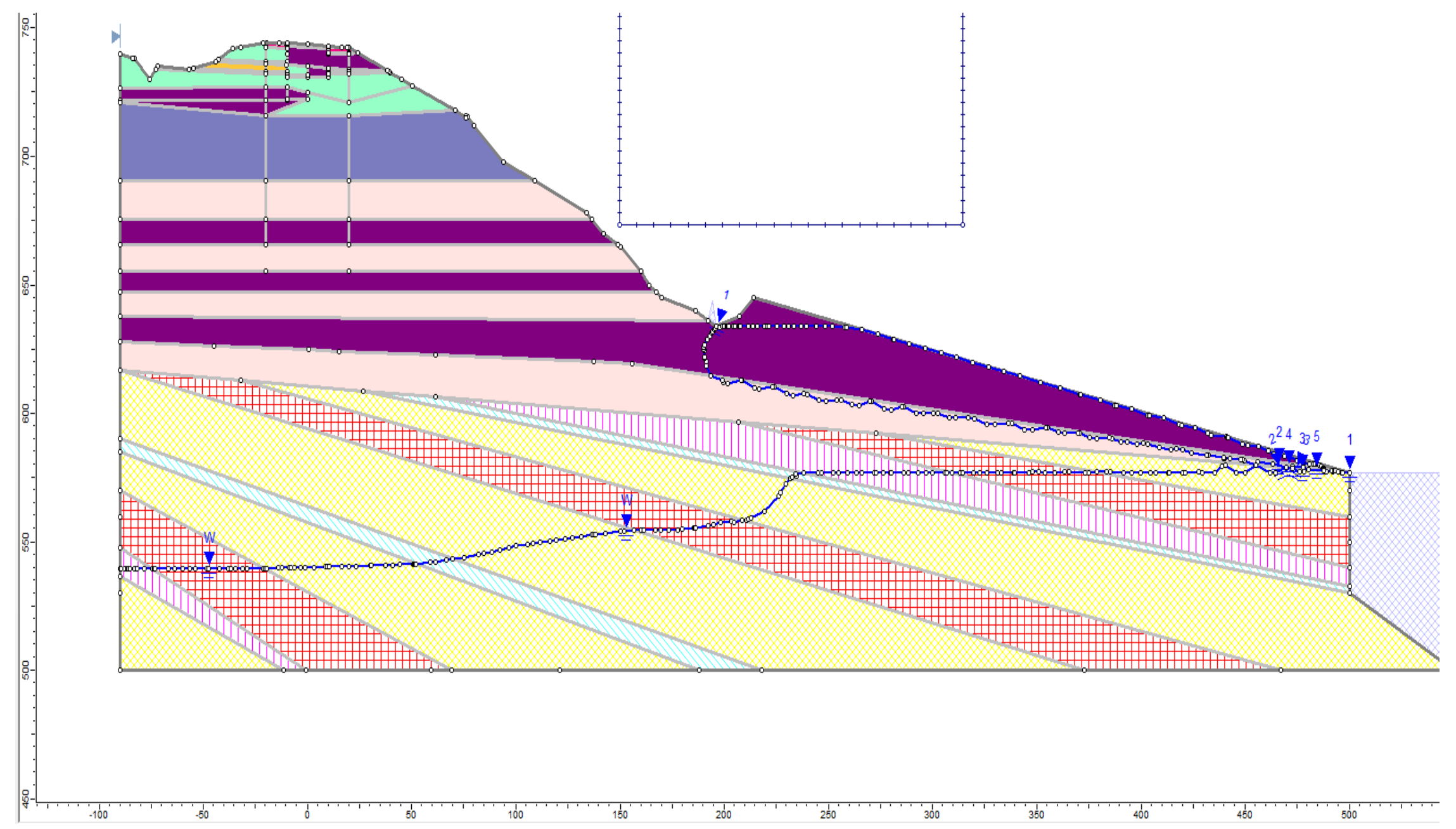

Figure 16: Multiple Water Tables

The water table is an entirely separate and an even more complex matter that will be discussed in 4.3 Ground Water Table Assumptions. 


\subsection{Reasoning behind Material Assumptions}

As mentioned at the beginning, much of the data was assumed from the MDOT boring log data. It is assumed that the data collected by the nine borings is representative of the slope, therefore the model was expected to have all specified soil types throughout the slope.

The bedrock consisted of mostly limestone and dolostone with some shale and sandstone. This is an assumption based off of the Niagara Escarpment and its geologic makeup because this section of the roadway is along the top of the Niagara Escarpment. The Niagara Escarpment is a geologic structure that formed as a result of the Michigan Basin. This basin formed over a period of approximately 25 million years when Michigan was an ancient sea. As the carbon-based sea creatures lived and died throughout this period, their shells eventually settled to the bottom of the sea and mixed with the natural sea sediment of sand, silt and clay. Over time these materials were compressed and hardened into layers of shale, sandstone, siltstone, limestone and dolostone.

\subsection{Ground Water Table Assumptions}

Since there are possibly two water tables on this slope, both were incorporated into the slope stability model. However, considering the water table depth (at the time of the initial modeling phase) was still technically unknown, the GWT was set as unknown and a test was run through the Limit Equilibrium Method (LEM) to determine where the GWT would be. What was discovered with this test is shown as the GWT in the Figure 16. While the placement of the shown GWT could be true, it would not explain why there are artesian conditions happening nearly 100' above the GWT.

Because the GWT was initially unknown, it should also be mentioned that a couple of different water tables (depth and number of GWT) were simulated. In the Appendix [Original LEM Modeler and DEQ LEM Modeler] show the other water tables tested. However, since all water tables were determined to be below the slough, the stability analysis results did not change with the different GWT levels. 
Subsequently, most of the tests that were performed used a single GWT that simply travel along an angle and barely touched the artesian well and continued downward to make contact with the lake. Shown below, Figure 17 is the LEM global minimum (Bishop simplified) analysis with a singular GWT resulted in a FS of 0.655 [Original LEM]. For clarification, global minimum implies that out of all failure surfaces, the one with the lowest value is the global minimum.

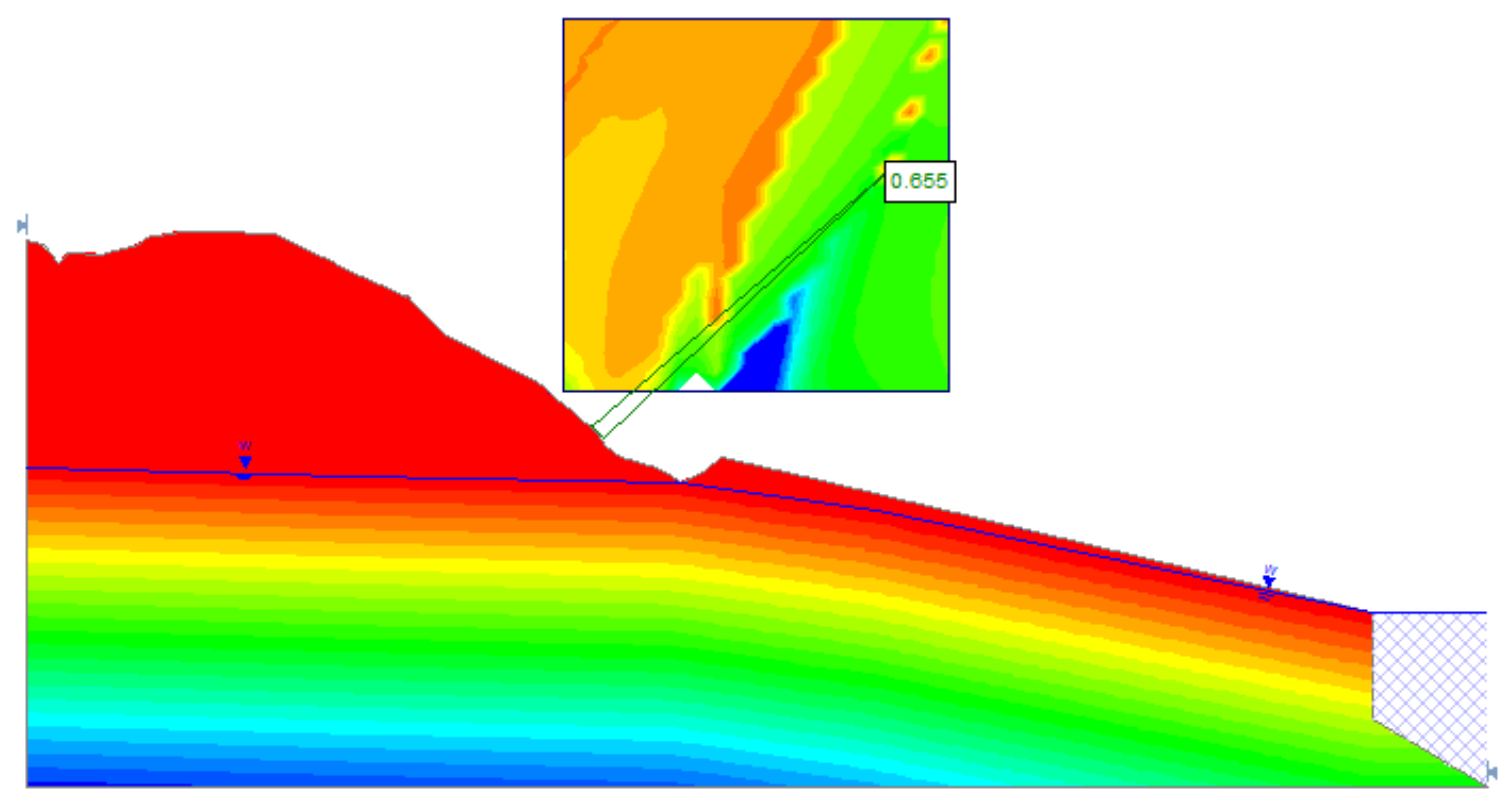

Figure 17: Bishop Simplified LEM FS

The cross-section that was programmed into Rocscience: Slide was later imported directly to Rocscience: Phase 2 to compare the strength reduction factor (SRF) to the LEM FS. Referencing Original FEA, the overall result of the critical SRF of 0.67 .

Although the SRF was determined to be slightly greater than the FS, they were more or less the same value, which was less than 1 ; implying that it is failing. While it is not the best news to see that every test run for this slope confirmed the slope is failing, it is encouraging to know that both very different methods give similar results, ensuring the quality of the analysis. 


\subsection{Post-Initial Analyses}

Considering there are many types of engineering properties and each material will change its engineering properties based on many things such as saturation and climate change. Because of this some more tests were run to develop a more accurate model of the slope. Some variances in these analyses included different types of failure search methods (for LEM) such as: grid search, slope search, block search and path search. Although these variations were completed, there was not a large enough difference in the FS results to go into more detail in this report.

Upon completing some further research regarding water well data from Michigan's DEQ, another model [DEQ LEM]/DEQ FEA]] was developed using this data (found in Appendix C: DEQ Well Water Levels and Bedrock Depths). Although the sands were not more specific than "fine, medium and coarse" the benefit of this data was the thickness of each major material layer, as well as the fact that they actually recorded the depth at which the bedrock began. Once the model had been redone using DEQ data, the analysis had determined that the FS (for DEQ LEM Grid Search) had been lowered slightly, to 0.527 and 0.615 (for DEQ Slope Search). This was likely a different value due to the addition of various limestone engineering properties and the fact that the sand was all the same density. In the original model, there was only one version of limestone and it was programmed to be a typical strong limestone with little to no weathering. However, if the DEQ data is considered it is quickly understood that there is only one small section of durable limestone. Unfortunately, since there was no core samples of any of the variations of limestone, the Hoek-Brown criterion was still assumed.

Even though all the results give nearly the same FS, it should be understood that a probable explanation for all the results showing failure is likely because the slope is actually heavily wooded-however, none of the vegetation is programmed in any of these models, due to a lack of accurate vegetation knowledge. One last thing to note would be the depth of all the failure surfaces $(\mathrm{FS}<1)$ is no greater than 11' into the slope-the deeper the failure, the higher the FS. In Appendix F: Stability Analysis Models are all tests ran for both LEM and FEA, as well as the depth for deepest (LEM) slip surface and the global minimum slip surface. 


\subsection{Analysis and Conclusions}

Instability has been observed along the slope between US-2 and Lake Michigan. The instability is a slough about midway up the slope. Artesian groundwater conditions were observed during the spring of 2012. An inspection sometime later did not observe artesian conditions. Instead a flow of water was observed emanating out of the slough area.

Sinkholes were present during the construction of the highway. It appears that for the most part the sinkholes have remained dormant. However, some soil movement appears to have occurred with the footprint of the existing sinkholes. The existing sinkholes appear to have all been mapped on the original highway construction plans.

Soil samples were obtained from the landslide site and analyzed. Soils consist of clean, uniform and rounded to sub-rounded sands, mostly from aeolian processes. The shear strength of the sand was found to be about $30^{\circ}$. The slope average angle was measured to be barely over $31^{\circ}$ and is heavily wooded, indicating that the slope is nearly at its maximum slope angle.

The sand that makes up the slope had been deposited by glacial action and is associated with the Laurentide Ice Sheet (Wisconsin glaciation). Also, regarding the glacial effect of the area-the section of the slope that is currently sloughing appears to correlate with a glacial lake stage. It was during this point in history when a silt or clay layer developed and now acts as an impermeable layer guiding water out of the slope.

Although the analysis in this research indicates that the slope is at a point of failure, some other aspects should be considered. For one thing, the soil samples were rather hard to collect with a hand auger standing on a steep slope surrounded by uprooting trees, thus only samples between one and three feet deep could be obtained. Another important factor is the fact that there is little to no history of landslides in the area and there are slopes just as steep in the area (the Cut River Bridge) with no instability. One more important issue is the fact that vegetation is likely playing a key role to slope stability and in the model that was created for this report-all of resisting and driving 
forces of the vegetation were neglected, undoubtedly giving a less accurate factor of safety.

For future work and recommendations, it is recommended to continue observing the slope as well as conducting further soil testing, deeper borings and a determination of the groundwater conditions to observe changes or irregularities. Since sinkholes are actually present in the area it cannot be ruled out that something is happening in the subsurface that is related to a change in the groundwater table-possibly in relation to karst. Unfortunately, since time did not allow for karst testing, a major future recommendation would be to use geophysics such as electrical resistivity (ERM) in order to test for karst topography.

The Electrical Resistivity Method (ERM) is an extremely useful device as it contains different electrical resistivity values for all types of soil and rock-directly in the instrument itself, making it as easy as possible for the engineer conducting the test. It works by sending an electrical wave into the ground and based on the resistive properties of the material it is penetrating, it will give different values for different materials as well as the depth of the layer. Specifically, the electrical resistivity values will decrease as fine and moisture content increases through the subsurface. In Appendix G: ERM (Electrical Resistivity Method) Examplethere is an example of what the karst imaging would look like after an ERM test was performed. 


\subsection{References}

Bell, F. G. and M. G. Culshaw (2005). Sinkholes and subsidence: Karst and cavernous rocks in engineering and construction, Springer.

Drzyzga, S., et al. (2002). Revealing uncertainty in maps of Glacial Lake Algonquin. Advances in Spatial Data Handling, Springer: 377-389.

Heath, A. J. and P. F. Karrow (2007). "Northernmost (?) Glacial Lake Algonquin Series Shorelines, Sudbury Basin, Ontario." Journal of Great Lakes Research 33(1): 264-278.

Lake, C. (2004). "St. Catharines 2004."

Larson, G. and R. Schaetzl (2001). "Origin and evolution of the Great Lakes." Journal of Great Lakes Research 27(4): 518-546.

Sage, R. P. and V. L. Sage (2006). Glacial Lakes Algonquin and Nipissing Shoreline Bedrock Features: Mackinac Island, Michigan, Institute on Lake Superior Geology.

Schaetzl, R. J., et al. (2002). "Measurement, correlation, and mapping of Glacial Lake Algonquin shorelines in northern Michigan." Annals of the Association of American Geographers 92(3): 399-415.

Sterrett, R. J. and T. B. Edil (1982). "Ground-Water Flow Systems and Stability of a Slope." Ground Water 20(1): 5-11.

Tihansky, A. B. and L. A. Knochenmus (2001). "Karst features and hydrogeology in west-central Florida-a field perspective." US Geological Survey Karst Interest Group, Proceedings US Geological Survey Water-Resources Investigations, St Petersburg, FL: 198-211. 
Appendix A: Grain Size Distribution Tables \& Comparison Chart

\begin{tabular}{|c|c|c|c|c|c|c|c|}
\hline \multicolumn{7}{|c|}{ Particle Distribution along the Top Slough } \\
\hline $\begin{array}{c}\text { Sieve } \\
\text { Number }\end{array}$ & $\begin{array}{c}\text { Sieve } \\
\text { Size } \\
(\mathbf{m m})\end{array}$ & $\begin{array}{c}\text { Sieve } \\
\text { Weight } \\
\mathbf{( g )}\end{array}$ & $\begin{array}{c}\text { Sieve } \\
\text { Weight } \\
\text { + Soil } \\
\mathbf{( g )}\end{array}$ & $\begin{array}{c}\text { Weight of } \\
\text { Soil } \\
\text { Retained } \\
\mathbf{( g )}\end{array}$ & $\begin{array}{c}\text { Cumulative } \\
\text { Soil Weight } \\
\text { Retained } \\
\mathbf{( g )}\end{array}$ & $\begin{array}{c}\text { Cumulative } \\
\text { Percent } \\
\text { Retained }\end{array}$ & $\begin{array}{c}\text { Percent } \\
\text { Passing }\end{array}$ \\
\hline \hline 4 & 4.75 & 718.3 & 718.5 & 0.2 & 0.2 & 0.25 & 99.75 \\
\hline 10 & 2 & 433.2 & 433.2 & 0 & 0.2 & 0.25 & 99.75 \\
\hline 16 & 1.18 & 454.2 & 454.5 & 0.3 & 0.5 & 0.63 & 99.37 \\
\hline 20 & 0.85 & 407.9 & 408.7 & 0.8 & 1.3 & 1.64 & 98.36 \\
\hline 40 & 0.425 & 389 & 412.9 & 23.9 & 25.2 & 31.74 & 68.26 \\
\hline 60 & 0.25 & 316.5 & 359.7 & 43.2 & 68.4 & 86.15 & 13.85 \\
\hline 100 & 0.15 & 352.7 & 360.7 & 8 & 76.4 & 96.22 & 3.78 \\
\hline 140 & 0.106 & 331.6 & 332.2 & 0.6 & 77 & 96.98 & 3.02 \\
\hline 200 & 0.075 & 291.7 & 292 & 0.3 & 77.3 & 97.36 & 2.64 \\
\hline pan & 0 & 278.6 & 278.8 & 0.2 & 77.5 & 97.61 & 2.39 \\
\hline
\end{tabular}

\begin{tabular}{|c|c|c|c|c|c|c|c|}
\hline \multicolumn{6}{|c|}{ Particle Distribution along the Surface of the Mid Slough } \\
\hline $\begin{array}{c}\text { Sieve } \\
\text { Number }\end{array}$ & $\begin{array}{c}\text { Sieve } \\
\text { Size } \\
(\mathbf{m m})\end{array}$ & $\begin{array}{c}\text { Sieve } \\
\text { Weight } \\
(\mathbf{g})\end{array}$ & $\begin{array}{c}\text { Sieve } \\
\text { Weight } \\
\text { + Soil } \\
\text { (g) }\end{array}$ & $\begin{array}{c}\text { Weight of } \\
\text { Soil } \\
\text { Retained } \\
\text { (g) }\end{array}$ & $\begin{array}{c}\text { Cumulative } \\
\text { Soil Weight } \\
\text { Retained } \\
\text { (g) }\end{array}$ & $\begin{array}{c}\text { Cumulative } \\
\text { Percent } \\
\text { Retained }\end{array}$ & $\begin{array}{c}\text { Percent } \\
\text { Passing }\end{array}$ \\
\hline \hline 4 & 4.75 & 718.1 & 718.3 & 0.2 & 0.2 & 0.32 & 99.68 \\
\hline 10 & 2 & 433 & 433.1 & 0.1 & 0.3 & 0.49 & 99.51 \\
\hline 16 & 1.18 & 454.1 & 454.4 & 0.3 & 0.6 & 0.97 & 99.03 \\
\hline 20 & 0.85 & 407.7 & 408.7 & 1 & 1.6 & 2.59 & 97.41 \\
\hline 40 & 0.425 & 388.8 & 410 & 21.2 & 22.8 & 36.89 & 63.11 \\
\hline 60 & 0.25 & 316.3 & 350.5 & 34.2 & 57 & 92.23 & 7.77 \\
\hline 100 & 0.15 & 352.5 & 356.8 & 4.3 & 61.3 & 99.19 & 0.81 \\
\hline 140 & 0.106 & 331.4 & 331.6 & 0.2 & 61.5 & 99.51 & 0.49 \\
\hline 200 & 0.075 & 291.6 & 291.7 & 0.1 & 61.6 & 99.68 & 0.32 \\
\hline pan & 0 & 278.4 & 278.5 & 0.1 & 61.7 & 99.84 & 0.16 \\
\hline
\end{tabular}




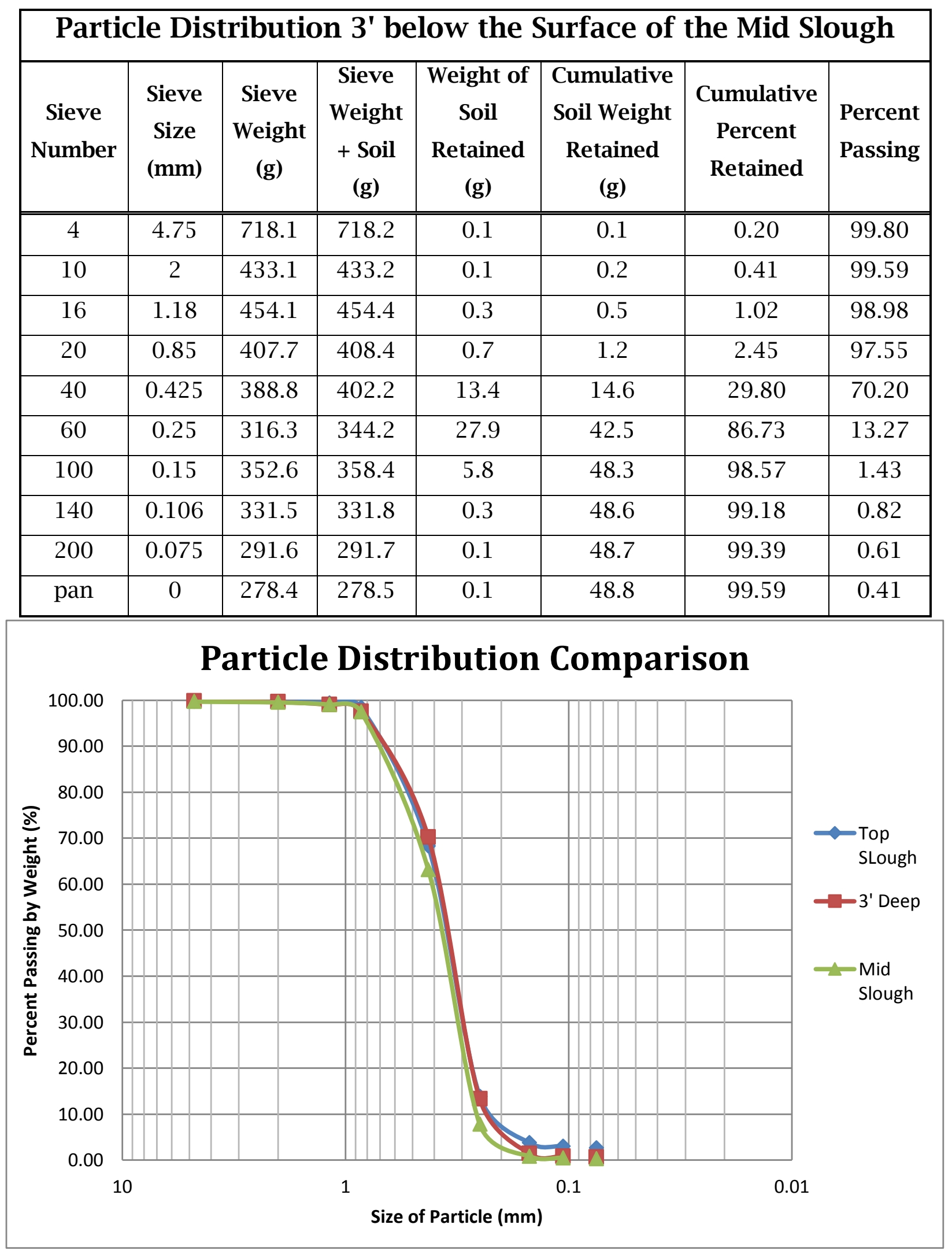




\section{Appendix B: Materials from MDOT}

\section{Ground Survey}

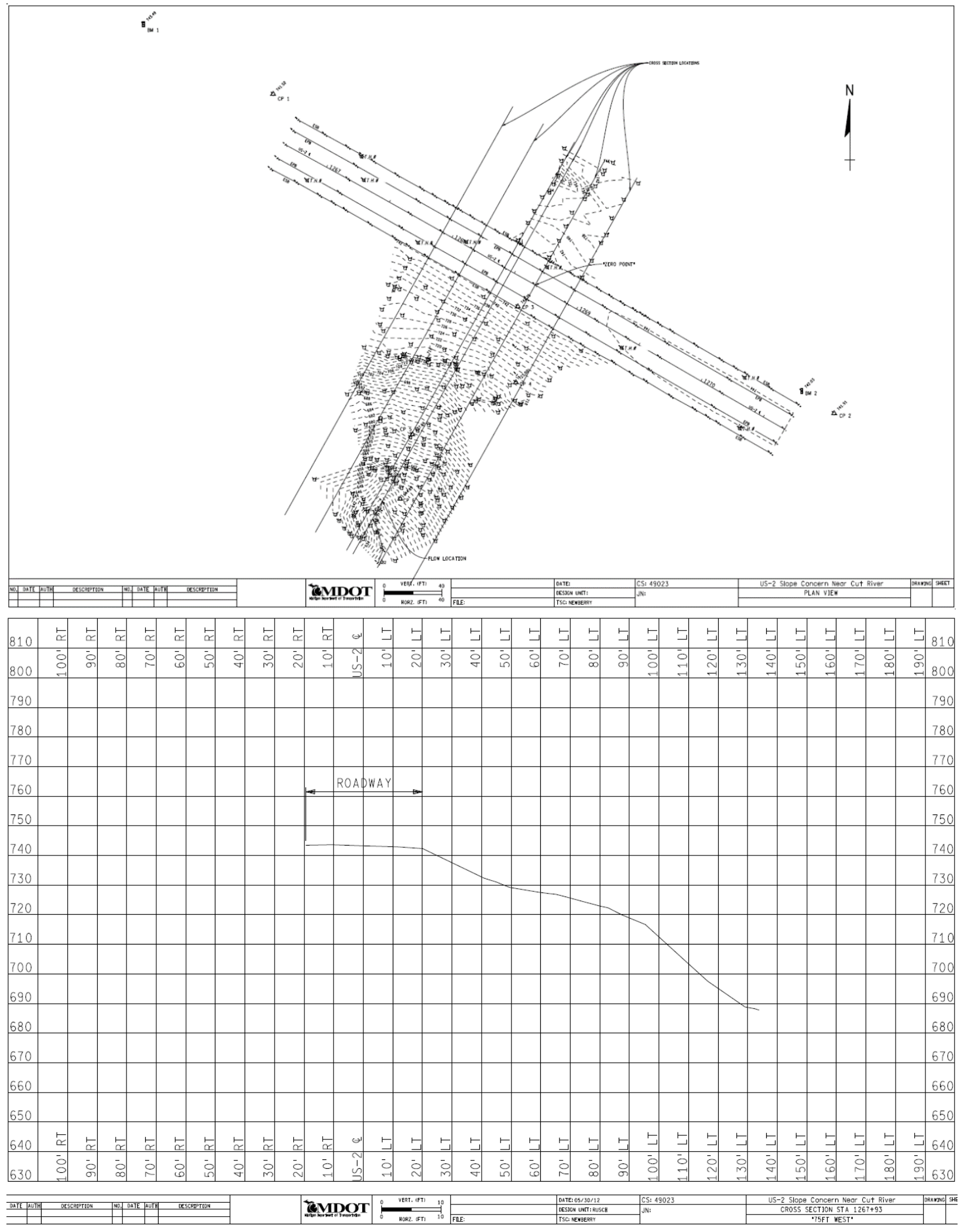




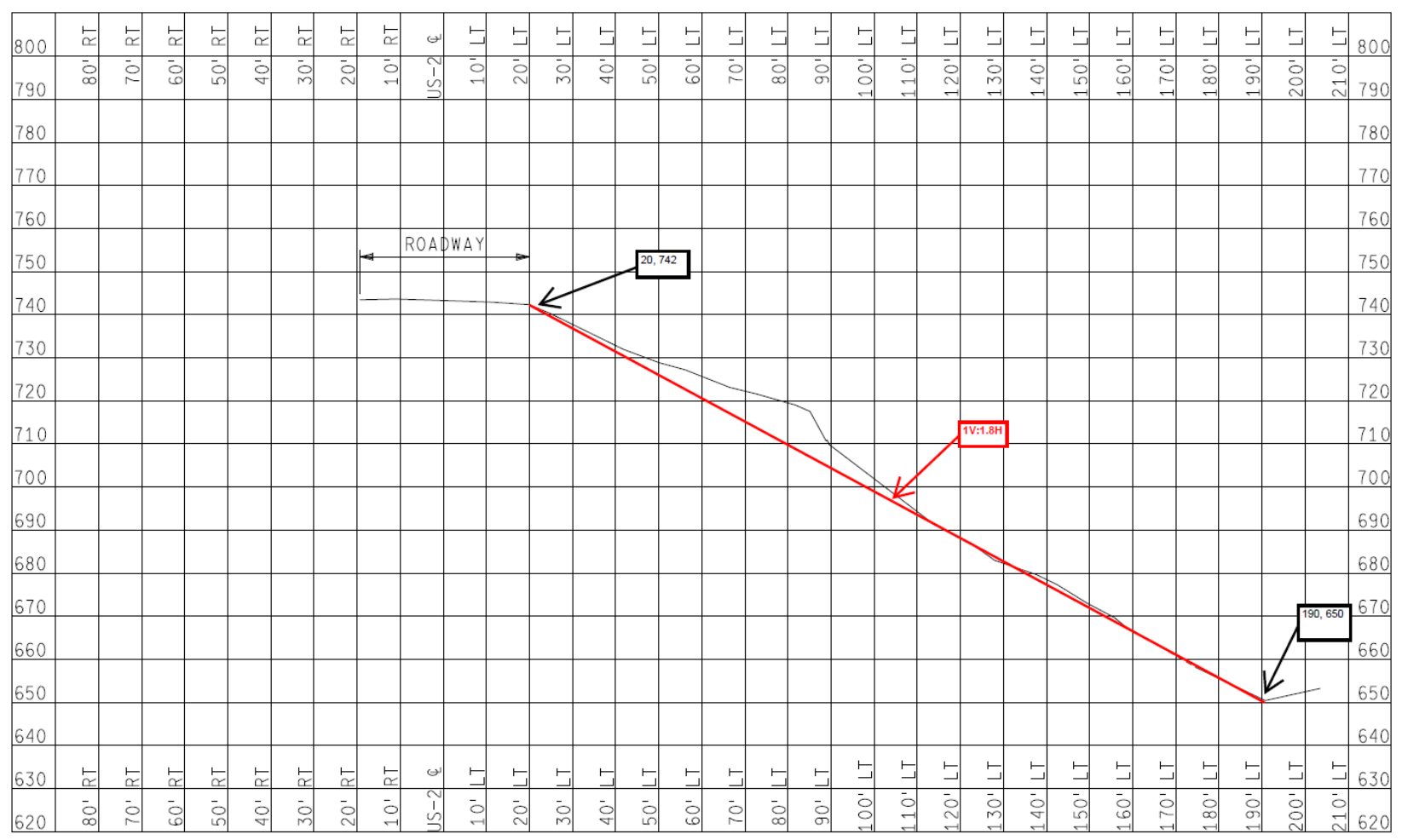

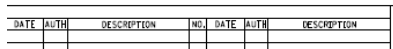

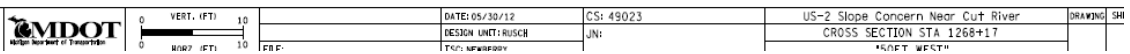

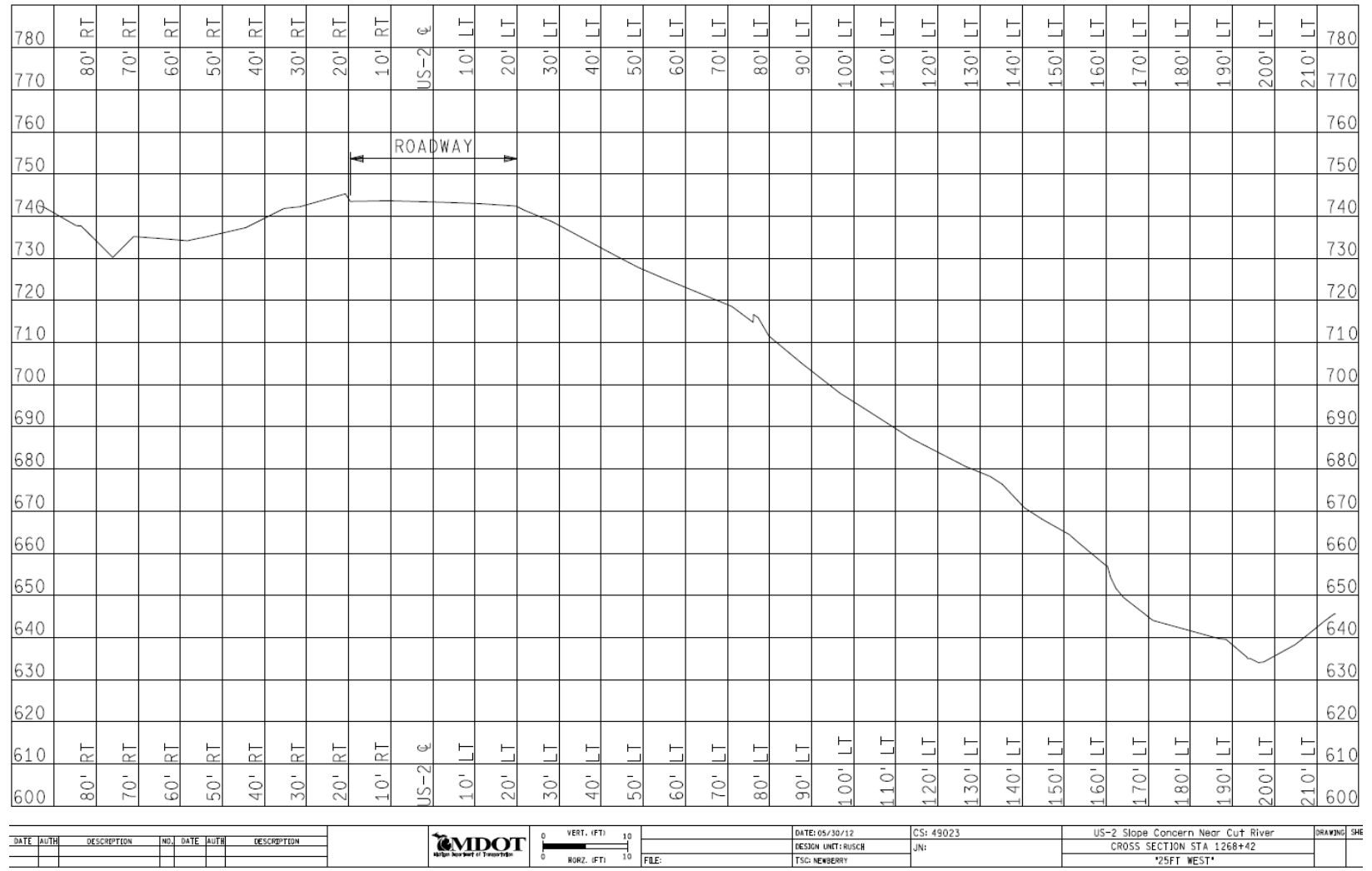



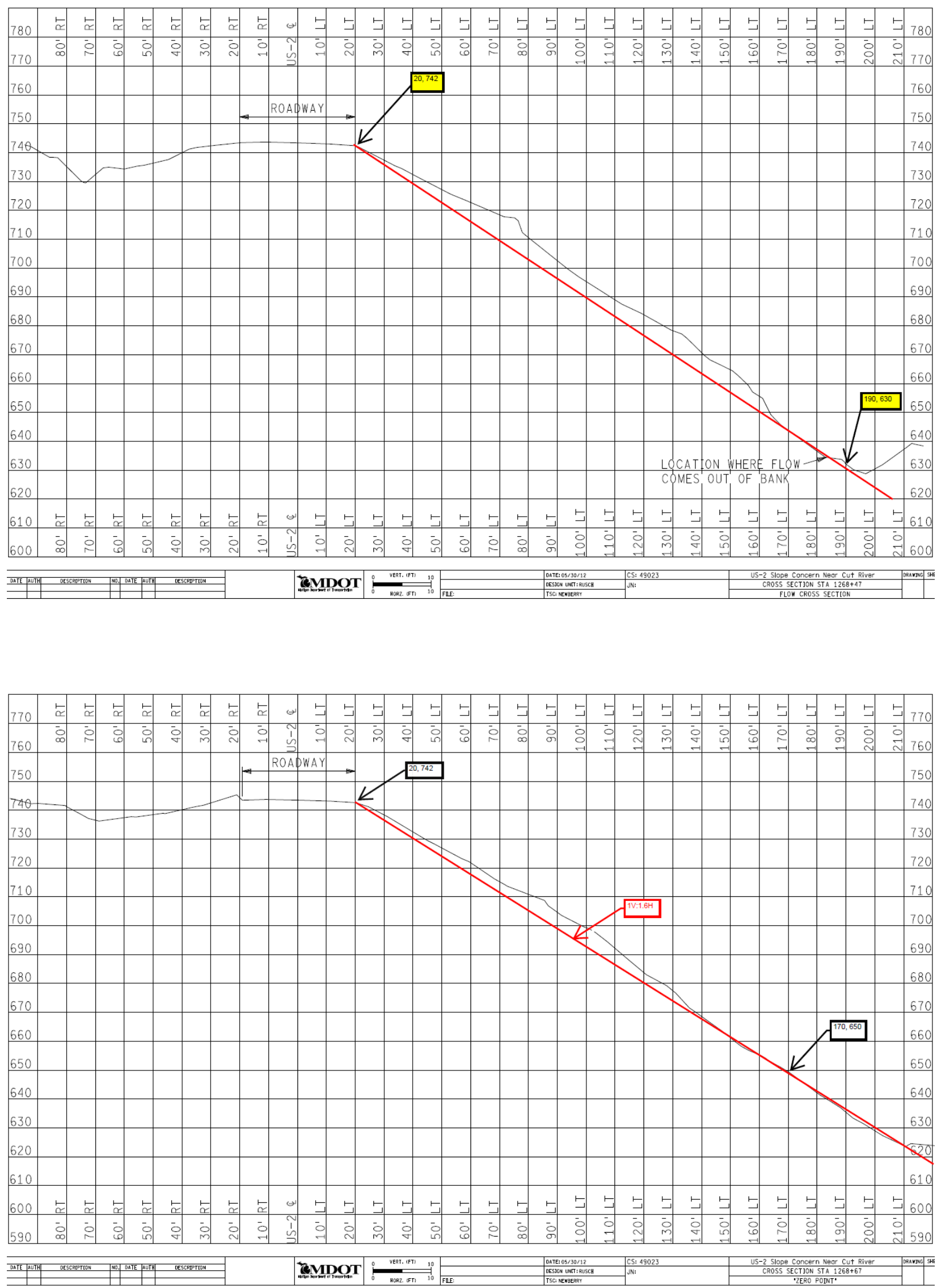


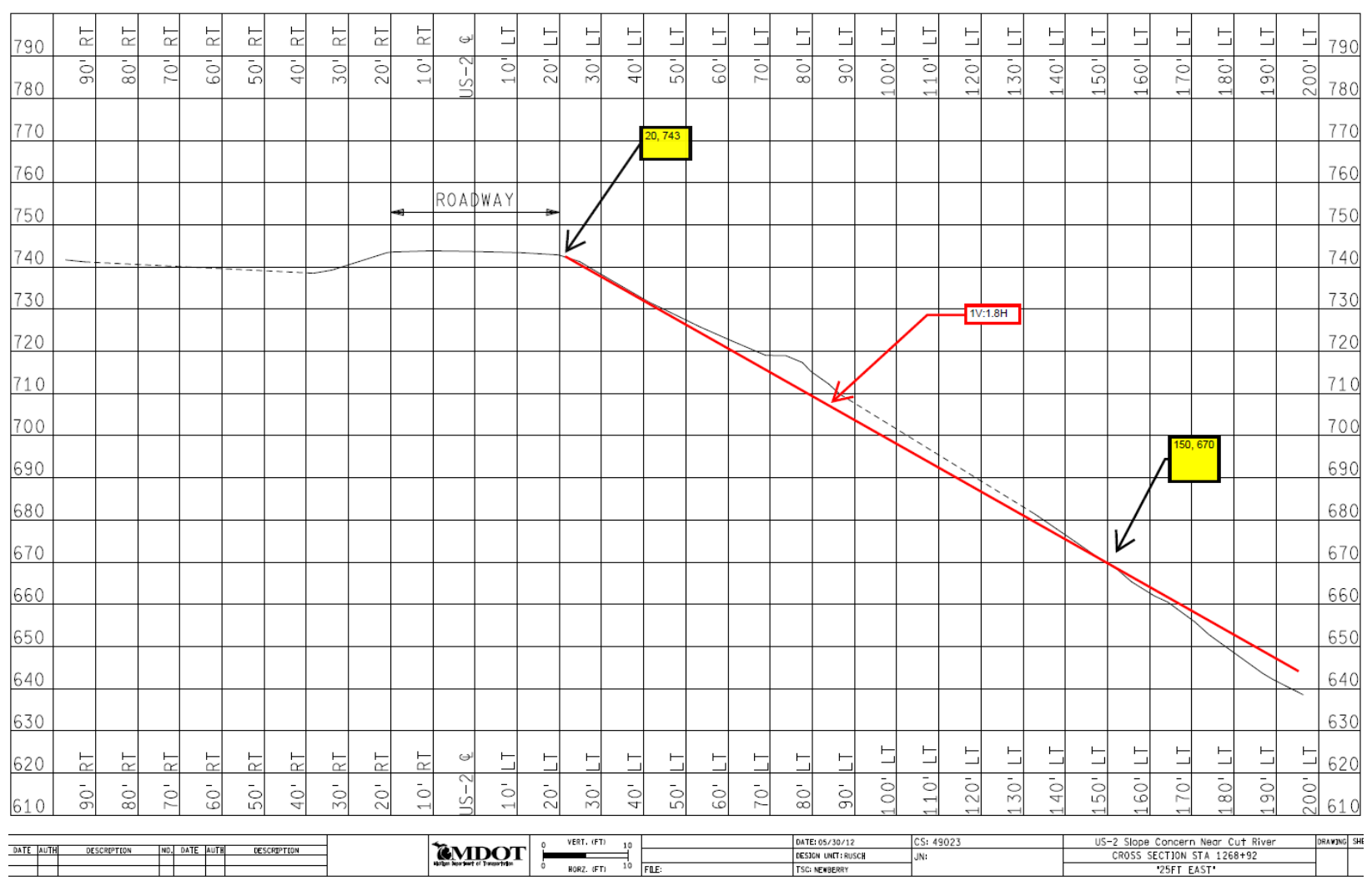




\section{Truth Boring Data}

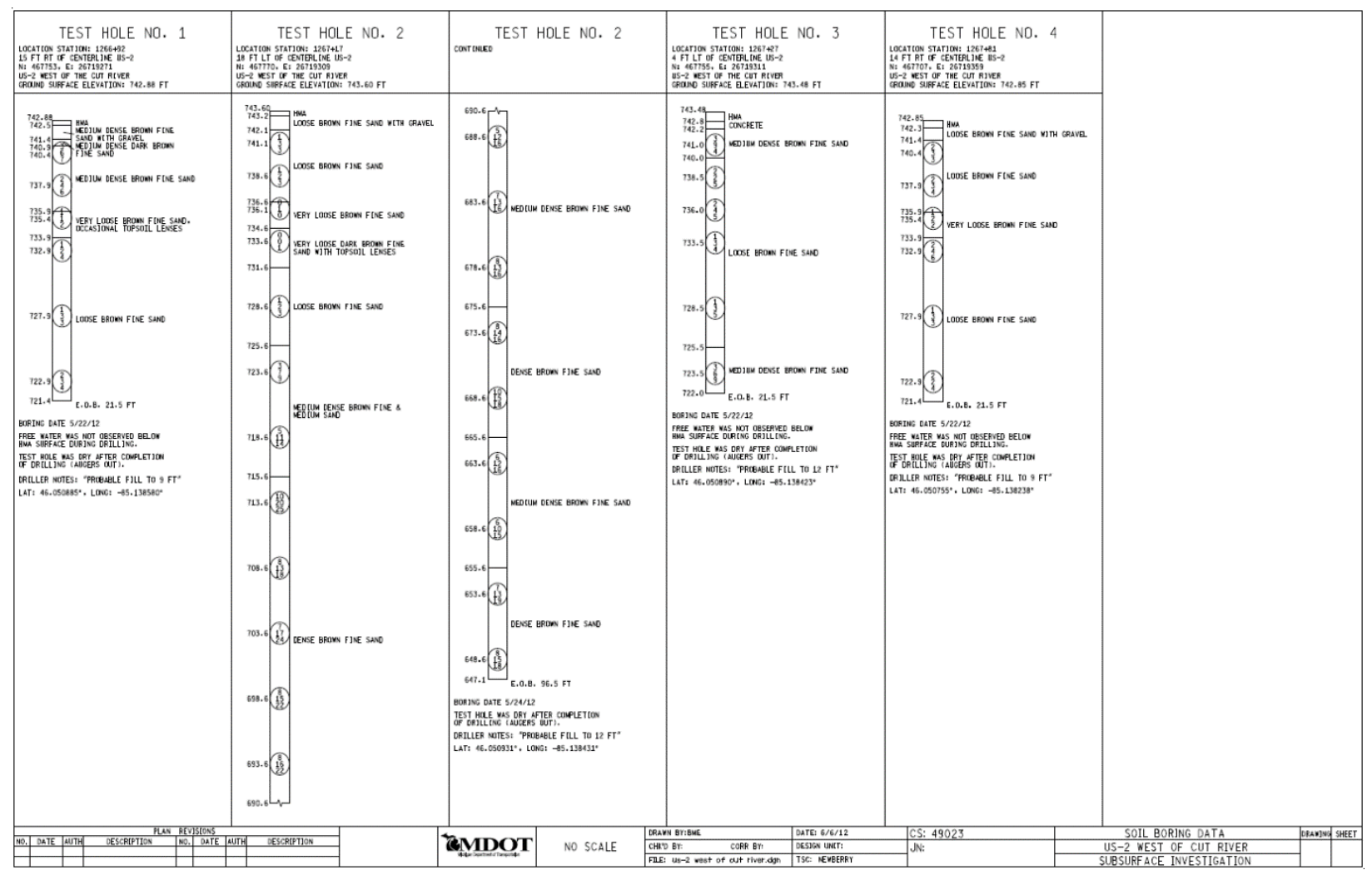

\begin{tabular}{|c|c|c|c|c|c|}
\hline 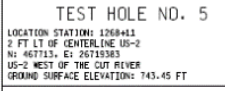 & 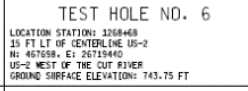 & 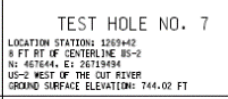 & 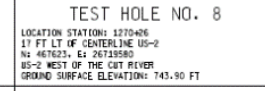 & 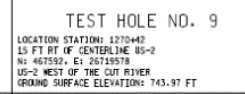 & \\
\hline 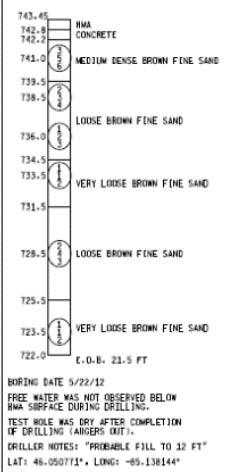 & 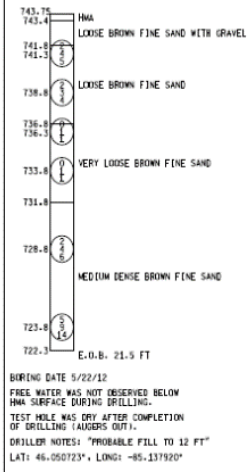 & 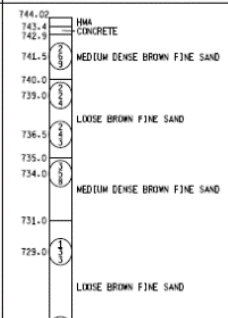 & 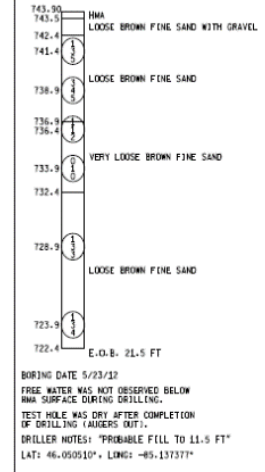 & 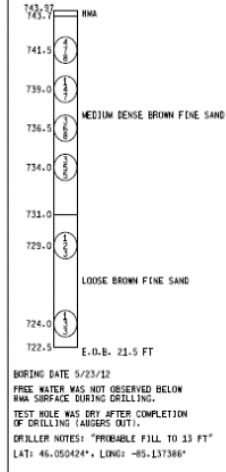 & \\
\hline & & & & \multicolumn{2}{|c|}{ 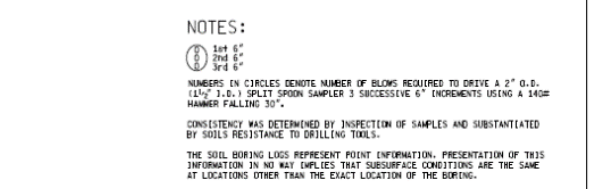 } \\
\hline 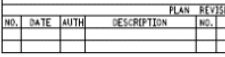 & 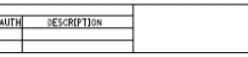 & TMDOT & 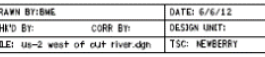 & CS: 49023 & 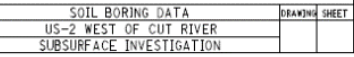 \\
\hline
\end{tabular}


FILE 300

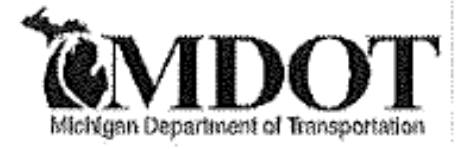

1845
REPORT OF TEST

SOIL ANALYSIS

\begin{tabular}{|l|}
\hline $\begin{array}{l}\text { Control Section } \\
\text { Identification }\end{array}$ \\
\hline Job No. \\
\hline Laboratory No, \\
\hline Date \\
\hline
\end{tabular}

\begin{tabular}{|c|c|}
\hline Report of Sample of & Soil \\
\hline Date Sampled & Date Received \\
\hline Source of Material & US-2, West of the Cut River \\
\hline Sampled From & TH\#2, Sample 2, Sta $1267+17,18^{\prime}$ Left of Centerline, Depth: $15^{\prime}$ to $16.5^{\prime}$ \\
\hline Submitted By & S. Green, State Wide Soil Boring Crew Chief \\
\hline Intended Use & Ground Elevation \\
\hline
\end{tabular}

\section{TEST RESULTS}

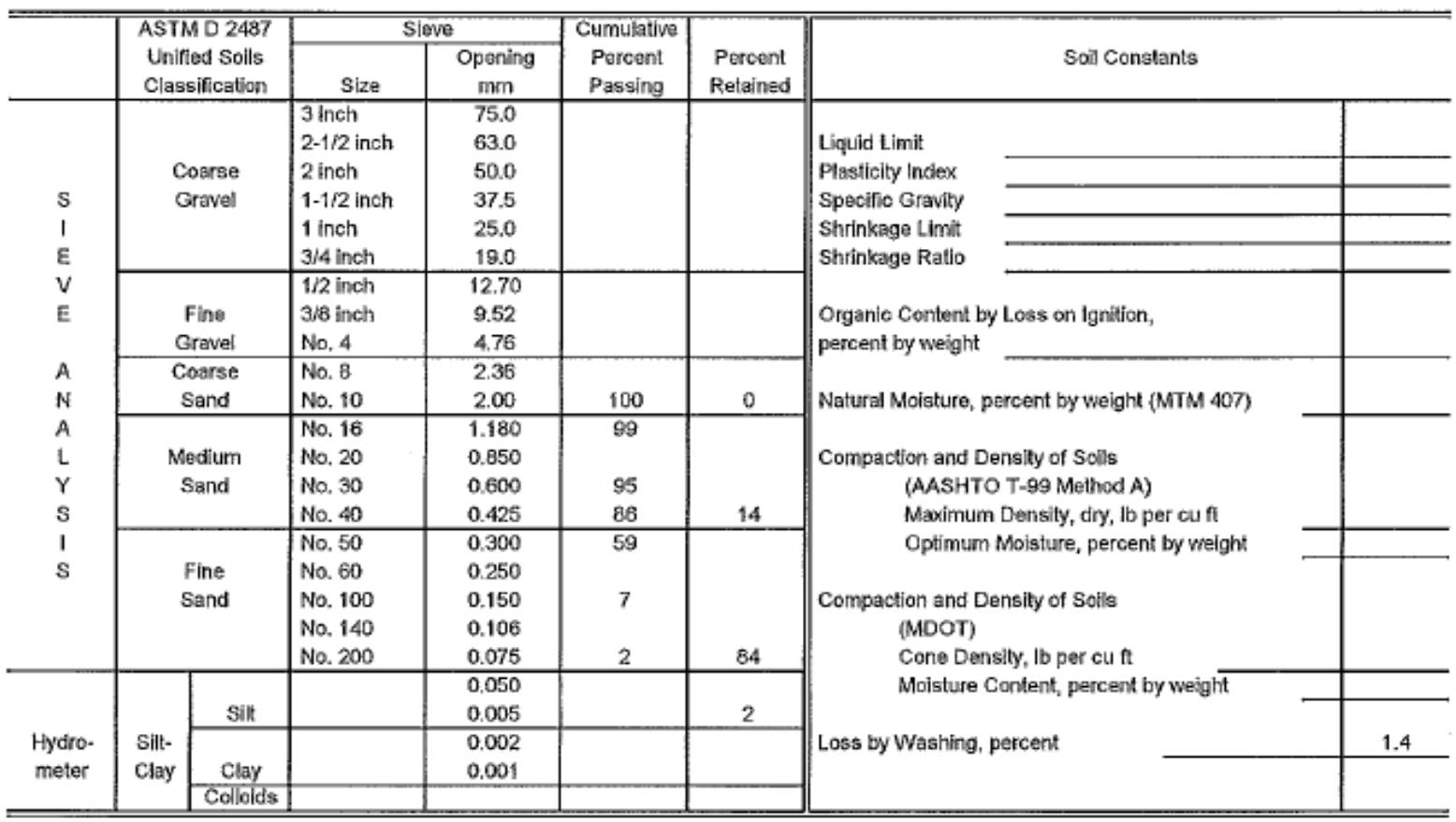

REMARKS: Except where noted, laboratory testing is performed in accordance with current AASHTO procedures. Sample was tested for information.

SP - Poorly Graded Sand

cc: File

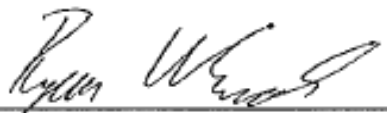

Foundation Analysis Engineer

Soll Testing

D. Endres 


\section{Appendix C: DEQ Well Water Levels and Bedrock Depths}

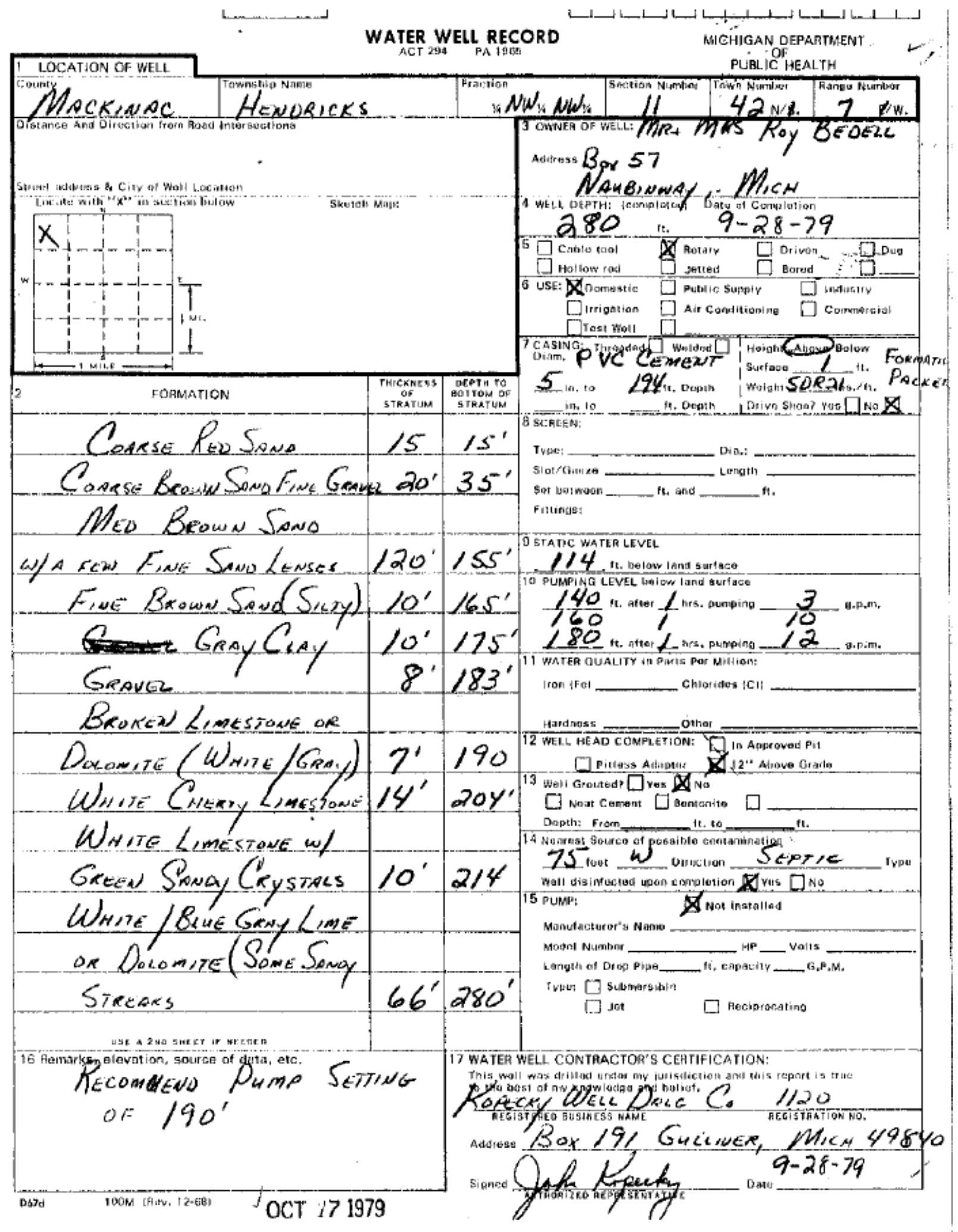

GEOLOGICAL SURVEY COPY 


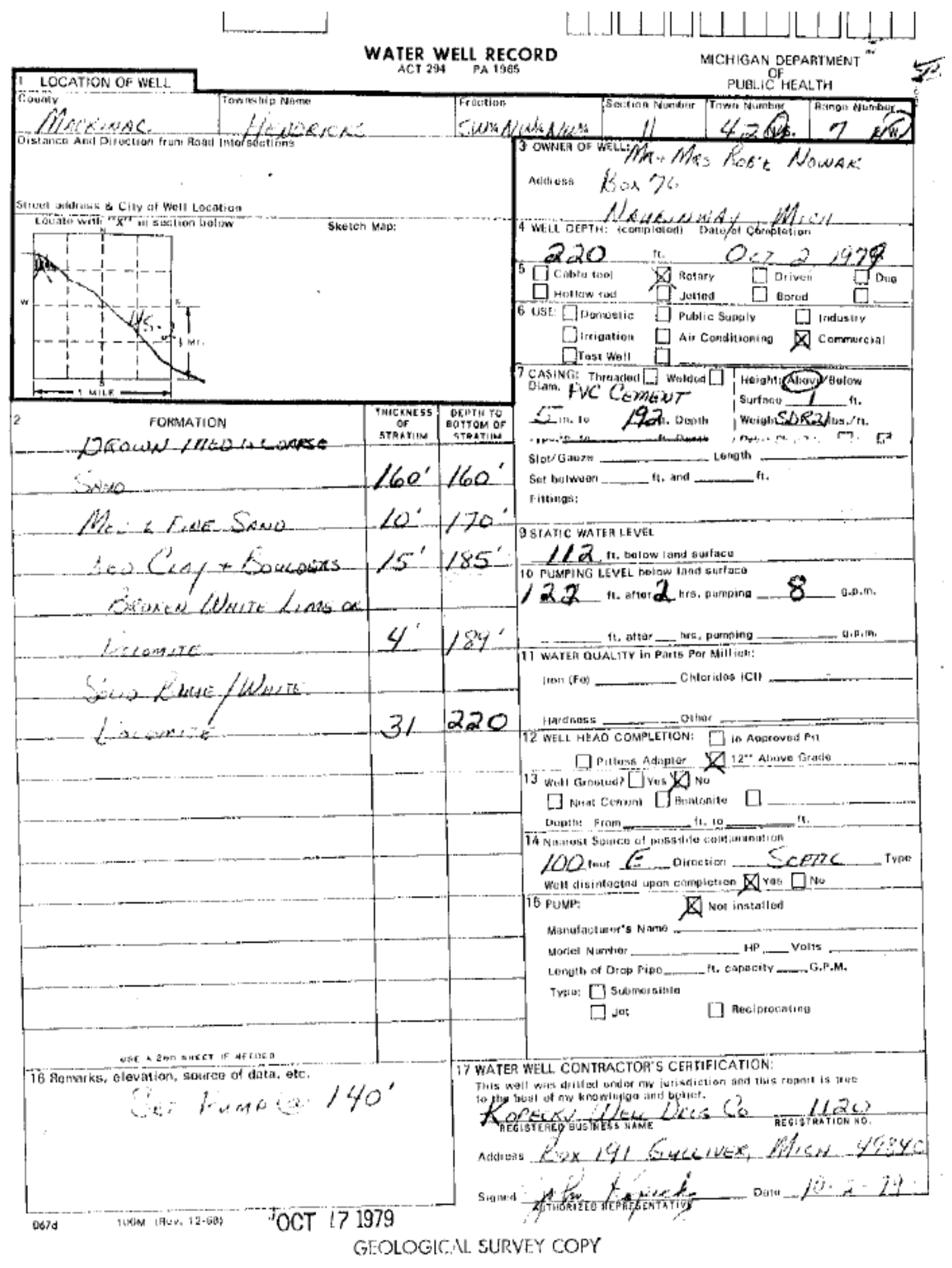




\section{Water Well And Pump Record}

Completion is required under authority of Part 127 Act 368 PA 1978.

Wellogic

Import ID: 49420711001

Failure to comply is a misdemeanor.

Tax N0: 4900501100610

Permit No:

\begin{tabular}{|c|c|c|c|c|}
\hline \multicolumn{2}{|c|}{ County: Mackinac } & \multicolumn{3}{|c|}{ Township: Hendricks } \\
\hline $\begin{array}{c}\text { Town/Range: } \\
\text { 42N 07W }\end{array}$ & $\begin{array}{c}\text { Section: } \\
11\end{array}$ & Well Status: & WSSN: & Source ID/Well No: \\
\hline \multicolumn{5}{|c|}{ Distance and Direction from Road Intersection: } \\
\hline \multicolumn{5}{|c|}{\begin{tabular}{|l} 
Well Owner: BEDELL, ROY \\
\end{tabular}} \\
\hline \multicolumn{3}{|c|}{$\begin{array}{l}\text { Well Address: } \\
\text { BOX } 57\end{array}$} & \multicolumn{2}{|c|}{$\begin{array}{l}\text { BOX } 57 \\
\text { NAUBINWAY, MI } 49762\end{array}$} \\
\hline
\end{tabular}

\section{Drilling Method: Rotary}

Well Depth: $280.00 \mathrm{ft}$.

Well Type: Replacement

Casing Type: PVC plastic

Date Completed: 9/28/1979

Casing Joint: Welded

Casing Fitting: None

Diameter: 5.00 in. to $194.00 \mathrm{ft}$. depth

Height:

Pump Installed: №

Pressure Tank Installed: №

Pressure Relief Valve Installed: $\quad$ No

Borehole:

\begin{tabular}{l}
\hline Static Water Level: $114.00 \mathrm{ft}$. Below Grade \\
Well Yield Test: $\quad$ Yield Test Method: Unknown \\
Pumping level $140.00 \mathrm{ft}$. after $1.00 \mathrm{hrs}$. at $3 \mathrm{GPM}$ \\
Pumping level $160.00 \mathrm{ft}$. after $1.00 \mathrm{hrs}$. at $10 \mathrm{GPM}$
\end{tabular}

Screen Installed: No Intake: Bedrock Well

Well Grouted: №

\begin{tabular}{|c|c|c|}
\hline Formation Description & Thickness & $\begin{array}{l}\text { Depth to } \\
\text { Bottom }\end{array}$ \\
\hline Red Sand Coarse & 15.00 & 15.00 \\
\hline Brown Sand \& Gravel Coarse & 20.00 & 35.00 \\
\hline Brown Sand Medium & 120.00 & 155.00 \\
\hline Brown Sand Fine Silty & 10.00 & 165.00 \\
\hline Gray Clay & 10.00 & 175.00 \\
\hline Gravel & 8.00 & 183.00 \\
\hline Limestone Broken & 7.00 & 190.00 \\
\hline White Limestone & 14.00 & 204.00 \\
\hline White Limestone WISand & 10.00 & 214.00 \\
\hline White Limestone Sandy & 66.00 & 280.00 \\
\hline & & \\
\hline & & \\
\hline & & \\
\hline & & \\
\hline \multicolumn{3}{|l|}{ Geology Remarks: } \\
\hline & & \\
\hline & & \\
\hline $\begin{array}{l}\text { Drilling Machine Operator Name: } \\
\text { Employment: Unknown }\end{array}$ & & \\
\hline
\end{tabular}




\section{Appendix D: Visual Walkthrough}

Dip on Roadway (color represents specified zoom)
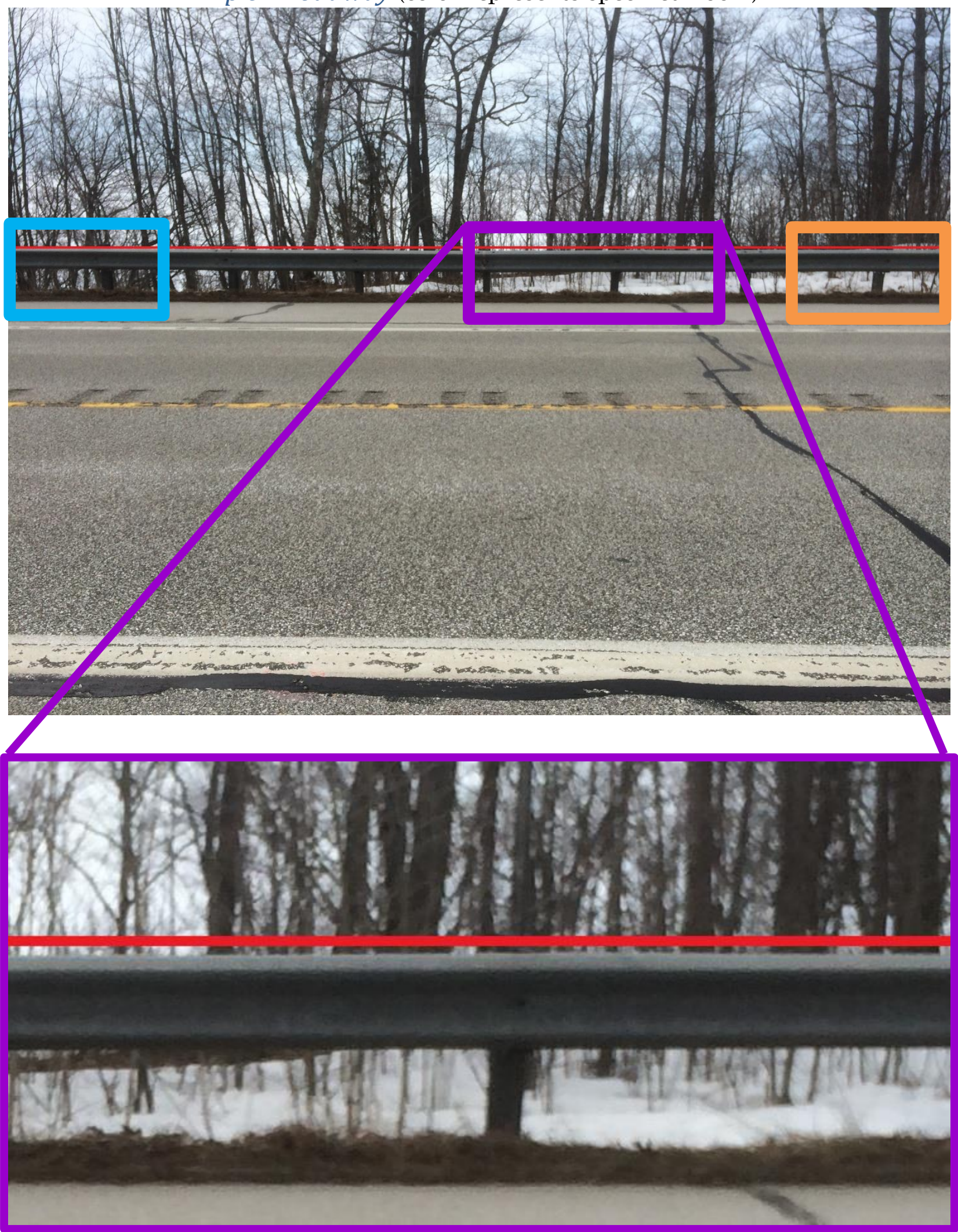

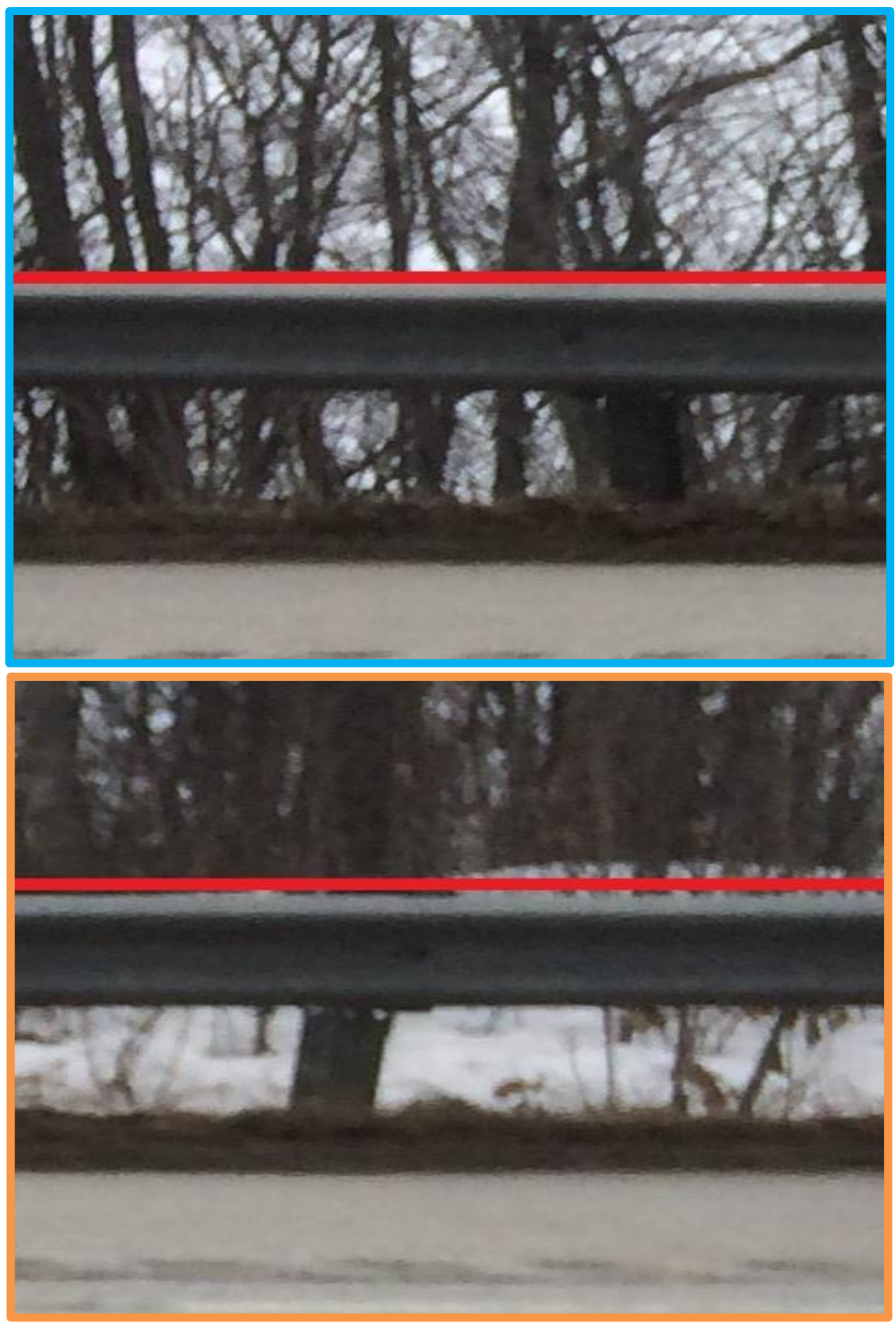


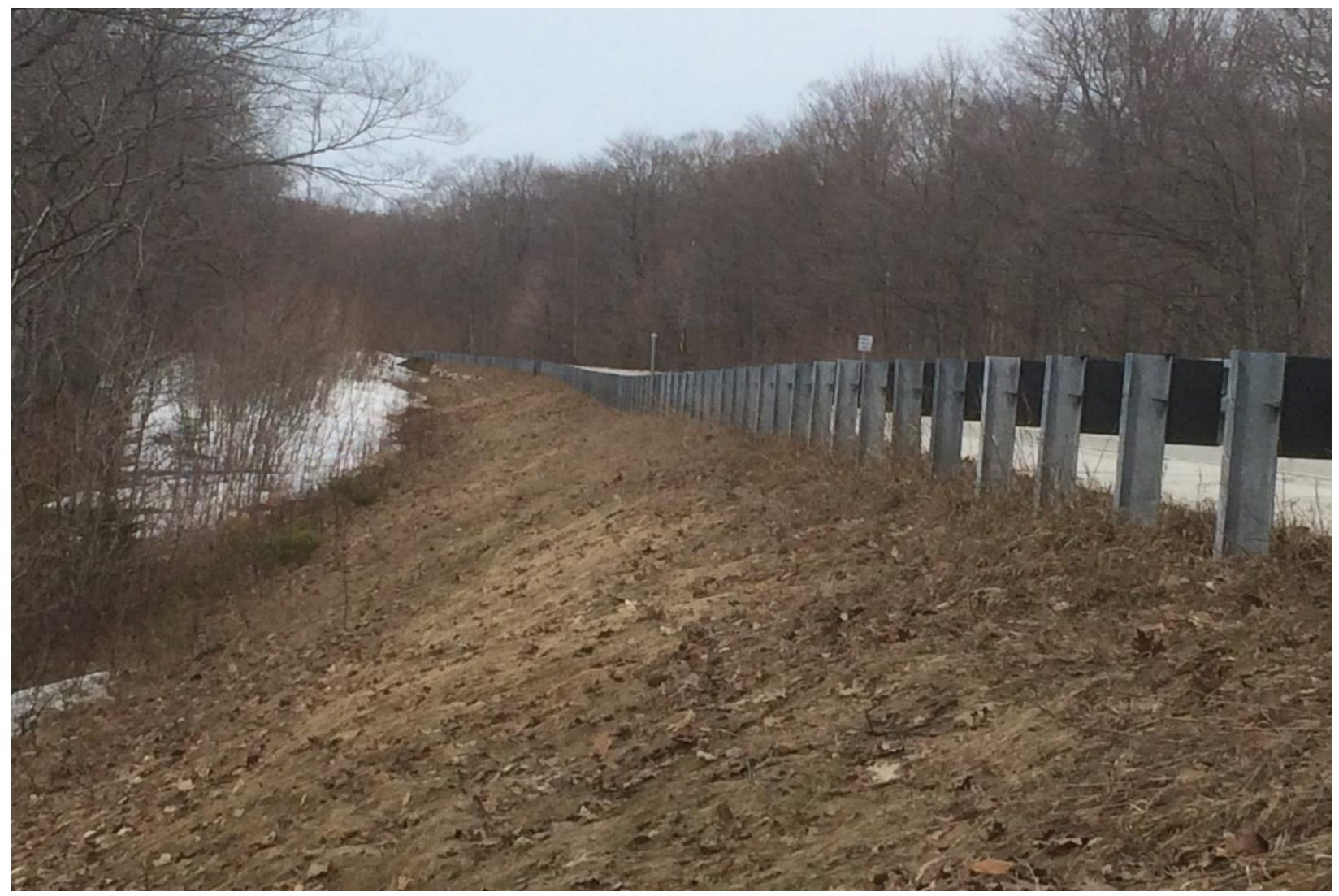

Sinkhole

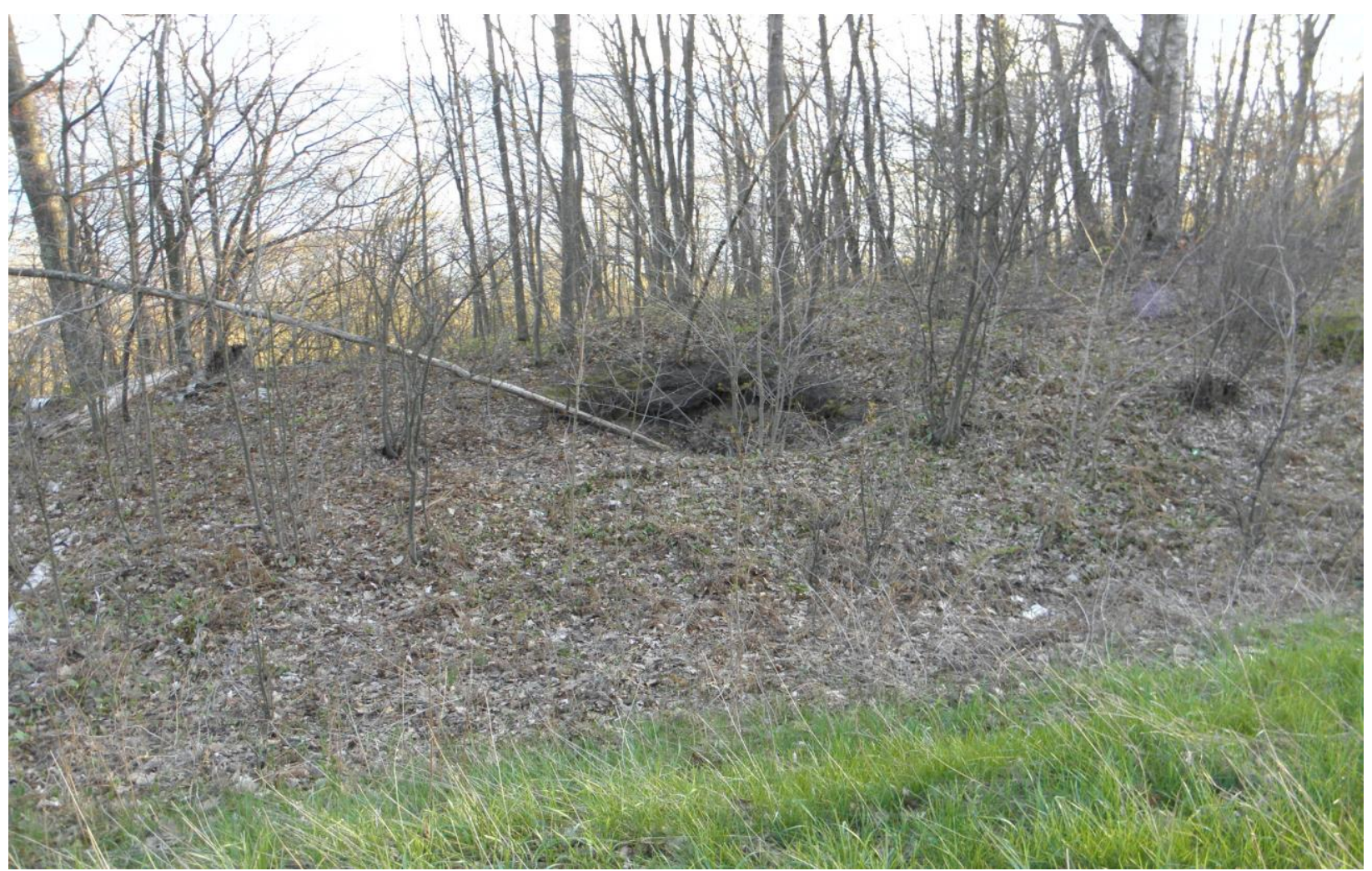



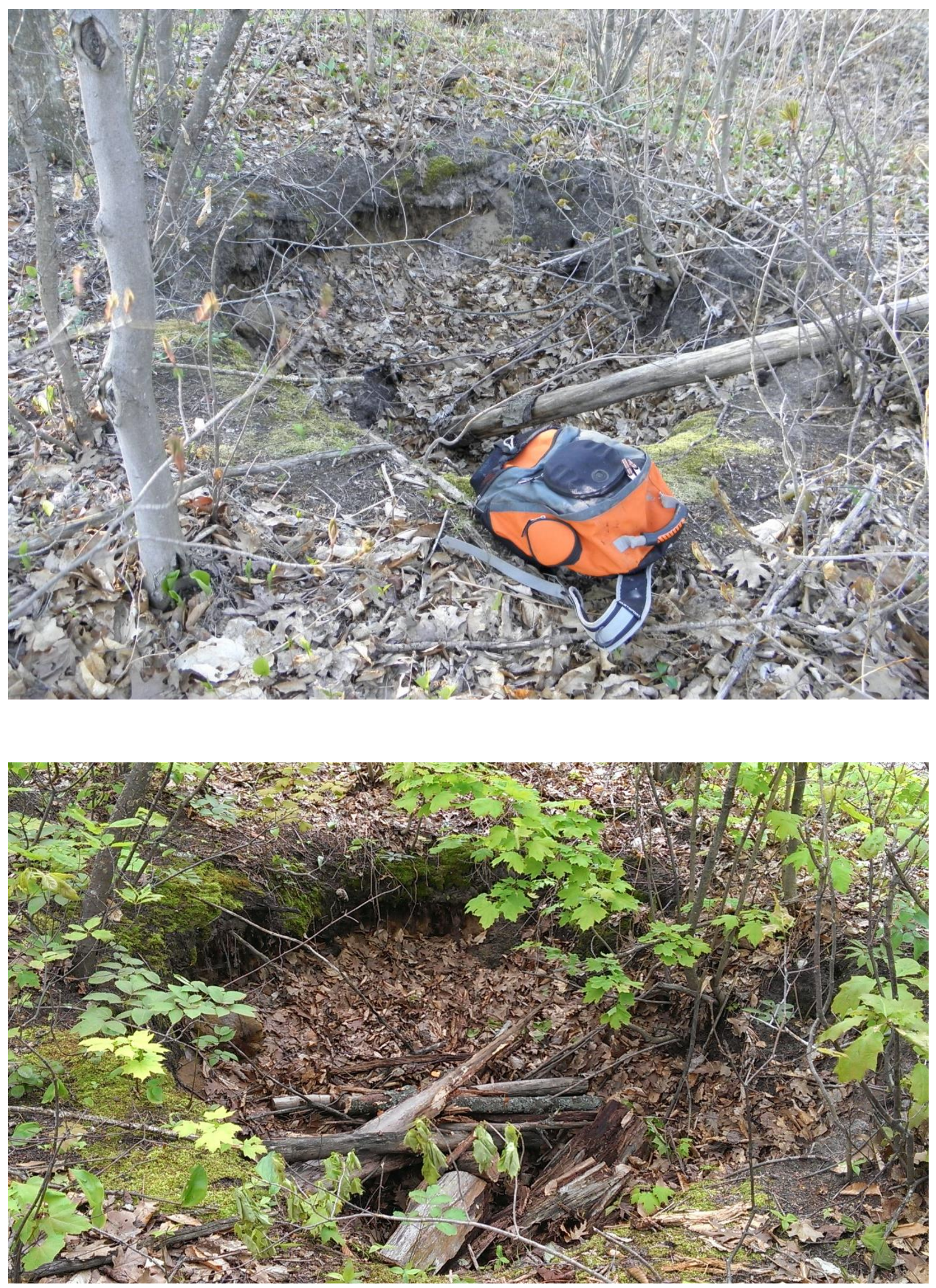
Slough May 2012
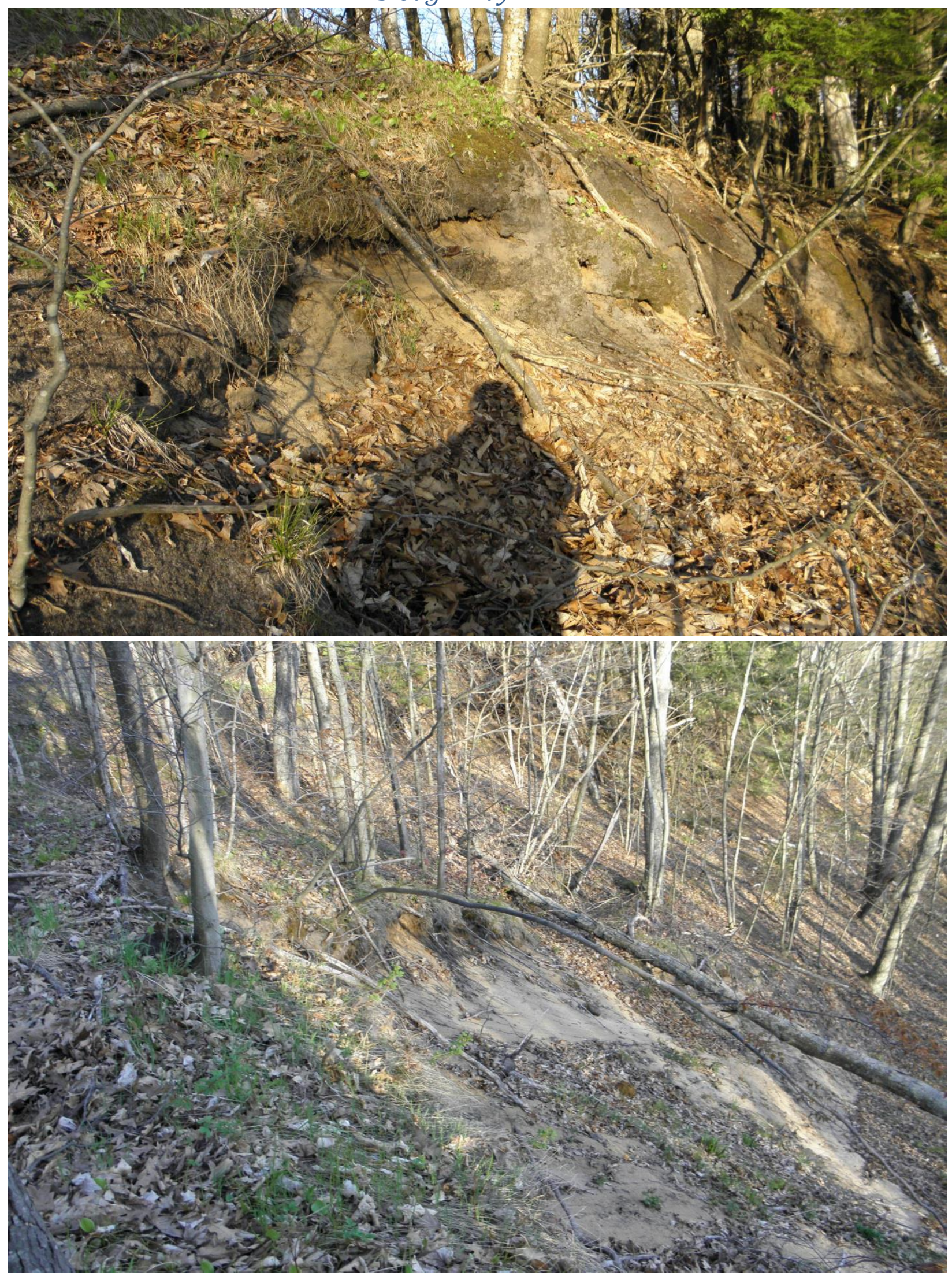
Water Flow 2012 (Looking North)

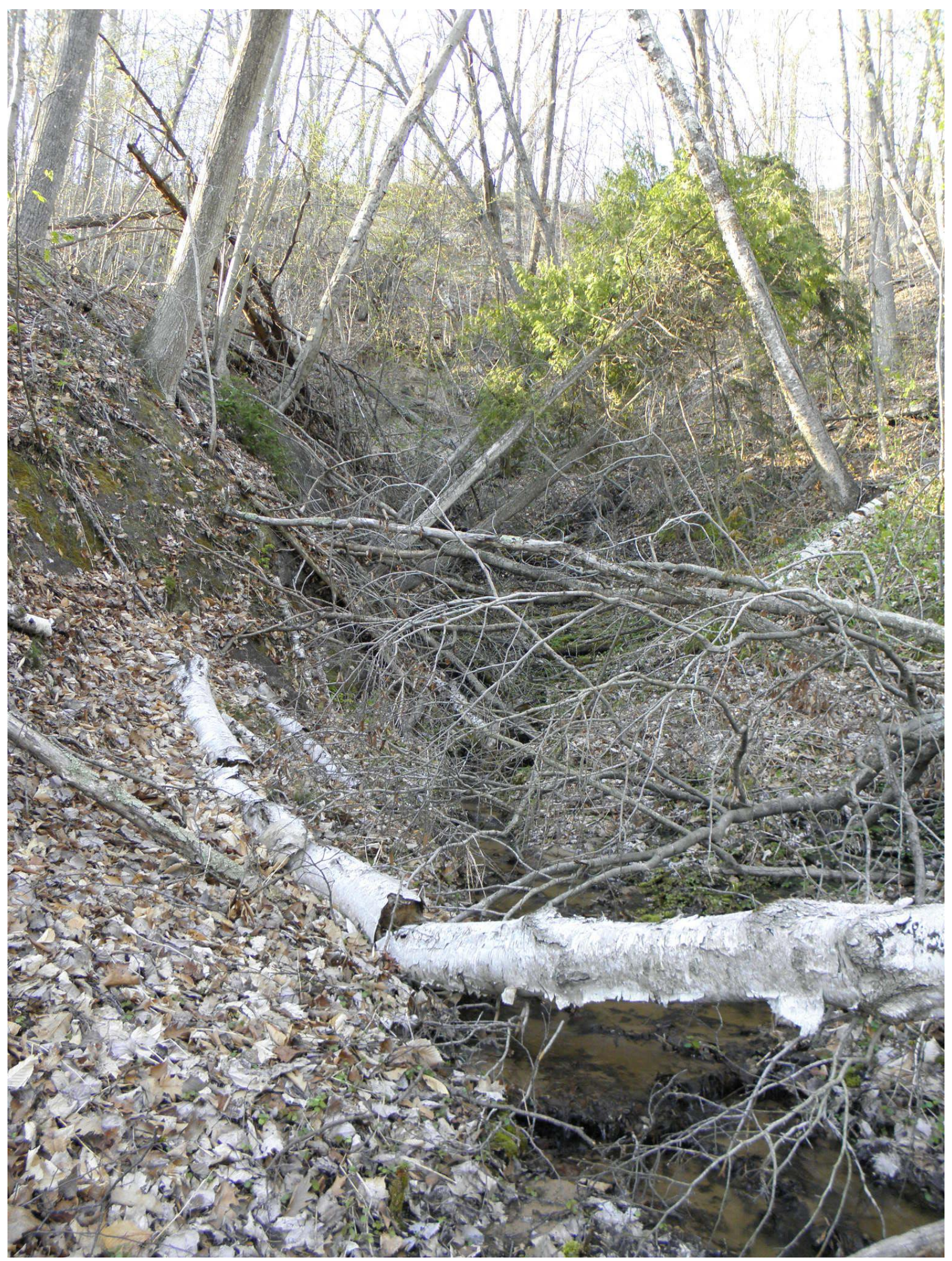


Small Stream 2012, 2013 respectively (Looking South)
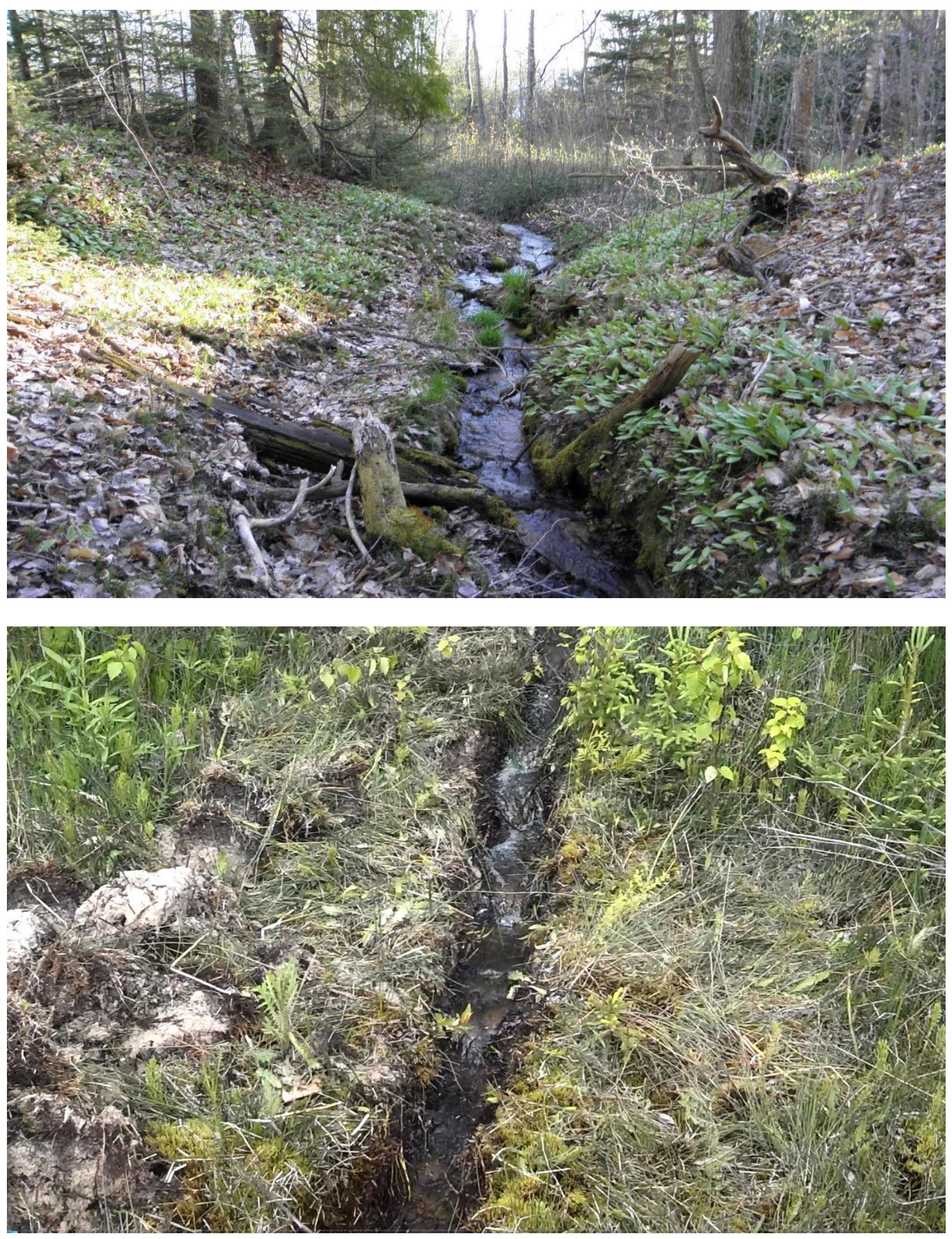
Slough June 2013
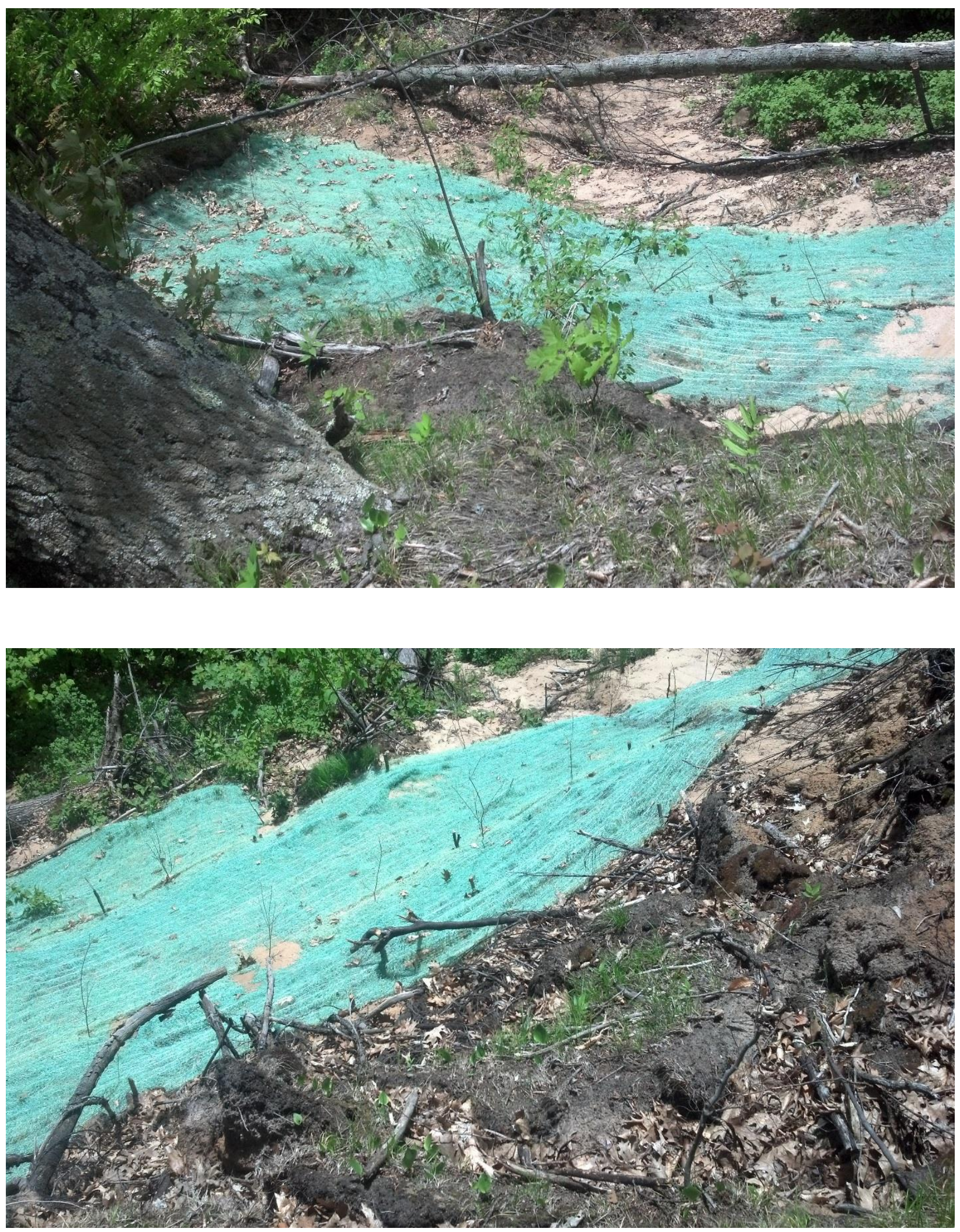

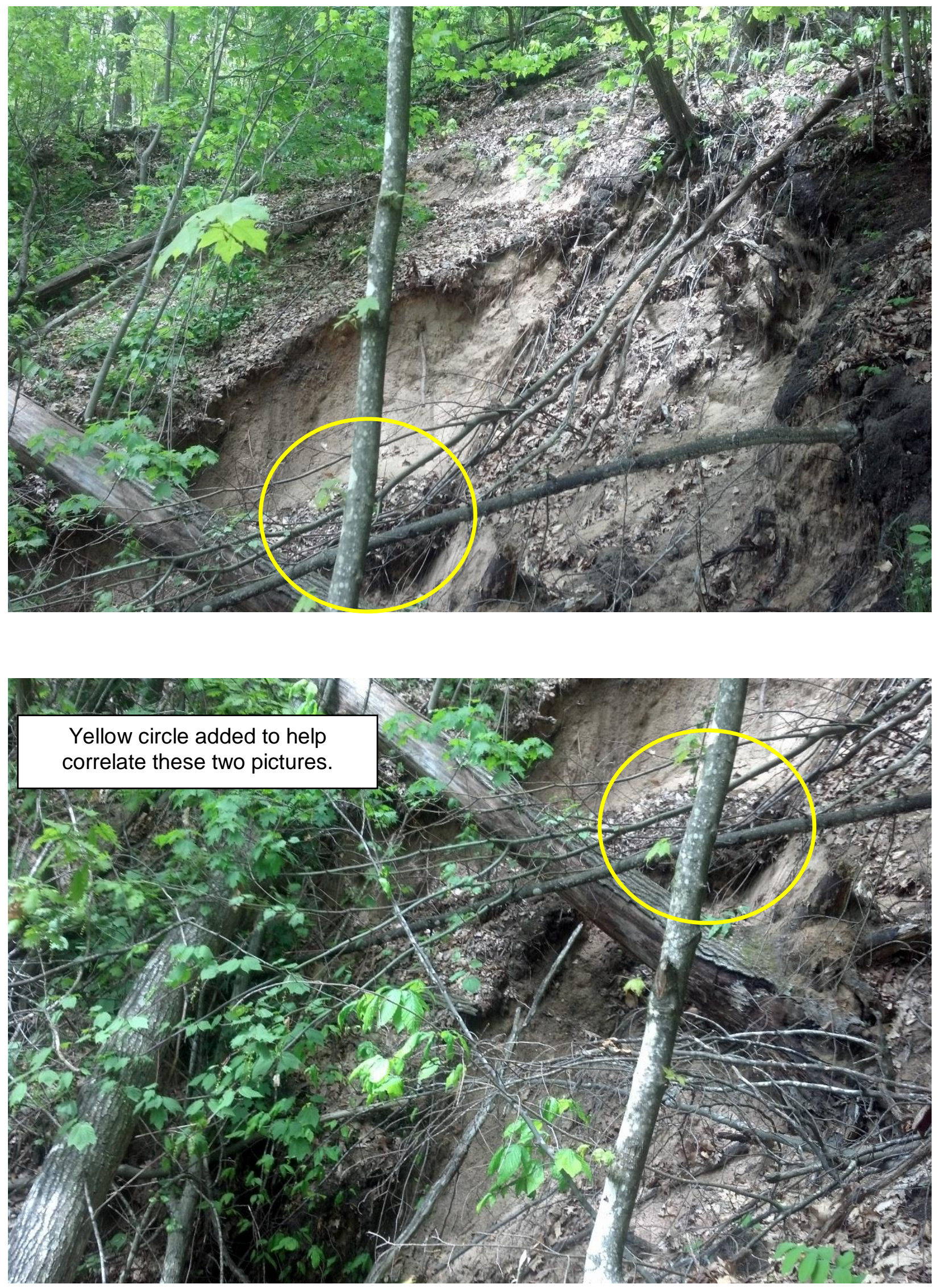
Slough April 2014
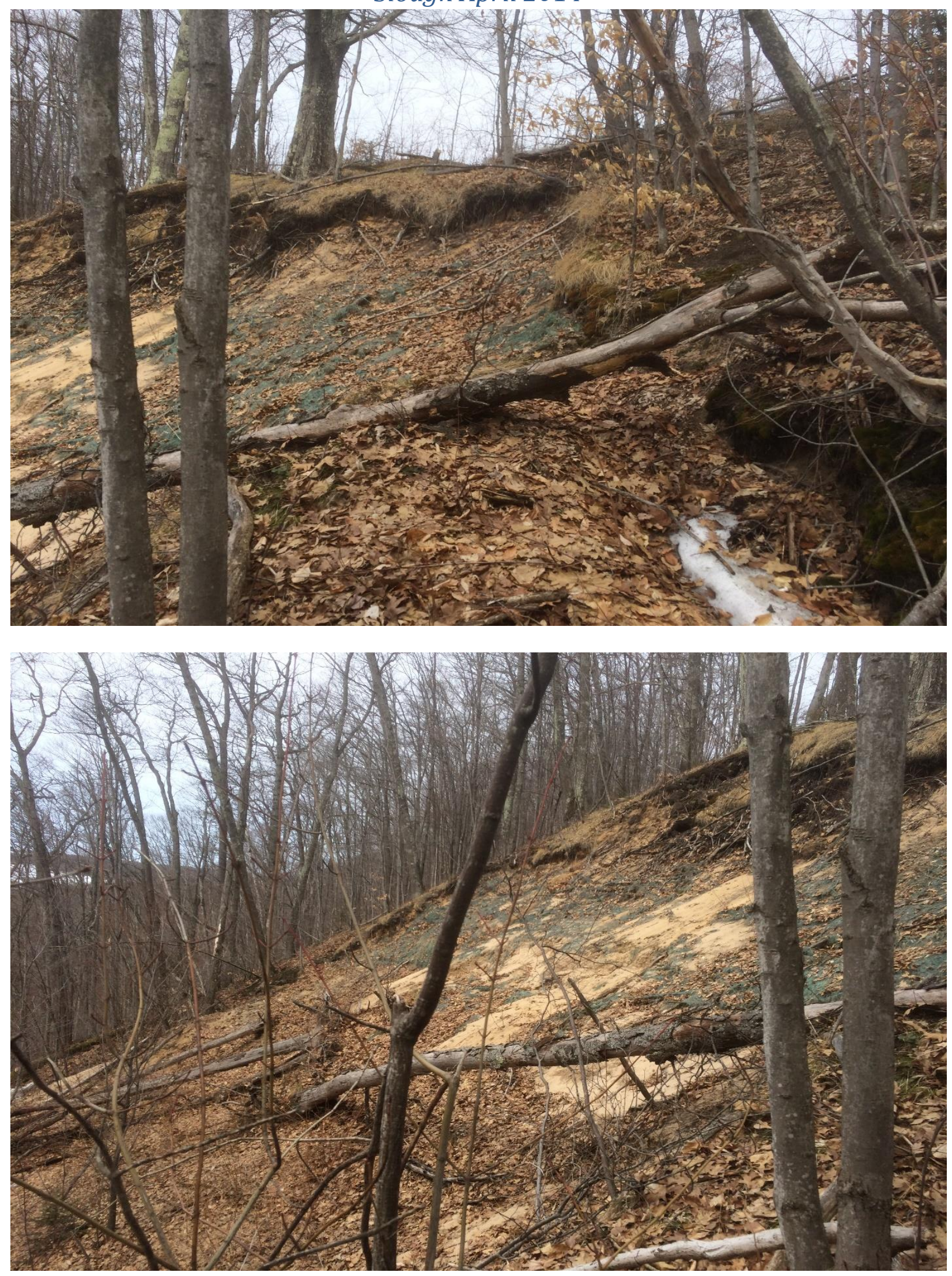
Water Flow April 2014 (Looking North)

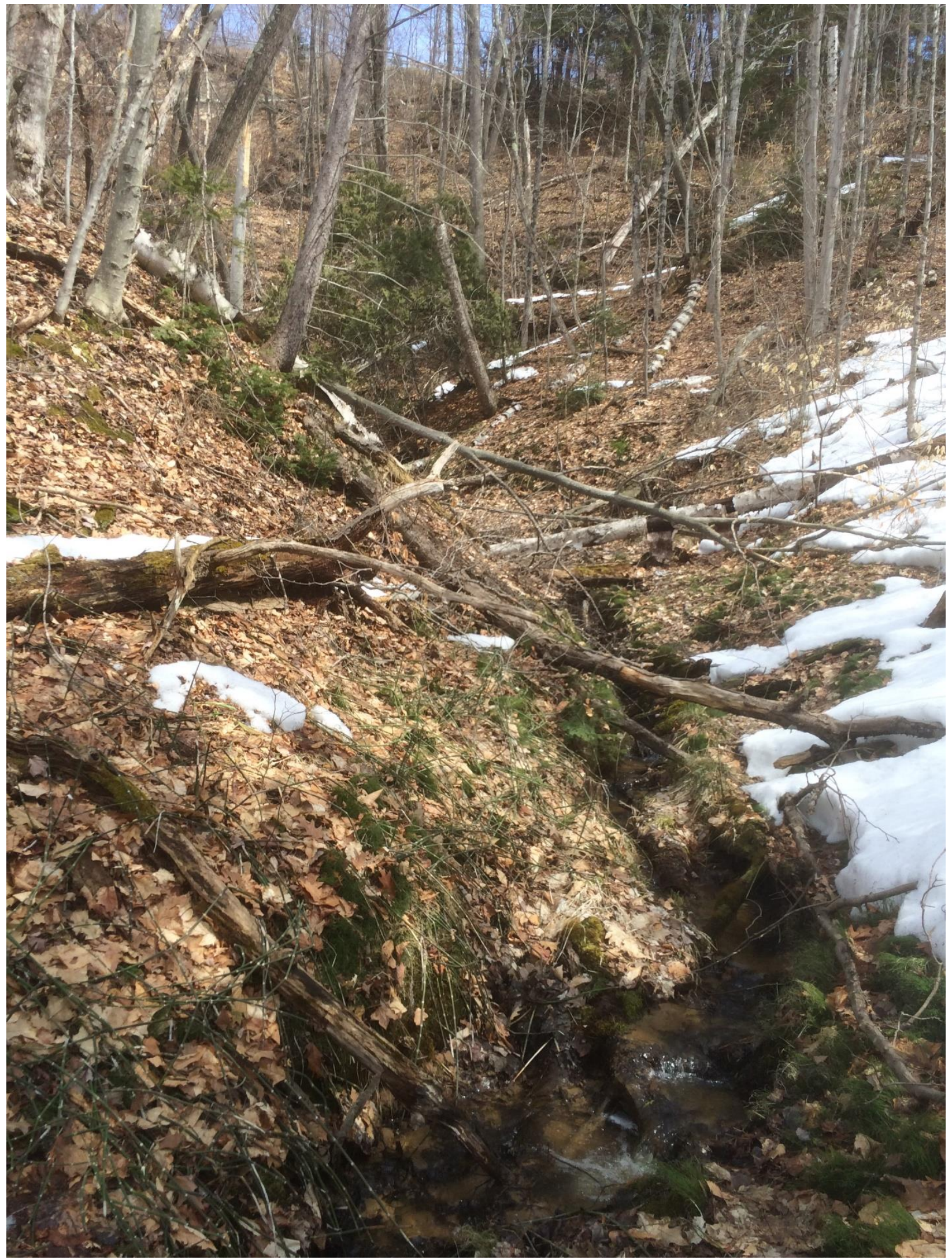


Stream April 2014

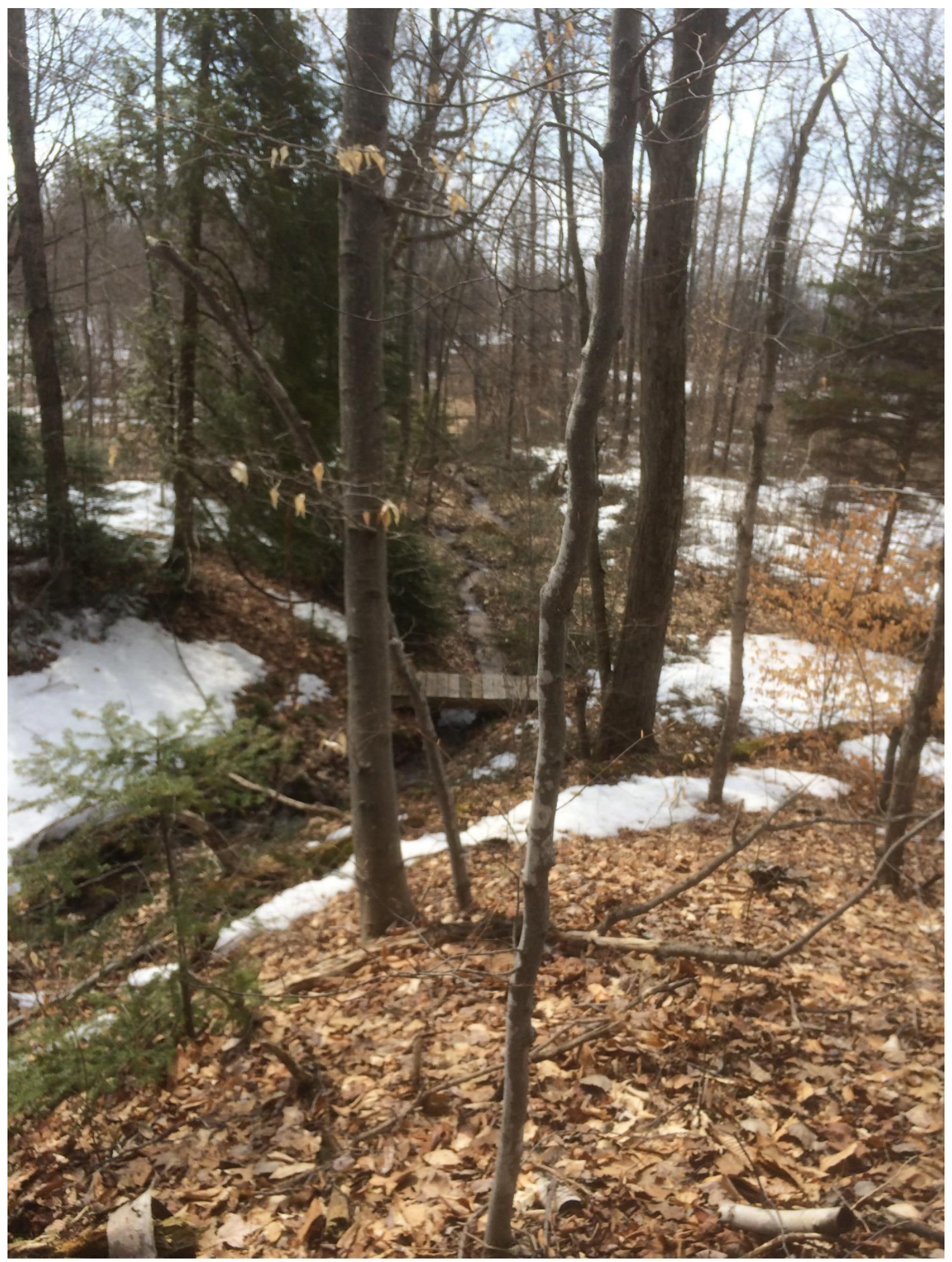




\section{Artesian Conditions}
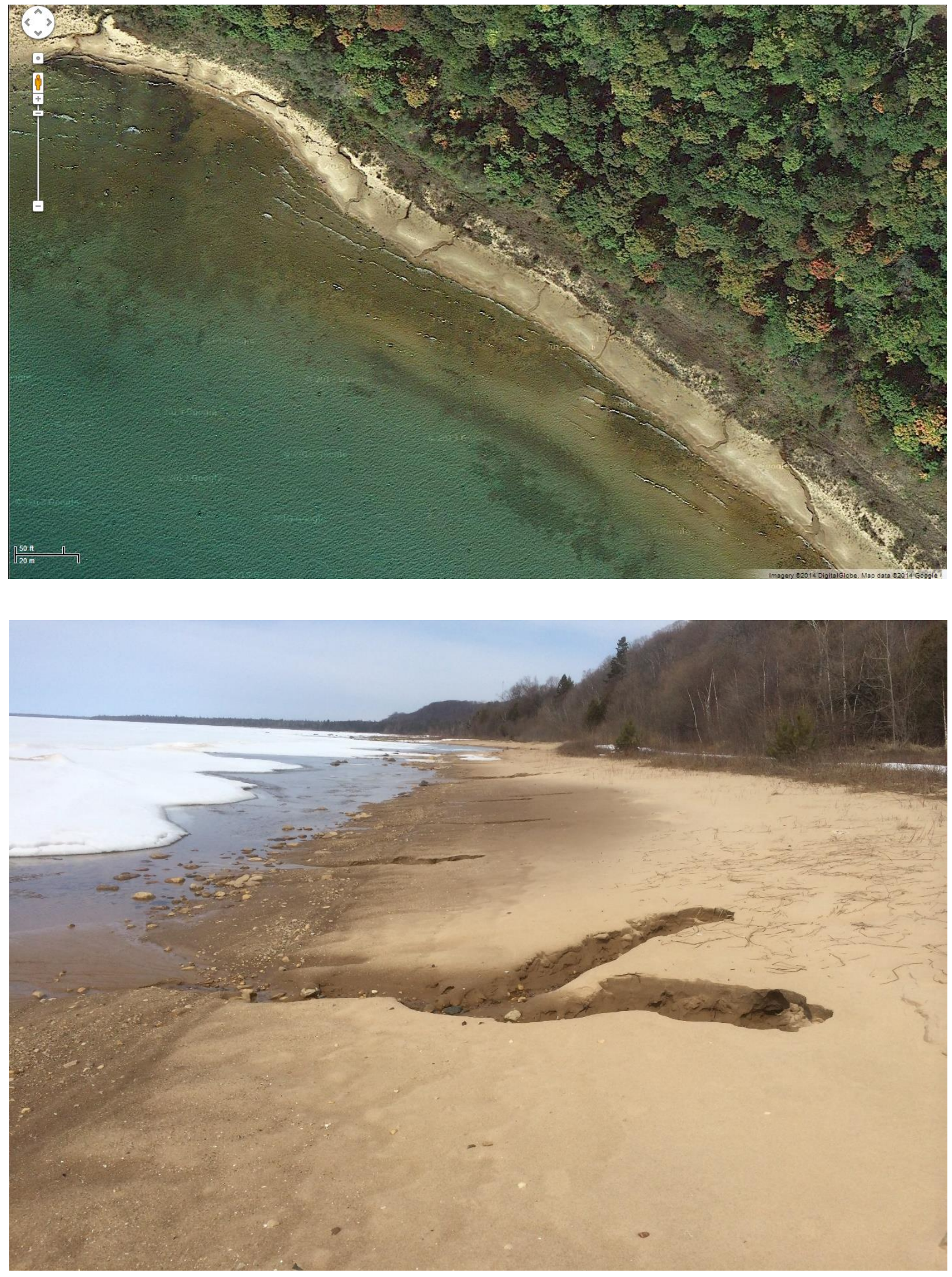


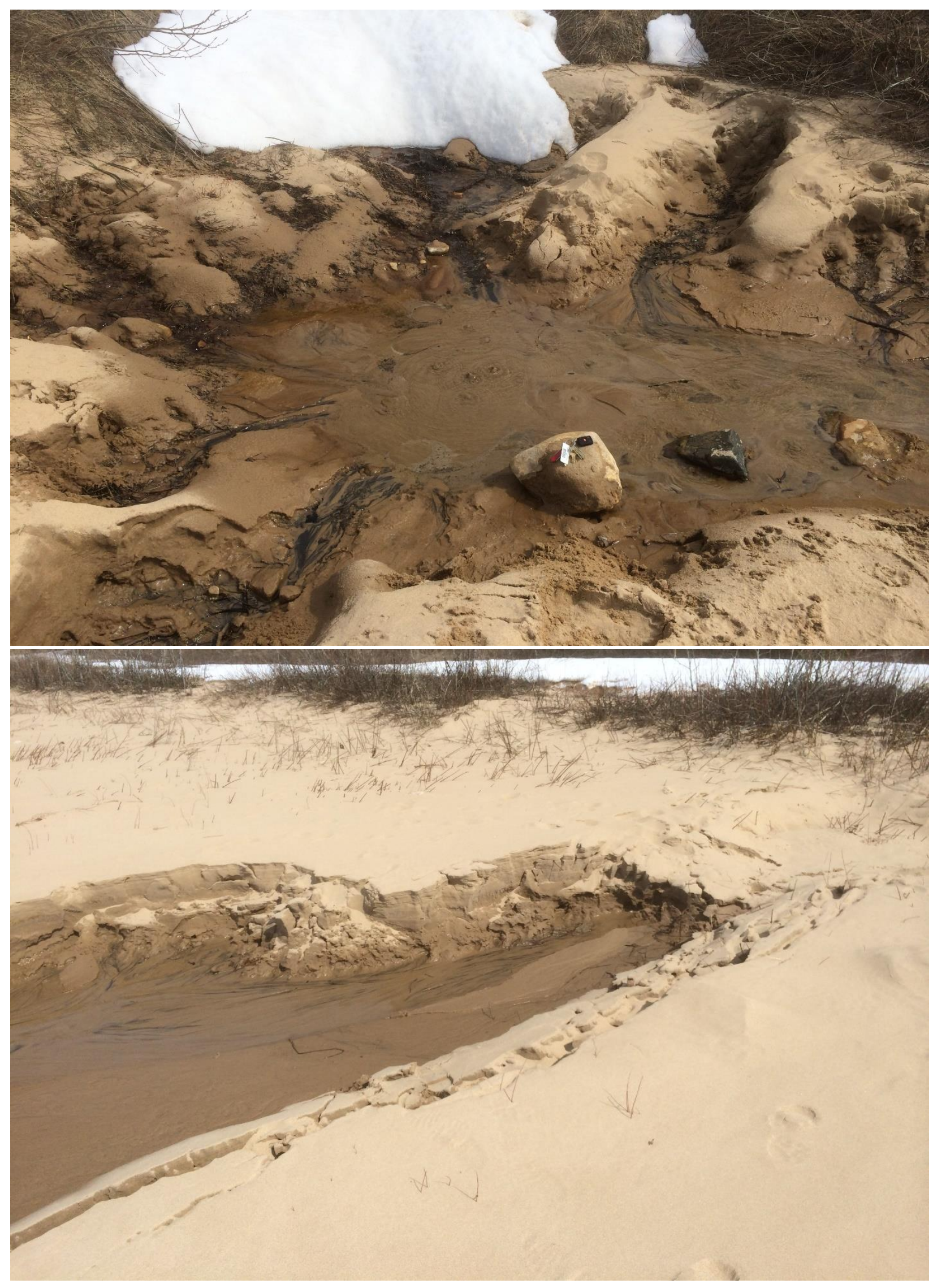




\section{Appendix E: Material Properties}

\section{Original LEM Model Hydraulic Properties}

\begin{tabular}{|c|c|c|c|c|c|c|c|}
\hline Material Name & Color & Model & $K S(f t / s)$ & $\mathrm{K} 2 / \mathrm{K} 1$ & $\begin{array}{c}\text { K1 } \\
\text { Angle } \\
\text { (deg) } \\
\end{array}$ & $\begin{array}{c}\text { WC } \\
(\mathrm{ft} 3 / \mathrm{ft} 3)\end{array}$ & Soil Type \\
\hline Med, Fine Sand w/ Gravel & & Simple & 0.0009 & 1 & 0 & 0.4 & Sand \\
\hline Med, Fine Dark Brown Sand & & Simple & $6.6 e-006$ & 1 & 0 & 0.4 & Sand \\
\hline Med, Fine \& Med Sand & & Simple & $3 e-006$ & 1 & 0 & 0.4 & Sand \\
\hline Very Loose Fine Sand & & Simple & 0.00066 & 1 & 0 & 0.4 & Sand \\
\hline Very Loose Dark Fine Sand w/ Topsoil & & Simple & 0.00066 & 1 & 0 & 0.4 & Sand \\
\hline Loose Fine Sand & & Simple & $6.6 e-005$ & 1 & 0 & 0.4 & Sand \\
\hline Loose Fine Sand w/ Gravel & & Simple & 0.00066 & 1 & 0 & 0.4 & Sand \\
\hline Concrete & & Simple & $3.28 \mathrm{e}-010$ & 1 & 0 & 0.4 & General \\
\hline $\mathrm{HMA}$ & & Simple & $3.28 \mathrm{e}-010$ & 1 & 0 & 0.4 & General \\
\hline Dense, Fine Sand & & Simple & $6.6 e-007$ & 1 & 0 & 0.4 & Sand \\
\hline Med, Fine Sand & & Simple & $6.6 e-006$ & 1 & 0 & 0.4 & Sand \\
\hline Limestone & & Simple & $3.28 \mathrm{e}-009$ & 1 & 0 & 0.4 & General \\
\hline Dolostone & 巴里 & Simple & $3.28 e-012$ & 1 & 0 & 0.4 & General \\
\hline Shale & & Simple & $3.28 e-013$ & 1 & 0 & 0.4 & General \\
\hline Sandstone & & Simple & $3.28 \mathrm{e}-009$ & 1 & 0 & 0.4 & General \\
\hline Clay & & Simple & $3 e-010$ & 1 & 0 & 0.4 & Clay \\
\hline
\end{tabular}

\section{DEQ LEM Model Hydraulic Properties}

\begin{tabular}{|c|c|c|c|c|c|c|c|}
\hline Material Name & Color & Model & KS (ft/s) & K2/K1 & $\begin{array}{c}\text { K1 Angle } \\
\text { (deg) }\end{array}$ & $\begin{array}{c}\text { WC } \\
\text { (ft3/ft3) }\end{array}$ & Soil Type \\
\hline $\begin{array}{c}\text { Red Sand Coarse } \\
\text { Brown Sand \& Gravel } \\
\text { Coarse }\end{array}$ & $\square$ & Simple & $3 e-008$ & 1 & 0 & 0.4 & Sand \\
\hline $\begin{array}{c}\text { Brown Sand Medium } \\
\text { Brown Sand Fine Silty }\end{array}$ & $\square$ & Simple & $1.8 \mathrm{e}-008$ & 1 & 0 & 0.4 & Sand \\
\hline Gray Clay & $\square$ & Simple & $3 e-010$ & 1 & 0 & 0.4 & Clay \\
\hline Gravel & $\square$ & Simple & 0.06 & 1 & 0 & 0.4 & General \\
\hline Limestone Broken & $\square$ & Simple & 0.003 & 1 & 0 & 0.4 & General \\
\hline White Limestone & $\square$ & Simple & $3 e-013$ & 1 & 0 & 0.4 & General \\
\hline White Limestone W/Sand & $\square$ & Simple & $3 e-010$ & 1 & 0 & 0.4 & General \\
\hline White Limestone Sandy & $\square$ & Simple & $3 e-009$ & 1 & 0 & 0.4 & General \\
\hline
\end{tabular}


Original LEM Model Material Properties

\begin{tabular}{|c|c|c|c|c|c|c|c|c|c|c|c|c|c|c|}
\hline Material Name & Color & $\begin{array}{l}\text { Unit Weight } \\
\text { (lbs/ft3) }\end{array}$ & Strength Type & $\begin{array}{c}\text { Cohesion } \\
\text { (psf) }\end{array}$ & $\begin{array}{l}\text { Phi } \\
\text { (deg) }\end{array}$ & UCS (psf) & $\mathrm{m}$ & 5 & a & Water Surface & Hu Type & Hu & $\begin{array}{l}\text { Phi b } \\
\text { (deg) }\end{array}$ & $\begin{array}{c}\text { Air Entry } \\
\text { (psf) }\end{array}$ \\
\hline Med, Fine Sand w/Gravel & - & 112 & Mohr-Coulomb & 0.02 & 36 & & & & & Water Surface & Custom & 1 & 0 & 0 \\
\hline Med, Fine Dark Brown Sand & & 107 & Mohr-Coulomb & 0.02 & 34 & & & & & Water Surface & Custom & 1 & 0 & 0 \\
\hline Med, Fine \& Med Sand & & 97 & Mohr-Coulomb & 0.02 & 35 & & & & & Water Surface & Custom & 1 & 0 & 0 \\
\hline Very Loose Fine Sand & & 85 & Mohr-Coulomb & 0.02 & 27 & & & & & Water Surface & Custom & 1 & 0 & 0 \\
\hline Very Loose Dark Fine Sand w/ Topsoil & & 82 & Mohr-Coulomb & 0.02 & 26 & & & & & Water Surface & Custom & 1 & 0 & 0 \\
\hline Loose Fine Sand & & 90 & Mohr-Coulomb & 0.02 & 29 & & & & & Water Surface & Custom & 1 & 0 & 0 \\
\hline Loose Fine Sand w/Gravel & & 95 & Mohr-Coulomb & 0.02 & 30 & & & & & Water Surface & Custom & 1 & 0 & 0 \\
\hline Concrete & & 150 & Generalised Hoek-Brown & & & 626600 & 3.52122 & 0.00386592 & 0.505734 & Water Surface & Custom & 1 & 0 & 0 \\
\hline HMA & & 145 & Generalised Hoek-Brown & & & 600000 & 3.52122 & 0.00386592 & 0.505734 & Water Surface & Custom & 1 & 0 & 0 \\
\hline Dense, Fine Sand & & 110 & Mohr-Coulomb & 0.02 & 37 & & & & & Water Surface & Custom & 1 & 0 & 0 \\
\hline Med, Fine Sand & & 105 & Mohr-Coulomb & 0.02 & 35 & & & & & Water Surface & Custom & 1 & 0 & 0 \\
\hline Limestone & & 153 & Generalised Hoek-Brown & & & $1.5 e+006$ & 1.67677 & 0.00386592 & 0.505734 & Water Surface & Custom & 1 & 0 & 0 \\
\hline Dolostone & 曲 & 175 & Generalised Hoek-Brown & & & $3.5 e+006$ & 1.5091 & 0.00386592 & 0.505734 & Water Surface & Custom & 1 & 0 & 0 \\
\hline Shale & $\nabla$ & 172 & Generalised Hoek-Brown & & & 700000 & 1.00606 & 0.00386592 & 0.505734 & Water Surface & Custom & 1 & 0 & 0 \\
\hline Sandstone & Ш & 137 & Generalised Hoek-Brown & & & $1.5 e+006$ & 2.85051 & 0.00386592 & 0.505734 & Water Surface & Custom & 1 & 0 & 0 \\
\hline Clay & & 115 & Mohr-Coulomb & 312.5 & 0 & & & & & Water Surface & Custom & 1 & 0 & 0 \\
\hline
\end{tabular}


DEQ LEM Model Material Properties

\begin{tabular}{|c|c|c|c|c|c|c|c|c|c|c|c|c|c|}
\hline Material Name & Color & $\begin{array}{c}\text { Unit Weight } \\
\text { (lbs/tt3) }\end{array}$ & Strength Type & $\begin{array}{c}\text { Cohesion } \\
\text { (psf) }\end{array}$ & $\begin{array}{c}\text { Phi } \\
\text { (deg) }\end{array}$ & UCS (psf) & $\mathrm{m}$ & $\mathrm{s}$ & a & Water Surface & Hu Type & $\begin{array}{l}\text { Phib } \\
\text { (deg) }\end{array}$ & $\begin{array}{c}\text { Air Entry } \\
\text { (deg) }\end{array}$ \\
\hline Red Sand Coarse & $\square$ & 90 & Mohr-Coulomb & 0.02 & 36 & & & & & Water Surface & Constant & 0 & 0 \\
\hline $\begin{array}{c}\text { Brown Sand \& Gravel } \\
\text { Coarse }\end{array}$ & $\square$ & 103 & Mohr-Coulomb & 0.02 & 37 & & & & & Water Surface & Constant & 0 & 0 \\
\hline Brown Sand Medium & $\square$ & 75 & Mohr-Coulomb & 0.02 & 35 & & & & & Water Surface & Constant & 0 & 0 \\
\hline Brown Sand Fine Silty & $\square$ & 93.6 & Mohr-Coulomb & 459.5 & 32 & & & & & Water Surface & Constant & 0 & 0 \\
\hline Gray Clay & $\square$ & 109 & Mohr-Coulomb & 683 & 0 & & & & & Water Surface & Constant & 0 & 0 \\
\hline Gravel & $\square$ & 120 & Mohr-Coulomb & 0 & 40 & & & & & Water Surface & Constant & 0 & 0 \\
\hline Limestone Broken & t & 97 & Generalised Hoek-Brown & & & $1.5 e+006$ & 0.983084 & 0.00101905 & 0.51302 & Water Surface & Constant & 0 & 0 \\
\hline White Limestone & $\square$ & 163 & Generalised Hoek-Brown & & & 4e+006 & 4.95753 & 0.0319225 & 0.501463 & Water Surface & Constant & 0 & 0 \\
\hline White Limestone W/Sand & & 156 & Generalised Hoek-Brown & & & $3.5 e+006$ & 2.32112 & 0.00602938 & 0.504342 & Water Surface & Constant & 0 & 0 \\
\hline White Limestone Sandy & & 120 & Generalised Hoek-Brown & & & $3.25 \mathrm{e}+006$ & 1.01701 & 0,000815988 & 0.514908 & Water Surface & Constant & 0 & 0 \\
\hline
\end{tabular}


Original FEA Model Material Properties

\begin{tabular}{|c|c|c|c|c|c|c|c|c|c|c|c|c|c|c|c|c|c|c|c|c|c|c|c|c|c|}
\hline Material Hame & Color & $\begin{array}{c}\text { Inital Element } \\
\text { loading }\end{array}$ & \begin{tabular}{|} 
UnitWeight \\
(lbs/t+3)
\end{tabular} & $\begin{array}{l}\text { Elastic } \\
\text { Type }\end{array}$ & $\begin{array}{c}\text { Young's } \\
\text { Modulus (pst) }\end{array}$ & $\begin{array}{l}\text { Poisson's } \\
\text { Ratio }\end{array}$ & \begin{tabular}{|c|} 
Failure \\
Criterion
\end{tabular} & $\begin{array}{c}\text { Material } \\
\text { Type }\end{array}$ & $\begin{array}{c}\text { Tensile } \\
\text { Strength } \\
\text { (losft) }\end{array}$ & \begin{tabular}{|c|} 
\\
Tensile \\
Strength \\
(residual) \\
(psf) \\
\end{tabular} & $\begin{array}{l}\text { Dilation } \\
\text { Angse } \\
\text { ldeal }\end{array}$ & $\begin{array}{c}\text { Friction } \\
\text { Angle (peak) } \\
\text { (deg) }\end{array}$ & $\begin{array}{l}\text { Friction Angle } \\
\text { (residual)(deg) }\end{array}$ & $\begin{array}{l}\text { Cohesion } \\
\text { peak) (pss) }\end{array}$ & $\begin{array}{c}\text { Cohesion } \\
\text { |residual| } \\
\text { (pst) }\end{array}$ & $\begin{array}{c}\text { Intact } \\
\text { Compressive } \\
\text { Strength pst }\end{array}$ & $\begin{array}{c}\text { mb } \\
\text { (peak) }\end{array}$ & $\begin{array}{c}\text { mb } \\
\text { (reseidual| }\end{array}$ & s|peakl) & s|stridual| & alpeak & | alesidual) & Dilation & $\begin{array}{l}\text { Piezo } \\
\text { line }\end{array}$ & Hu \\
\hline Med, Fine Sand w/ Graval & $\square$ & $\begin{array}{l}\text { Field Stress and } \\
\text { Body Force }\end{array}$ & 112 & |sotropic & $1.2531 e^{+}+006$ & 0.3 & $\begin{array}{l}\text { Mohr } \\
\text { Coulomb }\end{array}$ & Plartic & 0.02 & 0 & 0 & 36 & 36 & 0.02 & 0.02 & & & & & & & & & None & 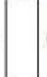 \\
\hline Med, Fine Dark Brown Sand & $\square$ & $\begin{array}{c}\text { Fiold Stress and } \\
\text { Body Force }\end{array}$ & 107 & Isotropic & $1.2531 \mathrm{e}+006$ & 0.3 & $\begin{array}{c}\text { Moht } \\
\text { Coulomb }\end{array}$ & Plastic & 0.02 & 0 & 0 & 34 & 34 & 0.02 & 0.02 & & & & & & & & & None & 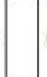 \\
\hline Med, Fine Q Med Sand & $\square$ & $\begin{array}{l}\text { Field Streess and } \\
\text { Body Force }\end{array}$ & 97 & |sotropic & $1.2531 e^{e} \cdot 006$ & 0.3 & $\begin{array}{l}\text { Mohr } \\
\text { Coulomb }\end{array}$ & Plastic & 0.02 & 0 & 0 & 35 & 35 & 0.02 & 0.02 & & & & & & & & & None & 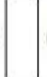 \\
\hline Very Loose Fine Sand & $\square$ & $\begin{array}{c}\text { Fieldo Stress and } \\
\text { Body force }\end{array}$ & 85 & |sotropic & 300000 & 0.25 & $\begin{array}{c}\text { Mohr } \\
\text { Coulomb }\end{array}$ & Plastic & 0.02 & 0 & 0 & 27 & 27 & 0.02 & 0.02 & & & & & & & & & None & 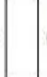 \\
\hline Very Loose Oark Fine Sand w/ Topsoil & $\square$ & $\mid \begin{array}{c}\text { Field Streess and } \\
\text { Body Force }\end{array}$ & 82 & |sotropic & 300000 & 0.25 & $\begin{array}{c}\text { Moht } \\
\text { Coulomb }\end{array}$ & Plastic & 0.02 & 0 & 0 & 26 & 26 & 0.02 & 0.02 & & & & & & & & & None & 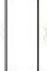 \\
\hline Loose Fine Sand & $\square$ & $\begin{array}{c}\text { Field Stress and } \\
\text { Body Force }\end{array}$ & 90 & Isotropic & 355045 & 0.28 & $\begin{array}{l}\text { Mohr } \\
\text { Coulomb }\end{array}$ & Plastic & 0.02 & 0 & 0 & 29 & 29 & 0.02 & 0.02 & & & & & & & & & None & 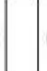 \\
\hline Loose Fine Sand w/ Gravel & D & $\begin{array}{l}\text { Field Stress and } \\
\text { Body force }\end{array}$ & 95 & |sotropic & 400000 & 0.25 & $\begin{array}{c}\text { Mohr } \\
\text { Coulomb }\end{array}$ & Plastic & 0.02 & 0 & 0 & 30 & 30 & 0.02 & 0.02 & & & & & & & & & None & 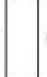 \\
\hline Concrete & $\square$ & $\begin{array}{c}\text { Field Stress and } \\
\text { Body Force }\end{array}$ & 150 & |sotropic & 1et+006 & 0.4 & $\begin{array}{l}\text { Generalized } \\
\text { Hoek-Brown }\end{array}$ & Plastic & & & & & & & & 626600 & 3.52122 & 23.52122 & 0.00386592 & 926.00386592 & 20.505734 & 4.0 .505734 & 0 & None & 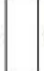 \\
\hline HMA & D & $\mid \begin{array}{c}\text { Field Stress and } \\
\text { Body Force }\end{array}$ & 145 & |sotropit & $10+006$ & 0.4 & $\begin{array}{l}\text { Generalized } \\
\text { Hoek-brown }\end{array}$ & Plastic & & & & & & & & 600000 & 3.52122 & 23.52122 & p.00386592 & 20.00386592 & 20.505734 & 140.505734 & 0 & Nono & 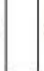 \\
\hline Dense, Fine Sand & $\square$ & $\begin{array}{c}\text { Fielolo Stress and } \\
\text { Body force }\end{array}$ & 110 & lsotropic & $1.04425+006$ & 0.4 & $\begin{array}{l}\text { Moht } \\
\text { Coulomb }\end{array}$ & Plastic & 0.02 & 0 & 0 & 37 & 37 & 0.02 & 0.02 & & & & & & & & & None & 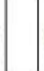 \\
\hline Med, Fine Sand & D & $\mid \begin{array}{c}\text { Field Stress and } \\
\text { Body Force }\end{array}$ & 105 & |sotropic & $1.2531 \mathrm{e}+006$ & 0.3 & $\begin{array}{c}\text { Mohr } \\
\text { Coulomb }\end{array}$ & Plastic & 0.02 & 0 & 0 & 35 & 35 & 0.02 & 0.02 & & & & & & & & & None & 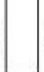 \\
\hline Limestone & $\square$ & $\begin{array}{c}\text { Field Stress and } \\
\text { Body Force }\end{array}$ & 153 & Isotropic & $1.156+009$ & 0.33 & $\begin{array}{l}\text { Generalized } \\
\text { Hoek-Brown }\end{array}$ & Plastc & & & & & & & & $1.5 \mathrm{e}+006$ & 1.67677 & 71.67677 & 0.00386592 & 26.00386592 & 20.505734 & 40.505734 & 0 & None & 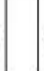 \\
\hline Dolostone & $\square$ & $\begin{array}{l}\text { Field Stress and } \\
\text { Body force }\end{array}$ & 175 & |sotropic & $1.18 \mathrm{e}+009$ & 0.3 & $\begin{array}{l}\text { Generalized } \\
\text { Hoek-Brown }\end{array}$ & Plastic & & & & & & & & $3.5 \mathrm{e}+006$ & 1.5091 & 15091 & p.00386592 & 260.0386592 & 20.505734 & 40.505734 & 0 & None & 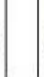 \\
\hline Shale & $\square$ & $\begin{array}{c}\text { Field Stross and } \\
\text { BodyForce }\end{array}$ & 172 & |sotropic & $1.04 \mathrm{e}+009$ & 0.25 & $\begin{array}{l}\text { Generalized } \\
\text { Hoak:Brown }\end{array}$ & Plastic & & & & & & & & 700000 & 1.00606 & 61.00606 & p.00386592 & 26.00386592 & 20.505734 & $4 \mid 0.505734$ & 0 & None & 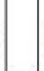 \\
\hline Sandstone & $\square$ & $\begin{array}{l}\text { Field Streess and } \\
\text { Body Force }\end{array}$ & 137 & Isotropic & $3.130+008$ & 0.29 & $\begin{array}{l}\text { Generalized } \\
\text { Hoek-Brown }\end{array}$ & Plastic & & & & & & & & $1.5 e+006$ & 2.85051 & 12.85051 & p.00386592 & 22.00386592 & 20.505734 & 40.505734 & 0 & None & 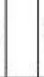 \\
\hline Clay & $\square$ & $\begin{array}{c}\text { Field Stress and } \\
\text { Body force }\end{array}$ & 115 & |sotropic & 208850 & 0.45 & $\begin{array}{l}\text { Mohr } \\
\text { Coulomb }\end{array}$ & Plastic & 312.5 & 0 & 0 & 0 & 0 & 312.5 & 312.5 & & & & & & & & & 1 & 1 \\
\hline
\end{tabular}


DEQ FEA Model Material Properties

\begin{tabular}{|c|c|c|c|c|c|c|c|c|c|c|c|c|c|c|c|c|c|c|c|c|c|c|c|c|}
\hline Material Name & Color & $\begin{array}{c}\text { Inital Element } \\
\text { loading }\end{array}$ & $\begin{array}{l}\text { UnitWointh } \\
|\| b s /(3)|\end{array}$ & $\begin{array}{c}\text { Elatic } \\
\text { Type }\end{array}$ & $\begin{array}{c}\text { Youngs } \\
\text { Modulus (pst) }\end{array}$ & $\begin{array}{c}\text { Poison's } \\
\text { Ratio }\end{array}$ & $\begin{array}{c}\text { filure } \\
\text { Criterion }\end{array}$ & $\begin{array}{c}\text { Material } \\
\text { Type }\end{array}$ & $\begin{array}{l}\text { Tensile } \\
\text { Strenghth } \\
\mid \text { |psil| }\end{array}$ & $\begin{array}{c}\text { Tensile } \\
\text { Strength } \\
\text { |residual| } \\
\mid \text { |psil| }\end{array}$ & $\begin{array}{l}\text { Distion } \\
\text { Angle } \\
\text { loded }\end{array}$ & $\begin{array}{l}\text { fiction Ande } \\
\text { |peex)| (dege }\end{array}$ & $\begin{array}{l}\text { Firition Andele } \\
\text { Iresidual||dege }\end{array}$ & $\begin{array}{l}\text { Cohesion } \\
\text { pesil| post }\end{array}$ & $\left|\begin{array}{c}\text { Cohesion } \\
\mid \text { |reidual } \mid \\
\mid \text { pas } \mid\end{array}\right|$ & $\begin{array}{c}\text { Intat } \\
\text { Compressive } \\
\text { Strength } \mid \text { psf }\end{array}$ & mblpeakl) & $\left|\begin{array}{c}m b \\
\mid \text { |residuat }\end{array}\right|$ & speakl & s/residual) & a peekik) & f(residual) & \begin{tabular}{|c|c} 
Dilation & Pi \\
Parmeter
\end{tabular} & lime \\
\hline Res Snot Corse & & \begin{tabular}{|c|} 
Feld Streess and \\
Body force
\end{tabular} & 90 & |sotropic| & 313275 & 0.4 & $\begin{array}{c}\text { Mohr } \\
\text { Coulontb }\end{array}$ & Plastic & 0.02 & 0 & 0 & 36 & 36 & 0.02 & 0.02 & & & & & & & & & 11 \\
\hline $\begin{array}{c}\text { Brownsand G Gravel } \\
\text { Conse }\end{array}$ & & 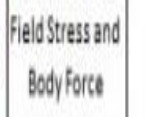 & 103 & |sotropict: & $1.618598++06$ & 0.3 & $\begin{array}{c}\text { Monr } \\
\text { Coulomb }\end{array}$ & Plastic & 0.02 & 0 & 0 & 37 & 37 & 0.02 & 0.02 & & & & & & & & & 1. \\
\hline Brown Sand Medium & & 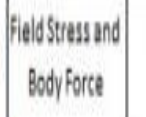 & 75 & |sotropic| & 730975 & 0.3 & $\begin{array}{c}\text { Moht } \\
\text { Coulomb }\end{array}$ & Plastic & 0.02 & 0 & 0 & 35 & 35 & 0.02 & 0.02 & & & & & & & & & 1. \\
\hline Brown Sand fine Silty & & $\mid \begin{array}{c}\text { Fiolostressund } \\
\text { Body Force }\end{array}$ & 93.6 & |sotcople & 939825 & 0.25 & $\begin{array}{c}\text { Moht } \\
\text { Coulomb }\end{array}$ & Plastc & 459.5 & 0 & 0 & 32 & 32 & 499.5 & 499.5 & & & & & & & & & 1. \\
\hline Grayclay & & \begin{tabular}{|c|} 
Fielostress ind \\
Body Force
\end{tabular} & 109 & |sotitopelt & 200850 & 0.45 & $\begin{array}{c}\text { Mohr } \\
\text { Coulomb }\end{array}$ & Plate: & 683 & 0 & 0 & 0 & 0 & 683 & 683 & & & & & & & & & 1. \\
\hline Grval & & $\begin{array}{c}\text { Field Streass and } \\
\text { Body Force }\end{array}$ & 120 & $\mid$ totropicte & 2506240006 & 0.3 & $\begin{array}{c}\text { Mohr } \\
\text { Coulomb }\end{array}$ & Plastic: & 0 & 0 & 0 & 40 & 40 & 0 & 0 & & & & & & & & & 11 \\
\hline limesitone Broken & & $\begin{array}{c}\text { Fiedodtress and } \\
\text { Body force }\end{array}$ & 97 & |sotropic| & $3.136+008$ & 0.18 & $\begin{array}{l}\text { Generalized } \\
\text { HoekBrown }\end{array}$ & Plastic & & & & & & & & $1.54+006$ & 0983084 & 0.983084 & 010101 & .010101905 & 0.51302 & 0.51302 & 0 & 11 \\
\hline White limestone & & $\begin{array}{c}\text { Feld Streess and } \\
\text { Body Forte }\end{array}$ & 163 & |sotropic| & $1.15 \mathrm{e}+109$ & 0.33 & Generallized & Plastic & & & & & & & & $48+006$ & 4.95753 & 495753 & 0.0319225 & 0.0319225 & 0.501463 & 0.504463 & 0 & 1 \\
\hline White Limestone W/Band & & $\begin{array}{c}\text { Piele Stross and } \\
\text { Body Focce }\end{array}$ & 156 & |sotropic| & 6.27et-208 & 0.28 & $\begin{array}{l}\text { Generalizad } \\
\text { Hoek-8rown }\end{array}$ & Plastic & & & & & & & & $3.5 \mathrm{t}+106$ & 232112 & 233112 & 0.00602938 & 00602938 & 0.504342 & 0.504342 & 0 & 1 \\
\hline White Limestone Sandy & & $\begin{array}{c}\text { Fiolostreas and } \\
\text { Body Foce }\end{array}$ & 137 & |sotopopic| & 73.1: +008 & 0.25 & $\begin{array}{l}\text { Generiliad } \\
\text { Hoek Brown }\end{array}$ & Plastic & & & & & & & & 3.25e+006 & 1.01701 & 10.1701 & 0.0008159 & 08159 & 5.544008 & 0.514908 & 0 & 1 \\
\hline
\end{tabular}




\section{Appendix F: Stability Analysis Models}

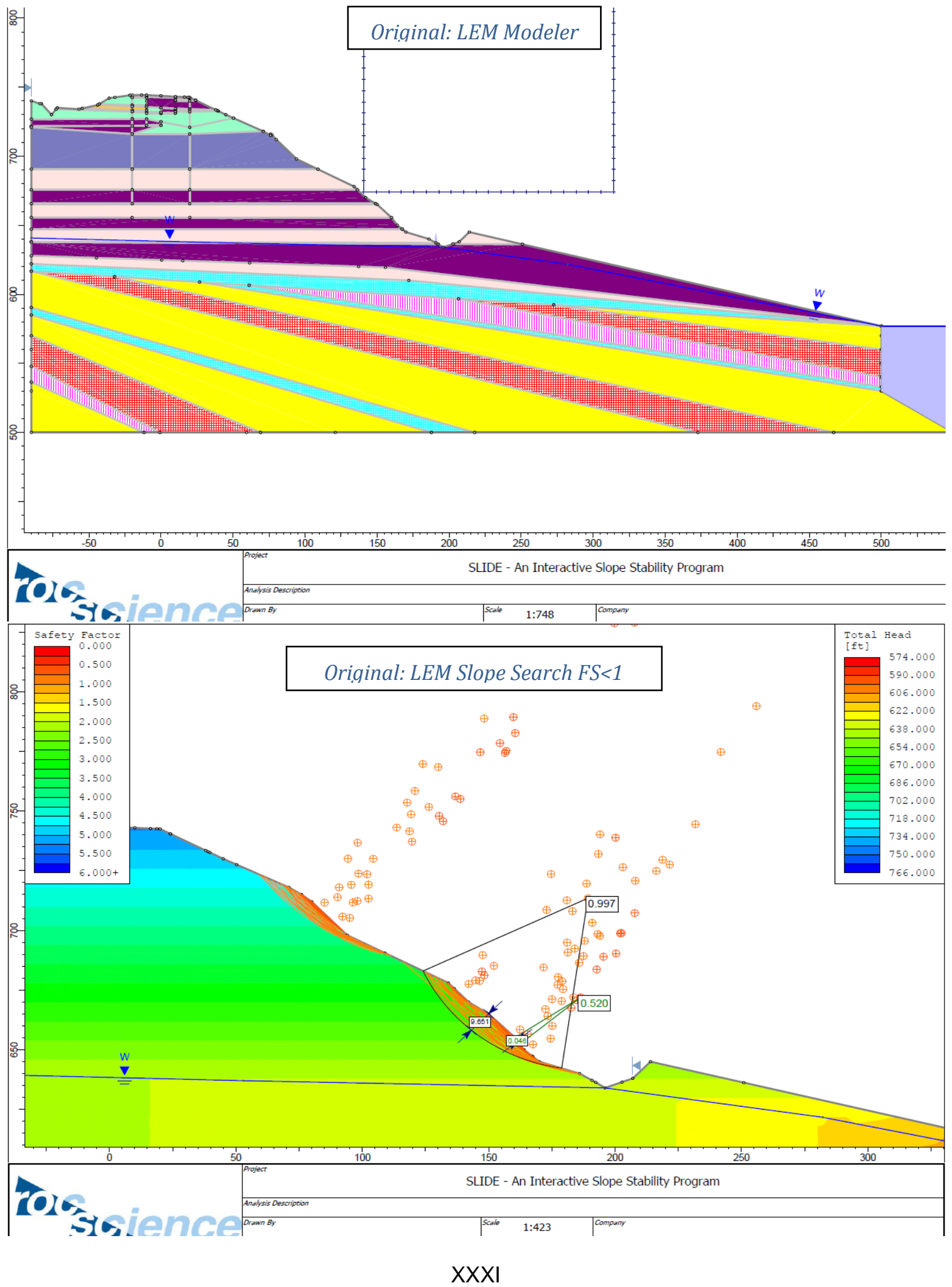




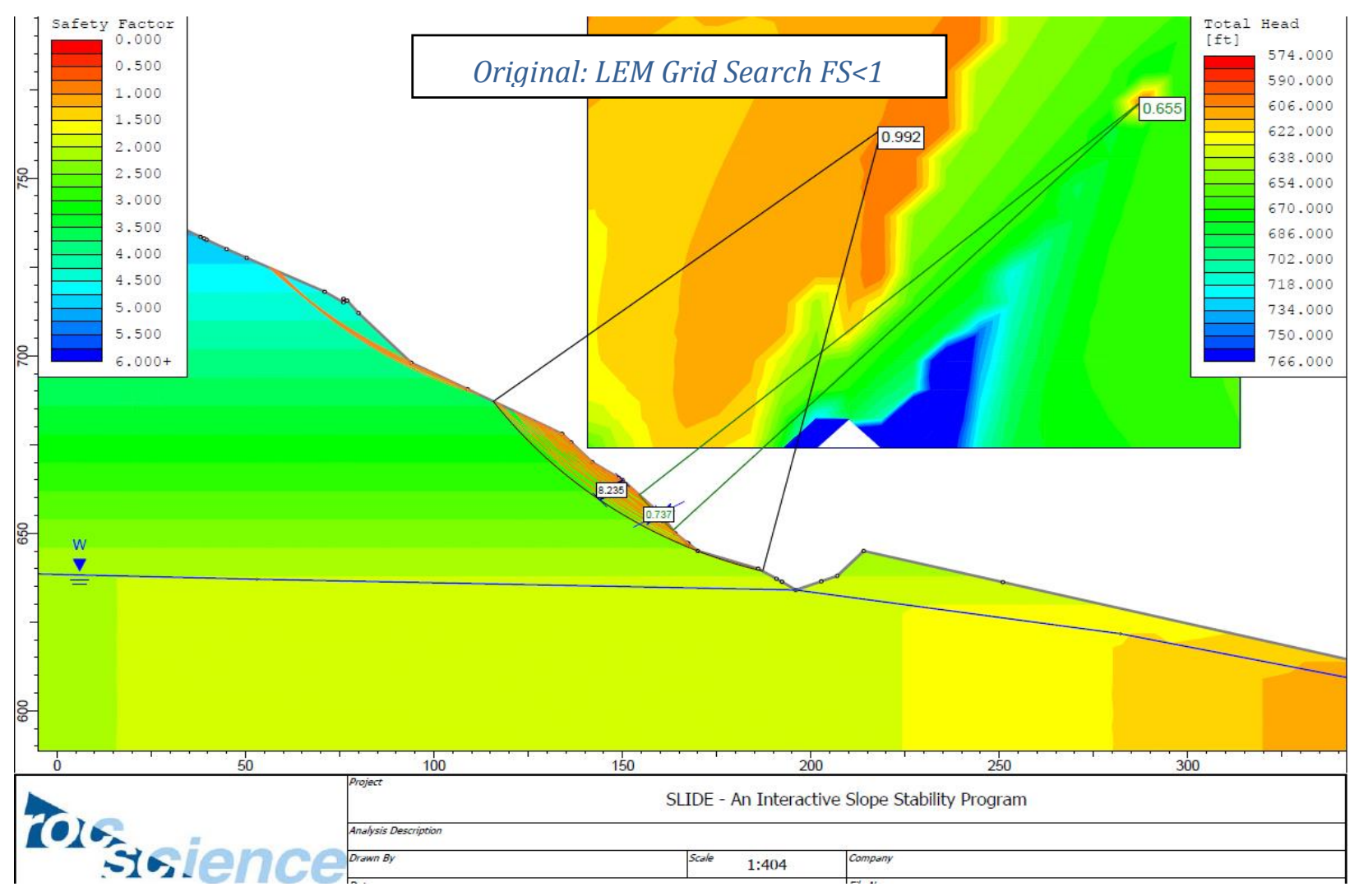




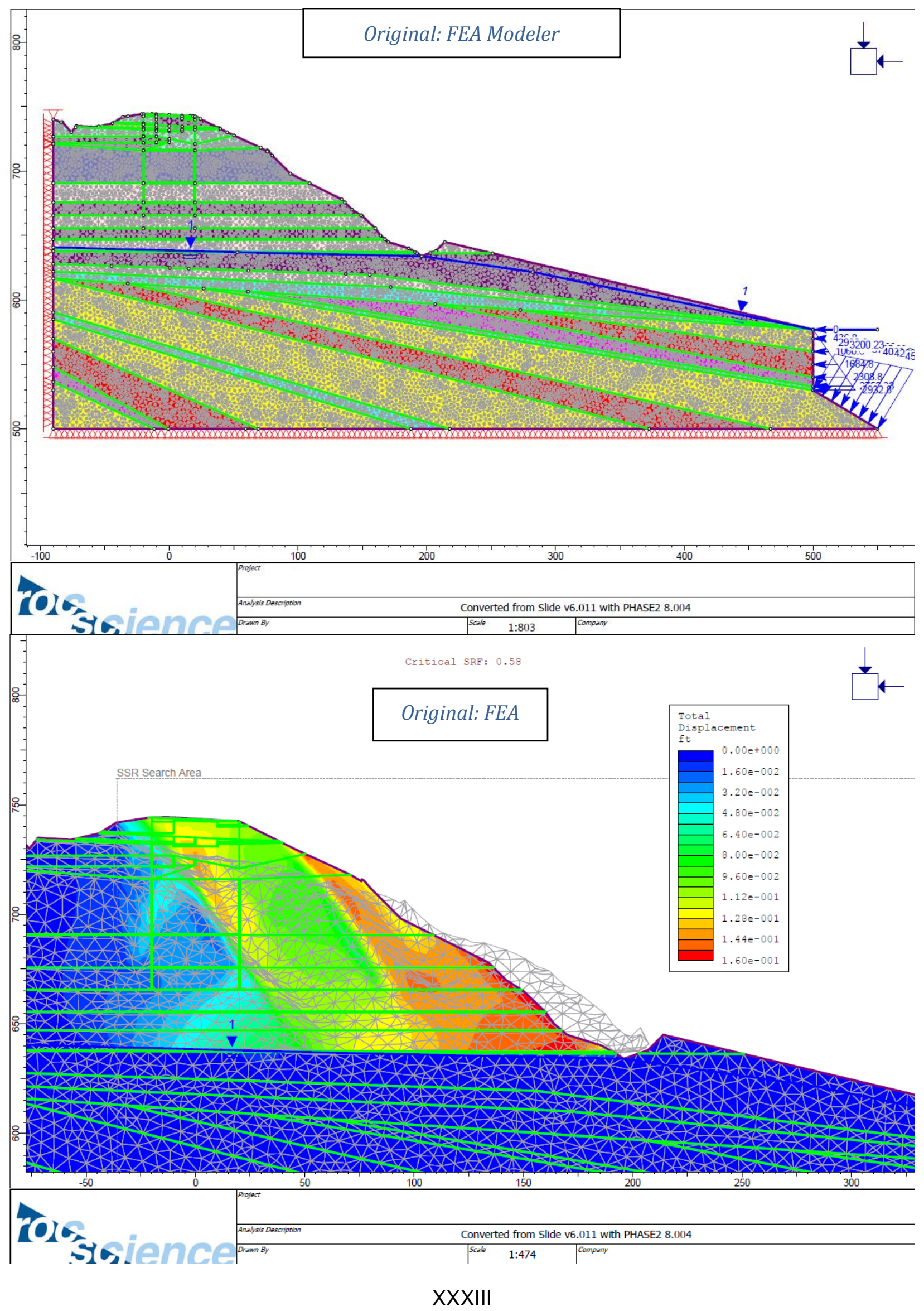




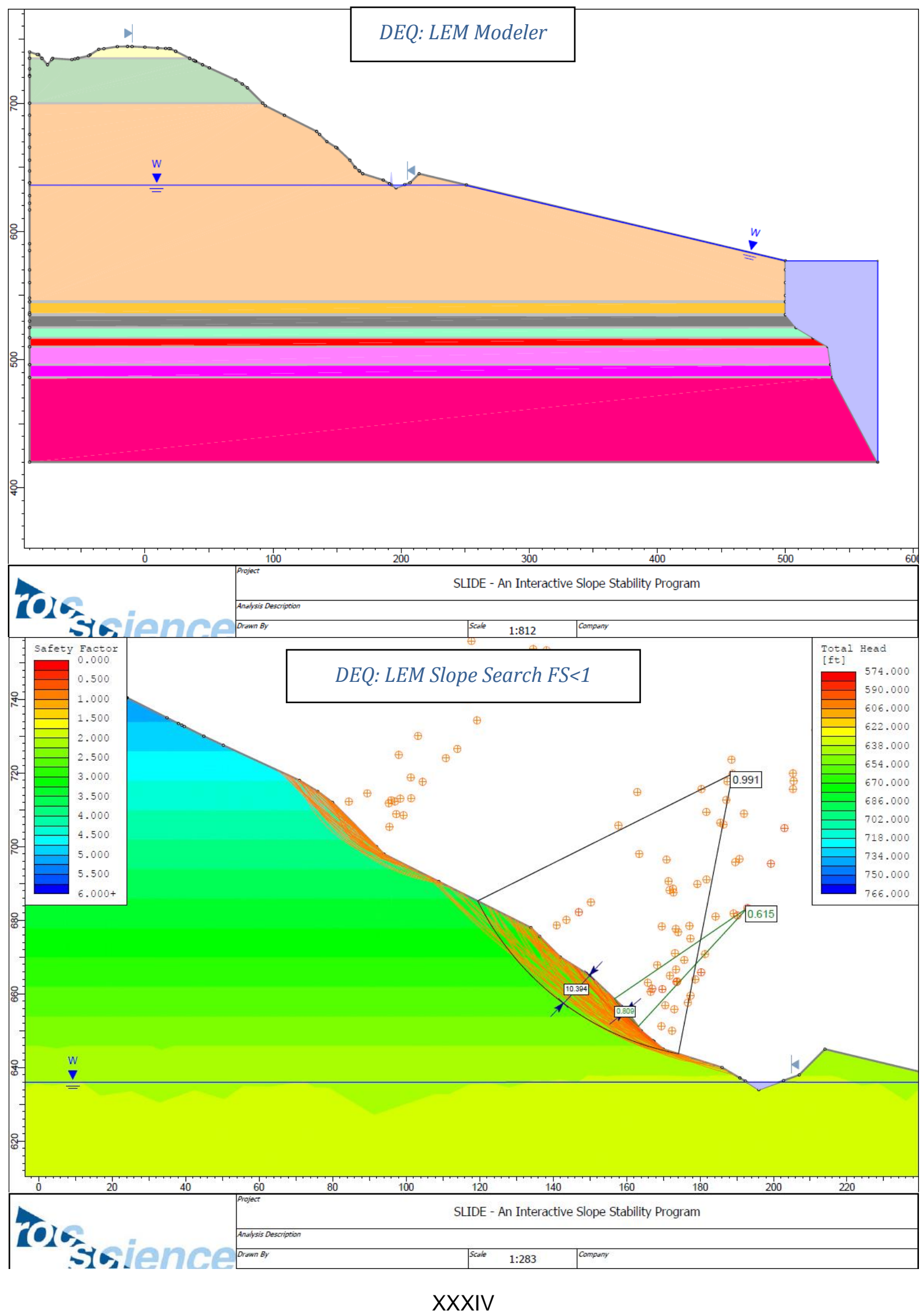




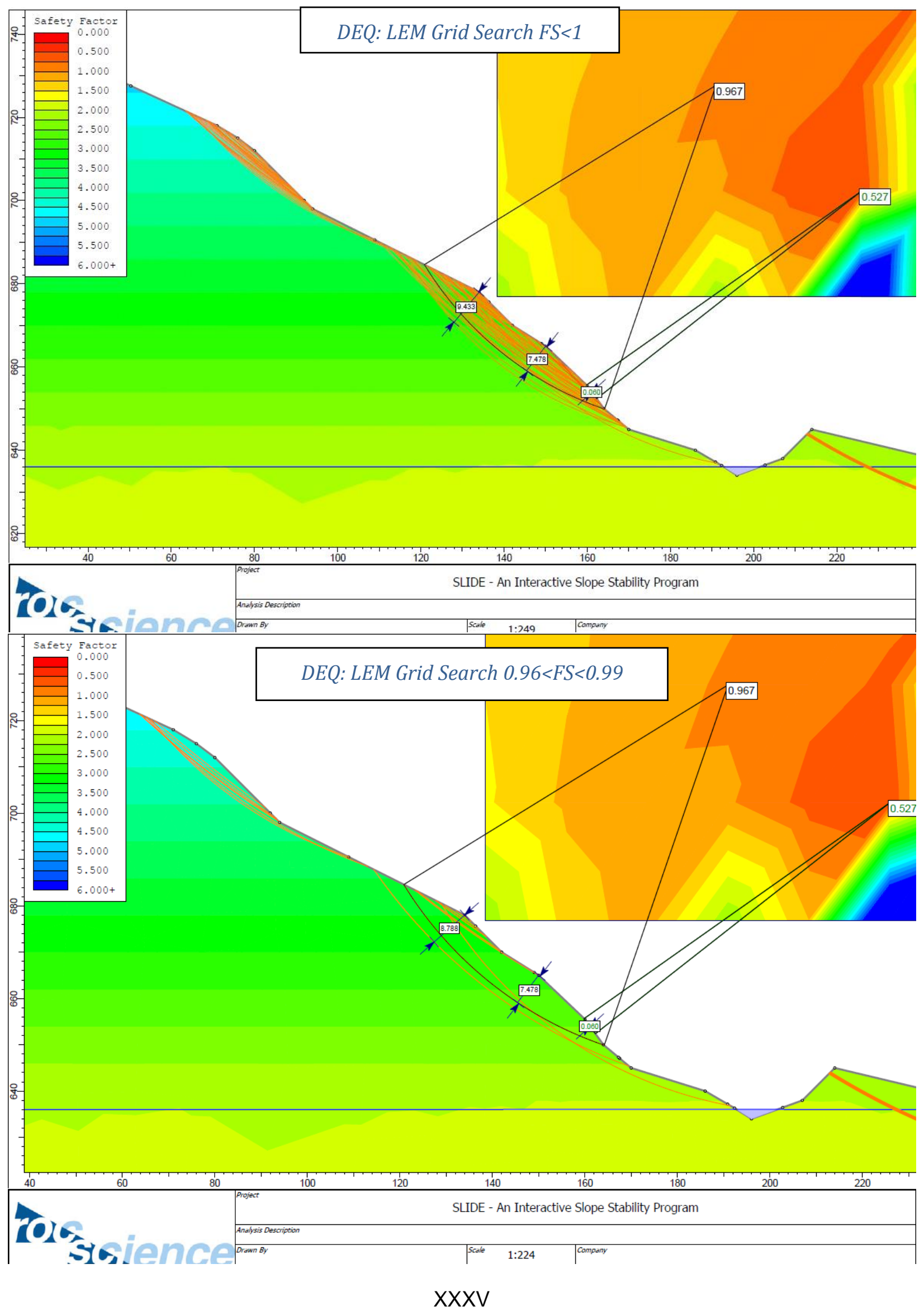




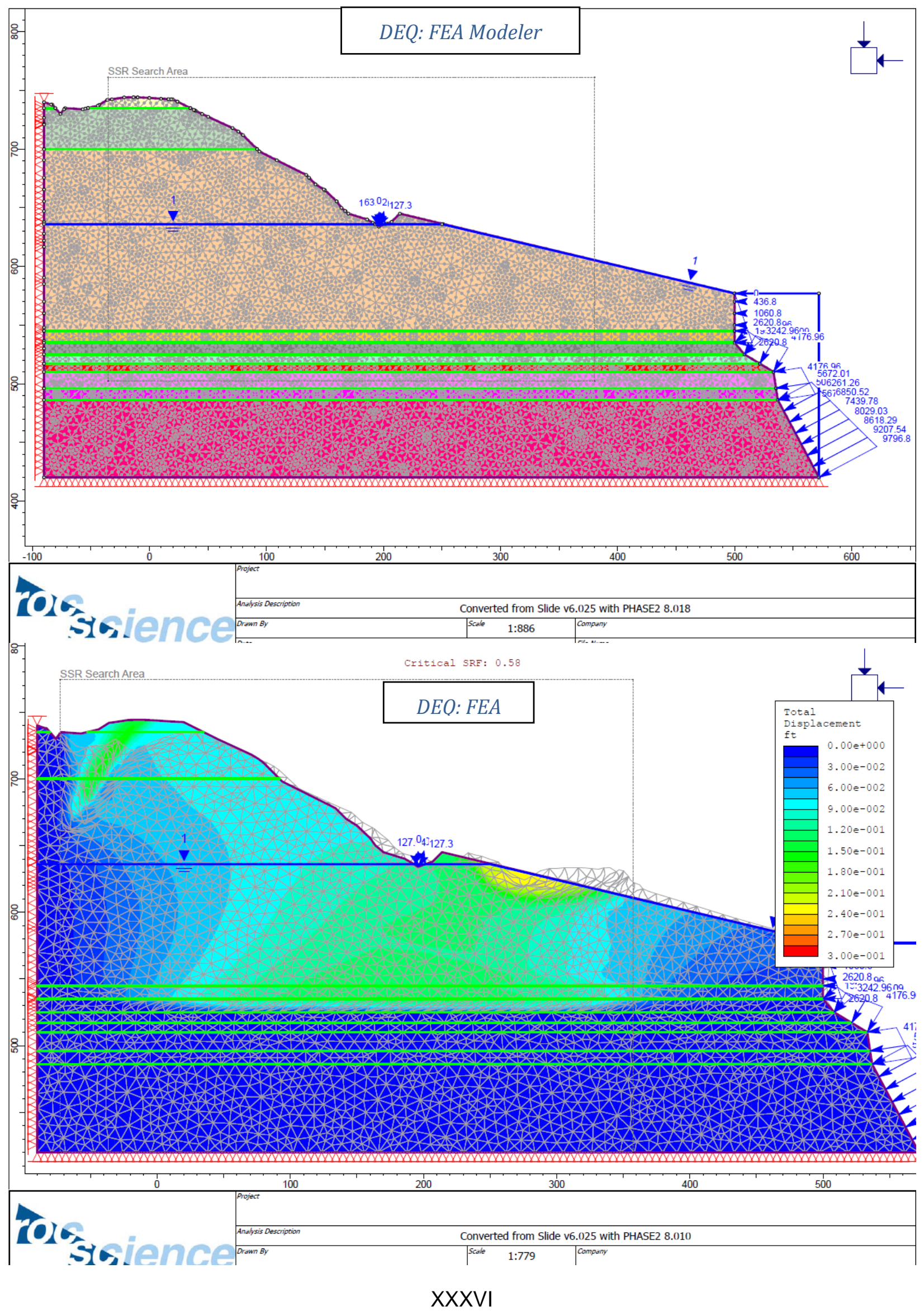




\section{Bedrock Mapping in Karst Terrain}

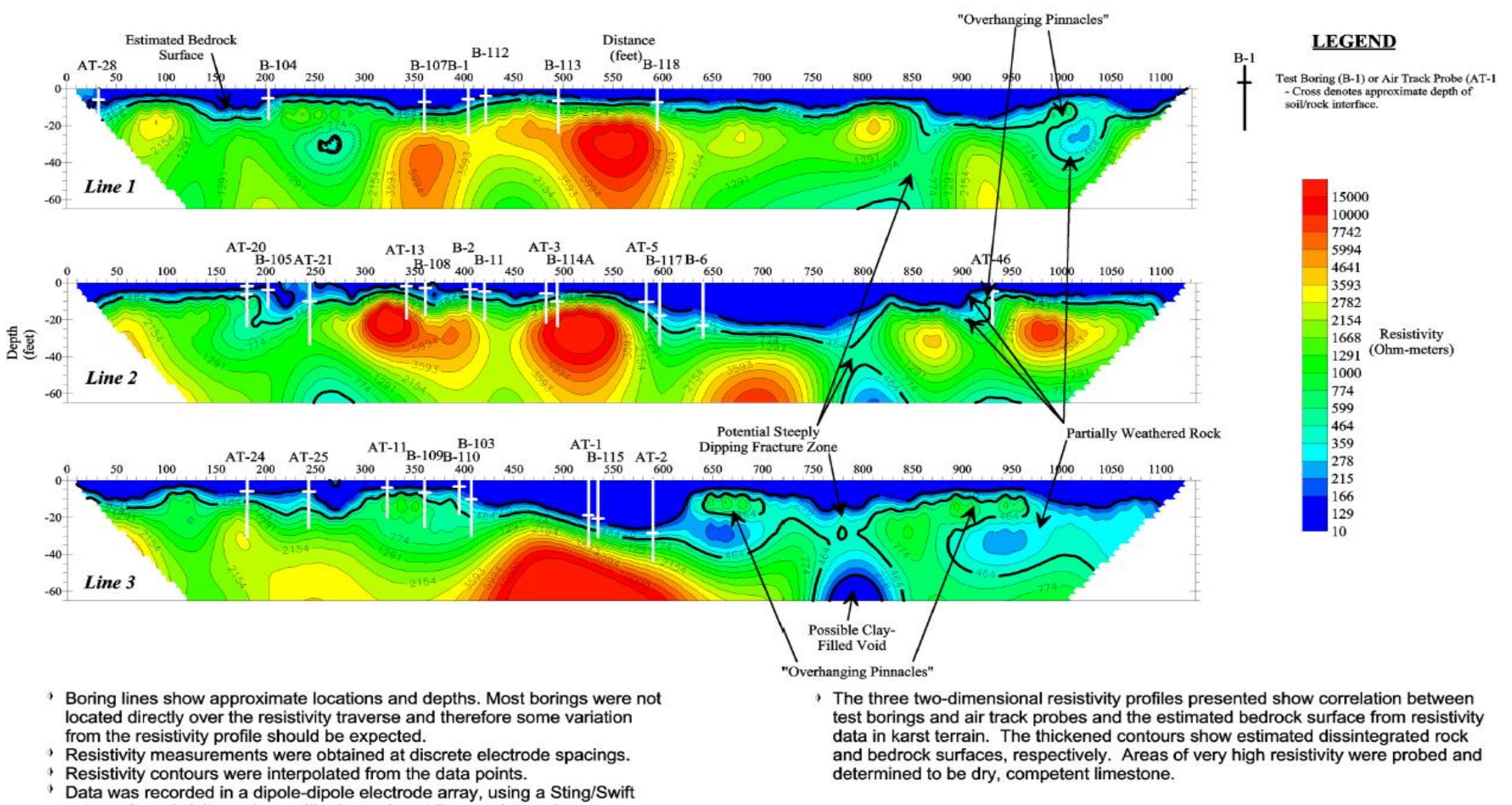

Rata was recorded in a dipole-dipole eloctrode atray usints.

using a Sting/Swift automatic resistivity system, with electrodes at 5 meter intervals.

SCALE:

Horizontal: $1^{\prime \prime}=100^{\circ}$

Vertical: $1^{\prime \prime}=50^{\prime}$

\section{Courtesy of}

Schnabel Engineering

Web site http://www.schnabel-eng.com

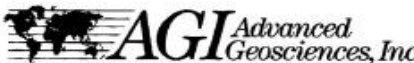

Tel: $\quad+1$ (512) 335-3338

Fax: +1 (512) 258-9958

E-mail sales@agiusa.com Web site http://www.agiusa.com 